Louisiana State University

LSU Digital Commons

\title{
Empirically evaluating and developing alarm rate standards for liquid pipeline control room operators
}

\author{
Glen David Uhack II \\ Louisiana State University and Agricultural and Mechanical College
}

Follow this and additional works at: https://digitalcommons.Isu.edu/gradschool_theses

Part of the Construction Engineering and Management Commons

\section{Recommended Citation}

Uhack II, Glen David, "Empirically evaluating and developing alarm rate standards for liquid pipeline control room operators" (2010). LSU Master's Theses. 4148.

https://digitalcommons.Isu.edu/gradschool_theses/4148

This Thesis is brought to you for free and open access by the Graduate School at LSU Digital Commons. It has been accepted for inclusion in LSU Master's Theses by an authorized graduate school editor of LSU Digital Commons. For more information, please contact gradetd@lsu.edu. 


\title{
EMPIRICALLY EVALUATING AND DEVELOPING ALARM RATE STANDARDS FOR LIQUID PIPELINE CONTROL ROOM OPERATORS
}

\author{
A Thesis \\ submitted to the Graduate Faculty of the \\ Louisiana State University and \\ Agricultural and Mechanical College \\ in Partial Fulfillment of the \\ requirements for the degree of \\ Master of Science in Industrial Engineering
}

in

The Department of Construction Management and Industrial Engineering

by

Glen D. Uhack II

B.S., University of New Orleans, 2007

May 2010 


\section{ACKNOWLEDGMENTS}

I would like to thank my major professor Dr. Craig Harvey for the guidance, direction, and support throughout this research. I would also like to thank the members on my committee, Dr. Fereydoun Aghazadeh and Dr. Gerald Knapp, for their guidance, direction, and support throughout my research.

We would like to thank all of the participants who volunteered and participated in this study. Their participation and feedback have contributed valuable new data towards understanding human factors in pipeline control rooms. We appreciate their willingness to provide time out of their schedules and the observations obtained from this work.

We thank the Center for Operator Performance for their support, funding, and guidance throughout the progression of this work. 


\section{TABLE OF CONTENTS}

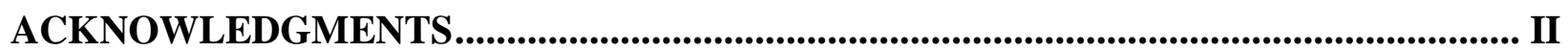

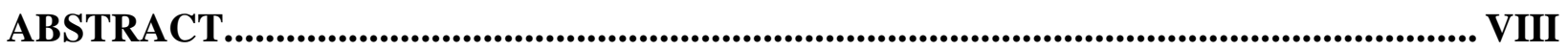

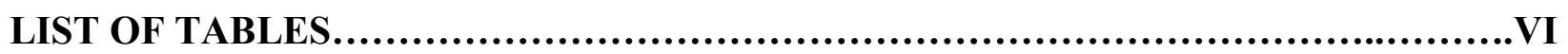

LIST OF FIGURES........................................................................

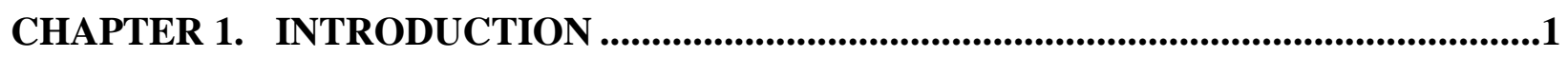

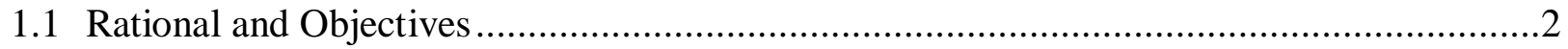

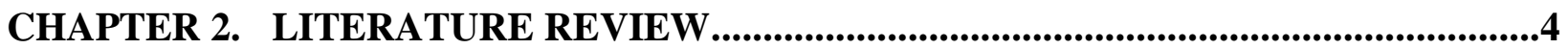

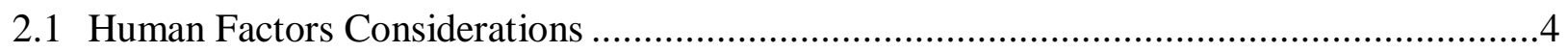

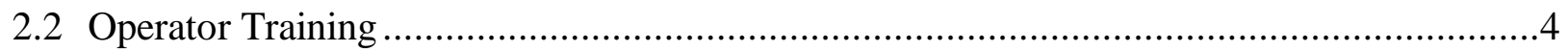

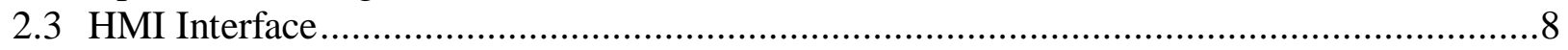

2.3.1 Console Design - Physical Design Considerations .................................................. 9

2.3.2 Graphical User Interface - Cognitive Design Considerations ..................................10

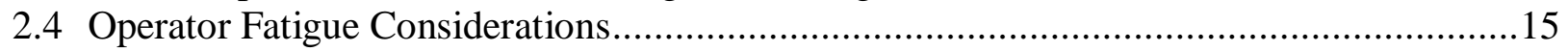

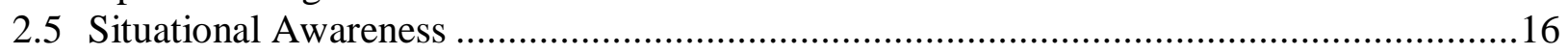

2.6 Alarm System Lifecycle and Benchmarking Standards ...............................................17

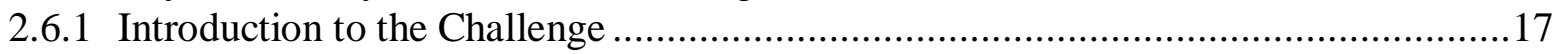

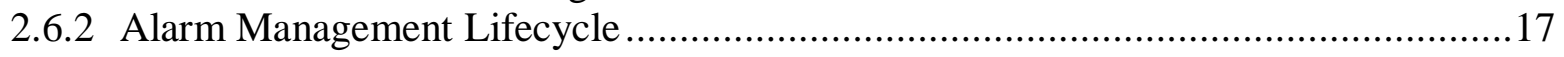

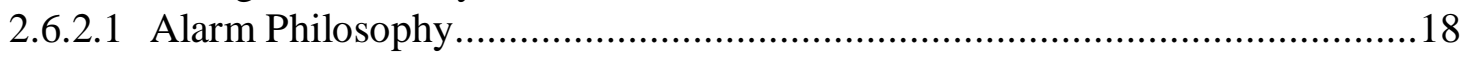

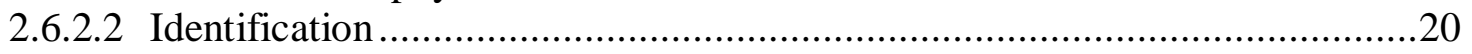

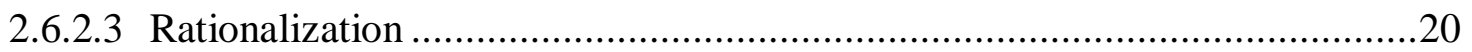

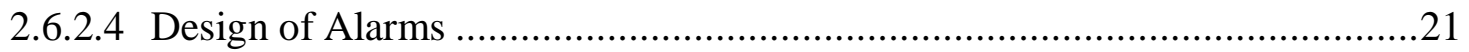

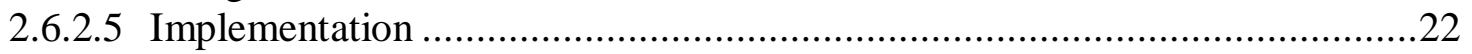

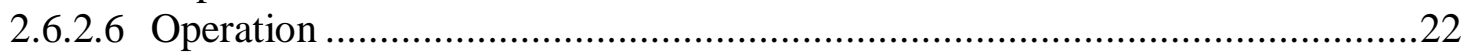

2.6.2.7 Lifecycle Loops (Maintenance, Performance Monitoring, and MOC) ...........23

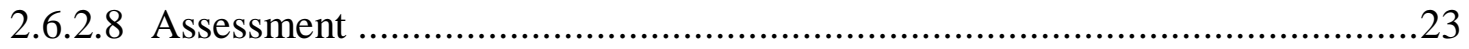

2.7 Observed Alarm Performance vs. EMMUA No. 191 Standard of Performance .................24

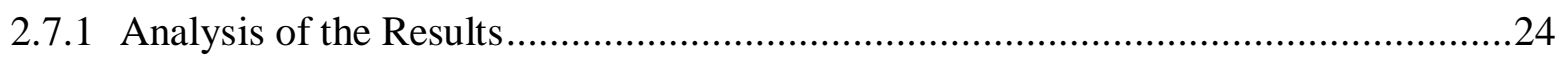

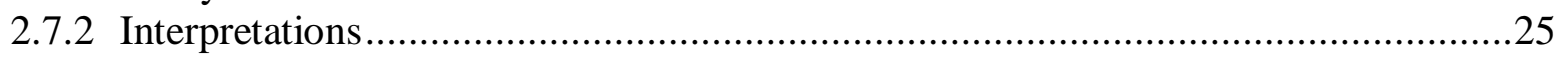

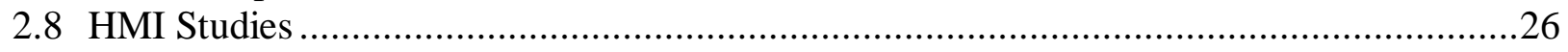

2.9 Roles and Responsibilities of the Operator.....................................................................2.

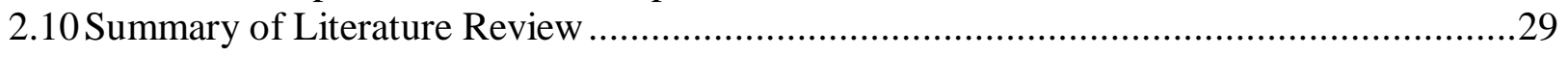

CHAPTER 3. EXPERIMENTAL METHOD AND PROCEDURE ...................................31

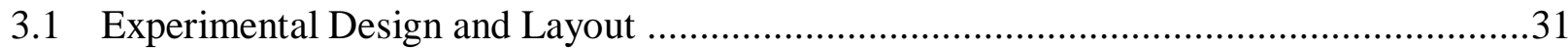

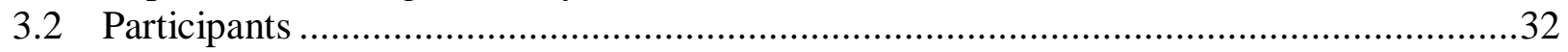

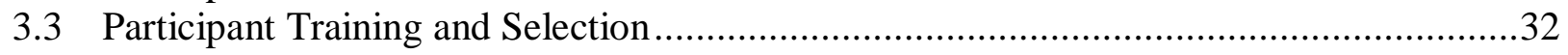

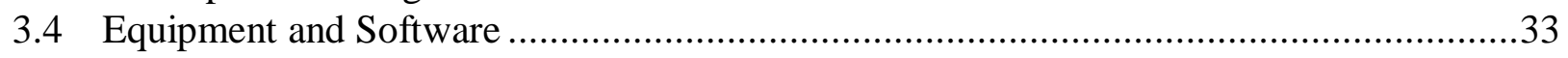

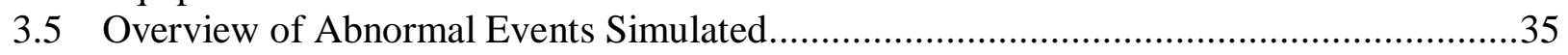

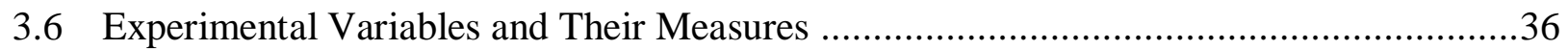




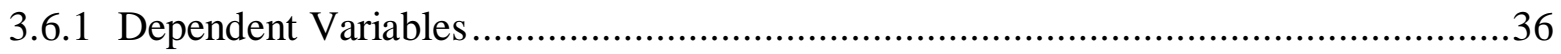

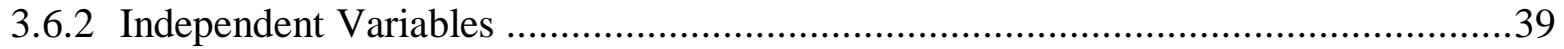

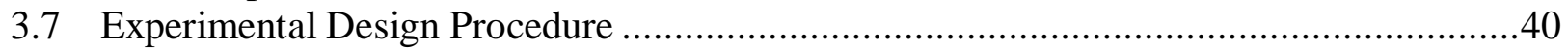

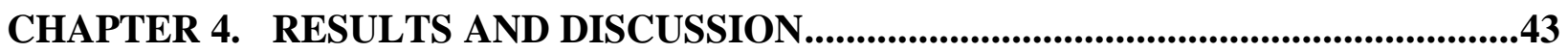

4.1 Experimental Model and Statistical Reporting Conventions .............................................43

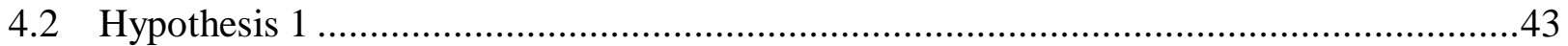

4.2.1 Differences in Accuracy of Response (All Alarms) ................................................4

4.2.2 Differences in Accuracy of Response (Low Priority Alarms) ..................................4

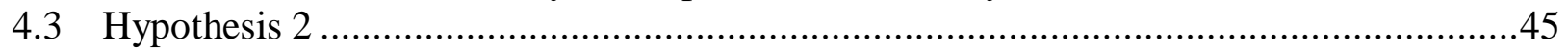

4.3.1 Differences in Response Time (Low Priority Alarms) ………………….............4

4.3.2 Differences in Response Time (Caution Priority Alarms) ......................................45

4.3.3 Differences in Response Time (High Priority Alarms) ..............................................46

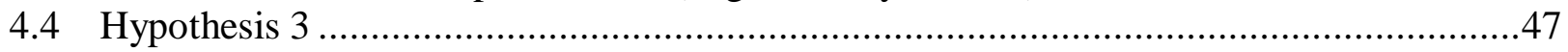

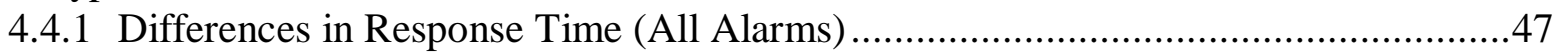

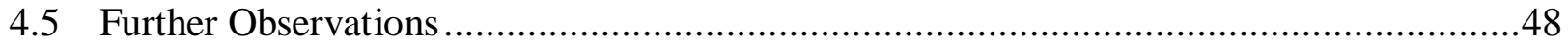

4.5.1 Differences in Acknowledgement Time (All Alarms) ………..............................48

4.5.2 Differences in Acknowledgement Time (Low Priority Alarms) ...............................49

4.5.3 Differences in Acknowledgement Time (Caution Priority Alarms) ..........................50

4.5.4 Differences in Acknowledgement Time (High Priority Alarms) ..............................51

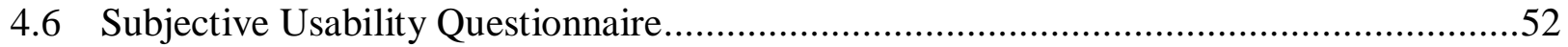

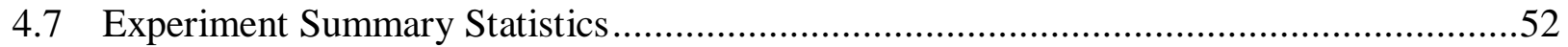

4.8 Discussion and Future Research Recommendations ........................................................53

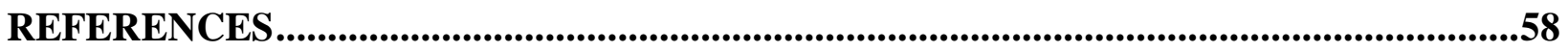

APPENDIX 1 - TABLE IDENTIFYING MEANING OF COLORS .................................61

APPENDIX 2 - EEMUA NO. 191 BENCHMARK AVERAGE ALARM RATE

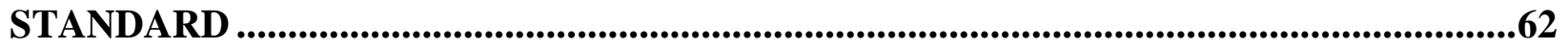

APPENDIX 3 - TABLE SHOWING ORDER OF EXPERIMENTS, WHICH DISPLAY USED FIRST, AND DEMOGRAPHIC INFORMATION .............................................63

APPENDIX 4 - PARTICIPANT TRAINING GUIDE ..........................................................65

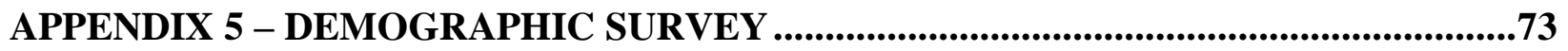

APPENDIX 6 - GENERAL KNOWLEDGE QUIZ ....................................................................74

$\begin{array}{llllll}\text { APPENDIX } 7 & - & \text { SUBJECTIVE USABILITY QUESTIONNAIRE AND }\end{array}$ SUMMARY DATA ..................................................................................................................75

APPENDIX 8 - DIFFERENCES IN ACCURACY OF RESPONSE (ALL ALARMS).......80 
APPENDIX 9 - DIFFERENCES IN ACCURACY OF RESPONSE (LOW PRIORITY ALARMS).

APPENDIX 10 - DIFFERENCES IN RESPONSE TIME (LOW PRIORITY ALARMS) .82 APPENDIX 11 - DIFFERENCES IN RESPONSE TIME (CAUTION PRIORITY ALARMS). .83

APPENDIX 12 - DIFFERENCES IN RESPONSE TIME (HIGH PRIORITY ALARMS) 84 APPENDIX 13 - DIFFERENCES IN RESPONSE TIME (ALL ALARMS) . .85 APPENDIX 14 - DIFFERENCES IN ACKNOWLEDGEMENT TIME (ALL ALARMS) 87 APPENDIX 15 - DIFFERENCES IN ACKNOWLEDGEMENT TIME (LOW PRIORITY ALARMS). .88

APPENDIX 16 - DIFFERENCES IN ACKNOWLEDGEMENT TIME (CAUTION PRIORITY ALARMS)

APPENDIX 17 - DIFFERENCES IN ACKNOWLEDGEMENT TIME (HIGH PRIORITY ALARMS). .90

APPENDIX 18 - DESCRIPTIVE STATISTICS .91

VITA. .97 


\section{TABLES}

Table 1 - Considerations When Designing Operator Consoles ......................................... 10

Table 2 - Roles and Responsibilities of the Console Operator .........................................29

Table 3 - Example participant Grading for Accuracy of Response and Successful Completion .39

Table 4 - EEMUA No. 191 Benchmark Average Alarm Rate Standard ...................................39

Table 5 - Draft ISA 18.02 Average Alarm Rate Standard ................................................39

Table 6 - Alarm Rates Used For Experiments ..........................................................40

Table 7 - Acknowledgement Time Summary Statistics ...................................................54

Table 8 - Reaction Time Summary Statistics........................................................55

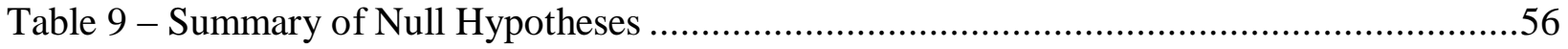




\section{FIGURES}

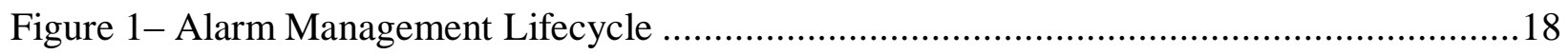

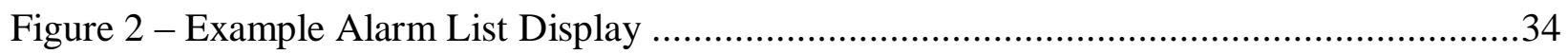

Figure 3 - User Interface Used for Qualifying Participants .......................................................34

Figure 4 - Partial Snapshot of Overview Display Used During Actual Experiment.....................34

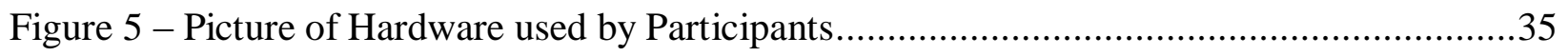

Figure 6 - Overview of Experimental Variables and Measures of Operator Performance ...........37

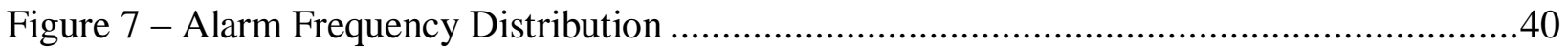

Figure 8 - Chronological Alarm Display …………............................................................

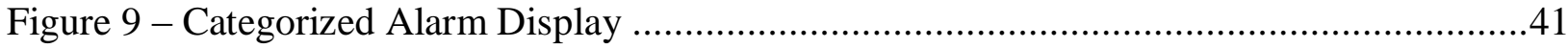

Figure 10 - Experimental Procedure Flow Chart .................................................................42

Figure 11 - Mean Acknowledgement Time ……………......................................................53

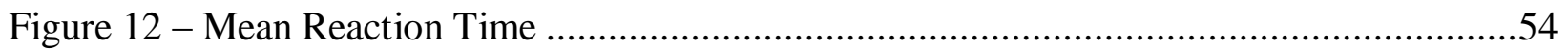




\section{ABSTRACT}

The liquid and gas pipeline community has recently been faced with the challenge of new governmental regulations set forth by congress which are being implemented by PHMSA (an arm of the DOT). These new governmental regulations need to understand the role of the human in the loop as part of alarm management systems. To investigate alarm rate standards a repeated measures design was developed that included a series of ten (10) simulated liquid pipeline operator scenarios utilizing high fidelity liquid pipeline simulation software (Stoner Pipeline Simulator). A total of 39 participants volunteered for this study. Participants completed two subsets of experiments, five were completed using an alarm display presenting alarms by time (chronological) and the remaining five experiments were completed using a categorical alarm display.

Statistically significant differences were found to exist in participant response time, acknowledgement time, and accuracy of response given different alarm display types and alarm rates. Use of the categorical alarm display resulted in significantly reduced alarm acknowledgement and response times. Also, a severe operator performance reduction with regard to alarm handling was observed when the alarm rate was increased from ten alarms per ten minutes (10-alarms/10-minutes) to twenty alarms per ten minutes (20-alarms/10-minutes). 


\section{CHAPTER 1. INTRODUCTION}

Human factors and alarm management in pipeline control rooms, in recent years, has become of increasing interest to many government entities. In 2005, the National Transportation Safety Board (NTSB) reported the results of their safety study titled "Supervisory Control and Data Acquisition (SCADA) in Liquid Pipelines." The NTSB study recommended improvements in graphics design, alarm management, human factors (e.g. fatigue), training, and leak detection. Further, In September 2006, the $109^{\text {th }}$ Congress passed Senate Bill 3961 (S.3961). This Bill specifies that no later than 18 months after the enactment of the Bill the Secretary of Transportation shall issue standards that implement the NTSB recommendations, and "issue regulations requiring operators of gas and hazardous liquid pipelines to evaluate and take measures to reduce risks associated with human factors, including fatigue, for pipeline controllers \& other employees.” This includes adoption of American Petroleum Institute's (API) 1165 standard on SCADA graphics, standards for review \& audit of alarms, standards for pipeline controller training, and regulations which deal with human factors in pipeline control rooms, particularly fatigue \& shift work.

Most recently, in response to congress and the president approving the PIPES Act (H.R. $5782\left[109^{\text {th }}\right]$ ) the Pipeline and Hazardous Materials Safety Administration (PHMSA), arm of the Department of Transportation (DOT) charged with protecting public and environmental interest by insuring safe and secure movement of hazardous materials, has been working towards revising Federal Pipeline Safety Regulations.

These legislative efforts are being pursued in an effort to help ensure companies operate safely, reduce economic loss, and reduce environmental damage. Many groups are available to provide guidance based on limited case studies and their operating experience. However, as 
much as these organizations try to standardize operations in the pipeline industry, much diversity in regards to human factors and alarm management best practices still exist within the pipeline community.

\subsection{Rational and Objectives}

The liquid and gas pipeline community has recently been faced with the challenge of new governmental regulations set forth by congress which are being implemented by PHMSA. As these new governmental regulations are passed, there is a need to conduct research in the area of alarm management in control rooms. Past work in alarm management in pipeline control rooms concentrated on improving training programs, designing more efficient/effective Human Computer Interfaces (HCI), development of the alarm management lifecycle, development of industry consensus standards stating best practices, and reducing fatigue situations. The research and work performed here fill empirical evaluation deficiencies with regards to alarm rate standards for liquid pipeline control room operators, although there are many areas of interest regarding this topic that are mentioned above.

To empirically investigate alarm rate standards a repeated measures design was developed that included a series of ten (10) operator scenarios utilizing high fidelity liquid pipeline simulation software (Stoner Pipeline Simulator). Participants completed two subsets of experiments, five were completed using an alarm display presenting alarms by time (chronological) and the remaining five experiments were completed using a categorical alarm display with alarm priority categories being high, medium, and low. For both, the chronological and categorical alarm display, experiments the alarm rates were derived from the Engineering Equipment Materials and Users Association (EEMUA) No. 191 average alarm rate standard and were randomly distributed between participants. The main operator performance metrics of 
interest were participant acknowledgement time, participant response time to take appropriate action to handle each alarm, and percentage of successful completion. With these metrics, a statistical model was developed to empirically derive alarm rate standards for liquid pipeline control room operators. 


\section{CHAPTER 2. LITERATURE REVIEW}

\subsection{Human Factors Considerations}

According to Ian Nimmo, studies conducted by the Abnormal Situation Management Consortium (ASM), American Institute of Chemical Engineers, American Petroleum Institute, American Chemistry Council, and similar organizations have concluded that about $80 \%$ of the root causes contributing to major accidents affecting safety, environment, and/or economics can be linked to human operator error (Nimmo 2002). Human error can be caused by many variables, some of which are poor human-machine interface (HMI), poor situational awareness, operator experience, workload, communication, and shift-fatigue. There is little published research regarding specific best-practices for pipeline control room operators. However, the Engineering Equipment Materials and Users Association (EEMUA) No.191 authors imply that research conducted in the process industry or elsewhere in a control room setting, (e.g. a refinery or similar control room environments), can be used to improve human factors design and benchmark performance in the pipeline industry, as well as other industries.

\subsection{Operator Training}

Rasmussen conducted a study of 190 accidents in chemical processing facilities which identified the top causes leading to an accident (Rasmussen 1989). Reasons identified include insufficient knowledge (34\%), procedure error (24\%), and operator error (16\%). A study conducted in petrochemical and refining operations by Butikofer (1986) observed that the leading sources attributed to causes of accidents include equipment and design failures (41\%), operator and maintenance errors (41\%), inadequate or improper procedures (11\%), inadequate or improper inspection (5\%), and miscellaneous (2\%). 
Between September 1993 and February 1994 the Abnormal Situation Management (ASM) Consortium team visited six chemical plants in the U.S and Europe to study and obtain an understanding of abnormal situations (Bullemer and Nimmo 1994). The method used for these site visits consisted of observing and interviewing personnel from operations, engineering, and management. Plant incident reports were also reviewed to gather further insight into the scope of abnormal situations. From the information collected at the six chemical plants, specifically from plant incident reports, the ASM Consortium team was able to identify the primary initiating causes of incidents. It was also observed that training programs tended to be narrowly focused due to a lack of formal training practices to effectively build the knowledge, skills, and abilities of operations personnel. It was noted that due to the low situational awareness of supervisors and field operators, since they were not console operators, they were not able to provide significant guidance to console operators who then by default managed the Distributed Control System (DCS) system. Because of this observation, the authors pointed out console operators expressed a need for more effective training. Bullemer and Nimmo also reported feedback from the companies who expressed a reluctance to identify people as the initiating cause of an incident (Bullemer and Nimmo 1994).

Moreover, observations revealed that operator training activities were not keeping pace with technological developments (Bullemer and Nimmo 1994). The authors found the causes initiating abnormal situations to be people and work practices (42\%), equipment (36\%), and processes (22\%) (Bullemer and Nimmo 1994).

Goldstein states essential components help ensure an effective training program (Goldstein 1986). These include (1) needs analysis; (2) practices; and (3) evaluation. Another study of twelve refineries yielded very similar findings to the framework proposed by Goldstein 
(Bullemer and Nimmo 1998). From the studies conducted by the ASM Consortium team it was observed that the plants studied lacked formal needs assessment activities and there was a general lack of understanding as to the initiating causes of abnormal situations. The training evaluation findings yielded similar observations which included lack of a formal evaluation effort and a short term focus on training. Training practices observed focus on "on-the-job" training (OJT), initial training for field operators, moderate training for console operators, and little training for remaining operations personnel. The authors interestingly noted for many companies organizational obstacles such as schedules, staffing, availability of trainers, and availability of training materials was hindering effective "hands-on" training and/or "on-the-job" training.

An interesting finding in Bullemer's and Nimmo's (1994) study was field operators were provided no formal refresher training. However, the new Instrumentation Society of America (ISA) Alarm Management standard 18.02, currently in draft form, states refresher training shall be conducted to ensure operators are able to execute the appropriate corrective action when required while maintaining consistency when executing procedures (ISA 2008). The ISA 18.02 standard also states the refresher training should cover a broad range of operating scenarios and be conducted over regular intervals. Moreover, the ISA 18.02 standard defines these respective training requirements for maintenance personnel. The EEMUA No. 191 standard on Alarm Management calls for training which encompasses all realistic operational usage of the alarm system, requiring all operators be trained on the portion of the alarm system with which they actually work, and this should include initial training, refresher training, and training on new alarm facilities. The EEMUA No. 191 standard further states operators should be trained in detecting and diagnosing fault diagnosis of the alarm system. 
Bullemer and Nimmo discuss characteristics of a good training program which include ensuring the workforce skill level meets or exceeds the national average. The authors also suggest training programs must be strong individual motivators, and act as an effective catalyst for change (Bullemer and Nimmo 1998). These authors reference a study conducted by The National Institute for Occupational Safety and Health that found traditional methods, (e.g. seminars, posters, videos), of training typically fail due to the lack of basic human factors. The authors report on their observation of successful training practices in industry which include "onthe-job" training coupled with manuals and introductory courses, training manuals for each role, peer to peer training, computer-based training, and independent study (Bullemer and Nimmo 1998). It is important to note that the authors indicate successful training programs consist of a combination of methods individually tailored to each plant. A variety of factors influencing a plant's training program structure and organization are offered ranging from the number of operators per training session up to and including accommodating training during a turnaround.

Given the wealth of research findings highlighting gaps and deficiencies in operator training Bullemer and Nimmo called for a new standard of training to be implemented (Bullemer and Nimmo 1994). The new standard would include a training program that is incorporated into the daily activities of an operator's job and provide a work environment conducive to continuous learning. The goal here would be to optimize an operator's knowledge base and skill set which should significantly improve operations efficiency and effectiveness. The authors cite that a significant obstacle to knowledge development is the lack of resources for managing abnormal situations.

In regards to skill development Bullemer and Nimmo state to improve an operator's skill set plants must provide operators a resource to practice managing realistic abnormal situations as 
a team, (e.g. high fidelity simulators), and these practice sessions should provide individualized feedback and be conducted on a regular basis (Bullemer and Nimmo 1994). However, using high fidelity simulators alone will not guarantee better results, because these resources must be used in combination with realistic operating constraints and scenarios (Bullemer and Nimmo 1998).

\subsection{HMI Interface}

In the mid-1990's, the Abnormal Situation Management Consortium set out to examine the value of developing an Abnormal Event Guidance Information System (AEGIS) (Nimmo 1995). This system would offer console operators and other operations team members unmatched levels of control over processes within a plant, especially during scheduled shutdowns and startups given that the chance for a process upset is high during this time (Nimmo 1995). The principle functions of this system would be to assist operators in knowledge acquisition, memory requirements, offer predictive hypothesis testing of the process state, provide training resources, and it would be able to dynamically assess process variables depending on the intended state of a process (Nimmo 1995). The author describes these features will produce a more efficient, effective, and safe operating environment.

One of the most discussed topics regarding human factors is the human-machine interface (HMI). One factor affecting the HMI is display design for the console. Two important design features need to be considered here, one is the ergonomics of the physical layout (physical design considerations) and two is the graphics layout presented to the operator (cognitive design considerations). There are many methods for presenting alarm and process information to an operator, but the industry is only concerned with the interface that allows an operator to work most efficiently and effectively. One study funded by the ASM Consortium showed implementing human factors engineering into the design of an operator's graphical user interface 
(GUI) resulted in a $41 \%$ faster resolution of an abnormal situation as compared to utilizing a traditional interface (Errington, Reising et al. 2005). Some key features implemented in their study's interface design are listed below (Errington, Reising et al. 2006).

- multi-windowing with controlled window management to minimize display overlays

- multi-level, simultaneous views of increasing plant detail

- yoked navigation between display levels (i.e., automated display invocation through preconfigured display associations for assisted, task-relevant navigation)

- tabbed navigation within a display level

- integrated trending of historical information

- integrated alarm management into graphics and navigation tabs

- right-mouse click access to online documentation

- human factors graphics design (e.g., principled/limited color-coding of critical changing information; limited 3-D objects; simple/effective symbols)

- access to online information (e.g., alarm rationalization documentation, operating procedures, shift logbook)

\subsubsection{Console Design - Physical Design Considerations}

To start, one of the first components to be designed for an operator's process and alarm system is the physical workstation or console. Console design begins with the development of the facility layout that must accommodate communication between operators \& supervisors, thru-traffic, and other disruptions to the operator (Smith and Walker 2001). According to Smith \& Walker (2001) the console design methodology must begin with an analysis of the user's needs. This analysis consists of the operator workload, task load, corporate culture, situational awareness, and communication. It should be noted that in a study conducted by Reising, Downs 
et al. (2004) it was determined that the average time required for an operator to detect, analyze, and respond to an alarm is 49 seconds. This helps determine how an operator's workload and task load can be defined, and console features can be designed accordingly. For example, the physical workstation can be designed to reduce operator movement when troubleshooting a problem during an upset. Also, the GUI could be designed to minimize the number of mouse clicks to access detailed process and alarm information. Moreover, a company's culture should also be considered in console design because behavioral characteristics and conflicting personalities could have a detrimental impact on an operator's ability to effectively and efficiently communicate operational needs (Smith and Walker 2001).

Once the task analysis has been completed the design of the console can begin. Factors to consider when designing the console should include postural considerations, visual comfort, and environmental factors (Smith and Walker 2001). Table 1 presents these factors.

Table 1 - Considerations When Designing Operator Consoles

\begin{tabular}{l|l|l}
\hline Postural Considerations & Visual Considerations & $\begin{array}{l}\text { Environmental } \\
\text { Considerations }\end{array}$ \\
\hline $\begin{array}{l}\text { 1. Height of console (adjustable } \\
\text { height) }\end{array}$ & $\begin{array}{l}\text { 1. Height of viewing } \\
\text { monitor }\end{array}$ & $\begin{array}{l}\text { 1. Through traffic } \\
\text { 2. Lighting levels } \\
\text { 2. Noise levels }\end{array}$ \\
$\begin{array}{l}\text { 2. Roach distances (keyboards or } \\
\text { pointing device) }\end{array}$ & $\begin{array}{l}\text { Angle of monitor relative } \\
\text { to vertical } \\
\text { tables (adjustable) }\end{array}$ & $\begin{array}{l}\text { 3. Eye-screen distance } \\
\text { 4. Lateral location }\end{array}$ \\
\hline
\end{tabular}

\subsubsection{Graphical User Interface - Cognitive Design Considerations}

Another component to consider when designing an operator user interface is the graphics display properties, (e.g. color, symbols, alpha-numeric attributes, flashing, audible annunciation, and a combination of the aforementioned). These tools should be used to design a display which can effectively draw an operator's attention to unexpected process deviations \& new alarms, 
provide a means for viewing the state of the process \& alarms, and it should allow the operator a safe amount of time to take action on the required response to alarms before an upset occurs (EEMUA 1999). An operator must be able to readily and easily detect relevant data flowing through the system in order to meet the EEMUA standard of drawing one's attention to new alarms.

A solution to this is offered by Woods (1984) using the idea of virtual momentum. Virtual momentum can be defined as a user's ability to extract relevant information across views and displays. When consistency across graphical user interfaces is increased virtual momentum will be high, thus allowing operators easy access to pertinent information (Watts-Perotti and Woods 1999). While the EEMUA No. 191 Alarm Management standard offers readers the industry's best practices regarding alarm management it was not intended to address the development and maintenance of graphical user interfaces. The API RP1165 (Recommended Practice for Pipeline SCADA Displays) was created to focus on design and implementation of displays used for SCADA systems (API 2007). Also, the EEMUA No. 201 standard published in 2002 offers high-level guidance or general principles on the development and maintenance of graphical user interfaces, or human computer interface (HCI) (EEMUA 2002). The standard is comprehensive in that it defines what the HCI is, briefly explains the role of the operator, and largely focuses on HCI design, (e.g. number of screens, display formatting, navigation, functional \& system requirements, and methodologies \& lifecycle stages for human computer interfaces).

The use of alpha-numeric and text has been the traditional method of presentation for the alarm list/summary to the operator (Errington, Reising et al. 2006). Using text to communicate important information has distinct advantages and disadvantages. Some advantages are that text 
provides quick recognition of data and accurately presents quantitative data (Shahriari, Shee et al. 2006). Disadvantages using text include difficulty locating individual data in list or tables, rate of data change can cause alarm list to become unmanageable, and text cannot effectively illustrate parameters being measured by the alarm system, (e.g. trendable information) (Shahriari, Shee et al. 2006). Also, care should be taken when designing text into displays because it may not be conducive to allowing an operator the ability to detect trends during operations. It should be noted that trend analysis was implemented by ASM in their graphical user interface, where a $40 \%$ increase in operator productivity was observed (Errington, Reising et al. 2005).

Color is yet another human factors consideration which should be well thought-out when designing the graphics display. It is a good idea to incorporate use of color when distinct categories of data presented to an operator need to be quickly and easily distinguished, such as a list of alarm text messages (MPR Associates and Laboratory 2004). The purpose of this is to aid the operator in navigating through alarms that are prioritized as either low, medium, or high; this prioritization schedule is chosen arbitrarily. Prioritization of alarms will be discussed in a later section. As with text, color has limitations on its usefulness if misused. It should be clear that color is not intended to be used for separating every aspect of the display design (MPR Associates and Laboratory 2004). If color is used excessively it may hinder an operator's ability to recognize and distinguish between alarm priorities.

The EEMUA No. 201 standard on HCI design parallels the practice of using color to enable an operator to more readily distinguish areas of importance. EMMUA No. 201 states that color should not overwhelm an operator, rendering the use of color meaningless or creating a hindrance. Also, over use of color could easily decrease the amount of time available for an 
operator to take action on an alarm's required response, leading to poor system performance or an accident.

According to research conducted by MPR Associates and Laboratory (2004) some ways to hedge against the shortcomings of implementing color is to use no more than a maximum of six colors, and apply color coding according to already standardized or typical user meanings. This can help avoid mentally overloading an operator because an operator will not have to distinguish between many or ambiguous shades of colors. Also, operators may be more likely to recognize, distinguish, and discriminate between alarms of different priority if alarms can be coded to colors in which operators already have associations with specific conditions, (e.g. red danger, yellow - abnormal condition, green - alarm cleared) (MPR Associates and Laboratory 2004). More information on common conditions associated with colors please refer to Appendix 1. Another consideration when implementing color into the design of graphical user interfaces is color blind operators. The EEMUA No. 201 HCI standard offers an alternative that may help combat the presence of color blind operators. This standard suggest that it is a good practice to design the graphical user interface to be monochrome (EEMUA 2002). The authors do not specifically state this design technique can be used design around color blind operators, but this may offer an attractive and practical design alternative. The writers emphasize that this is a good technique to practice during interface design in general to help prevent implementation of excessive color use (EEMUA 2002). Also, high priority alarms should be assigned a readily distinguishable color which is easily recognizable against the background \& low priority alarms presented in progressively less conspicuous colors, but still identifiable (EEMUA 1999).

The use of icons and symbols can be incorporated into an operator's graphical user interface to allow better use of space and promote quick detection of an abnormal situation 
(MPR Associates and Laboratory 2004). For these types of display characteristics to be operationally effective, designers must consider human factors during the design stage. Some important factors to incorporate into the design of symbols and icons are listed below (MPR Associates and Laboratory 2004).

- Must be distinct and readily identifiable

- Must be large enough to be distinguished by the operator

- Meaning should be easily discernible

- Design should incorporate typical conventions known by the operator

- Alarm communication or state change should be readily identifiable by the operator

- Should accurately reflect the unit, process, or state it represents

Designers may also want to incorporate design features like hidden text or right-click help dialog boxes to aid operators, particularly new operators, with the identification \& meanings of symbols and icons.

Further, the EEMUA No. $201 \mathrm{HCI}$ design standard begins to define detailed system and functional requirements (EEMUA 2002). The first of several recommendations in executing HCI design is to perform task analysis to determine the functional and system needs for an operator. Second, operators and other end users should be included in the HCI design process. Third, the number of screens implemented in the HCI should provide an operator complete access to all required process information and controls during any operational state. Next, the concept of situational awareness should be addressed by highlighting the fact that an operator's overall view of the process can be negatively impacted when using a GUI, if designed poorly, in place of a hardwired panel annunciator system.

Given the limitation of the GUI to display large amounts of information on a single fixed 
size screen the EEMUA No. $201 \mathrm{HCI}$ standard recommends that a screen be solely dedicated to displaying an overview of the plant, thus attempting to provide an equivalent level of situational awareness or better than that of a hardwired panel display. This standard also recommends an HCI design where alarm information is continuously accessible. The standard also recommends that system expendability be considered during the design of a HCI. Finally, the reliability requirements of the HCI system must be evaluated against any respective or unique operating conditions or system constraints to ensure compliance with regulatory requirements and/or safe operation of the process.

\subsection{Operator Fatigue Considerations}

Operator fatigue is another important challenge designers of alarm system must contend with to ensure optimum performance. Many factors lead to operator fatigue and companies should be aware of the debilitating mental and physical affects and the impact on system performance. One challenge which is conducive to increased fatigue in any control room setting is due to 24 hours a day 7 days a week operations. Further, twelve hour shifts are common in the

process control and pipeline industry leading to negative effects on an operator's circadian rhythm (Walker, Smith et al. 2003). These authors specifically state this is particularly relevant to operators on the night shift. Furthermore, they proceeded to suggest methods and practices to help prevent the affects of shift-work fatigue. Some of Walker et al. (2003) suggestions are listed below.

- Reduce glare on monitors

- Play music

- Reduce ambient noise (printers, copiers, fax)

- Vary employees' posture 
- Keep temperatures cool

- Allow naps (no longer than 45 min.)

- Add simulated daylight

- Use bright lighting (in the workplace)

- Get 6-8 hours of sleep each night

- Improve sleep environment (dark room, lock doors, reduce noise \& distractions)

The above steps provide examples on how to reduce operator fatigue and reduce its adverse affects on alarm system performance. Increased alarm system performance should result in safer operations, reduced economic losses, reduced risk to environmental \& equipment damage, and decreased product loss.

In September 2008, PHMSA released a document proposing to revise the current Federal Pipeline Safety Regulations, noting that the NTSB recognizes fatigue as one of its top ten safety hazards (Pipeline and Hazardous Materials Safety Administration (PHMSA) 2008). In this proposed rule the need to educate and train operators and supervisors regarding fatigue mitigation strategies is addressed. PHMSA specifically noted that operators would be trained on how non-work related activities contribute to fatigue and ultimately impact performance negatively.

\subsection{Situational Awareness}

An operator's situational awareness has been diminished progressively as automation has increased (Smith and Walker 2001). This affects an operator's ability to have a clear comprehensive visual representation or model of the unit, plant, pipeline, or process being controlled. Some sites and pipeline companies have tried to overcome the decreased situational awareness by implementing overview displays, which depict a high level graphical 
representation of the unit, pipeline, plant, or process onto a large display screen big enough for every operator in the control room to view from their console. Overview displays can also be scaled down for incorporation into an operator's graphical user interface.

Some guidance to help increase an operator's situational awareness is offered indirectly in EEMUA's No. 201 HCI standard. Some key design principles to emphasize when developing an operator's workstation HCI are, in order of importance, (1) Abnormal situation handling; (2) Normal operation; (3) Optimization; and (4) Informational retrieval. The point being made here is that proper workstation design can significantly aid an operator's situational awareness.

\subsection{Alarm System Lifecycle and Benchmarking Standards}

\subsubsection{Introduction to the Challenge}

According to the ASM Consortium, it is estimated that poor alarm management (e.g. consequences being safety, environmental, and economic) practices cost the industry approximately $\$ 13$ billion dollars each year (Dunn and Sands 2005). An earlier finding found abnormal situations cost the industry over $\$ 20$ billion each year (Nimmo 1995). The purpose of quantifying alarm system performance is simply to make the system operate more efficiently and effectively so to reduce and eventually eliminate losses due to poor alarm management. Factors which contribute to the performance of the alarm system include human operator error, operator training, task load, workload, HMI, SCADA/DCS/alarm system components, the site's alarm management philosophy, alarm overloads, stale alarms, nuisance alarms, and bad alarm settings among others.

\subsubsection{Alarm Management Lifecycle}

To achieve optimum alarm system performance a lifecycle approach is a logical choice to 
implement because of its structured methodology for approaching and working towards deficiencies. Dunn \& Sands (2005) offer this through their seven step lifecycle approach, adapted from the most current draft of ISA's 18.02 standard, geared towards aiding companies during the alarm management process. EEMUA No. 191 standard follows a similar approach and method, however Dunn and Sands (2005) illustration of the methodology adapted from the ISA 18.02 standard offers an easily understandable view of the overall alarm management process. A figure of this alarm management lifecycle is presented in Figure 1.

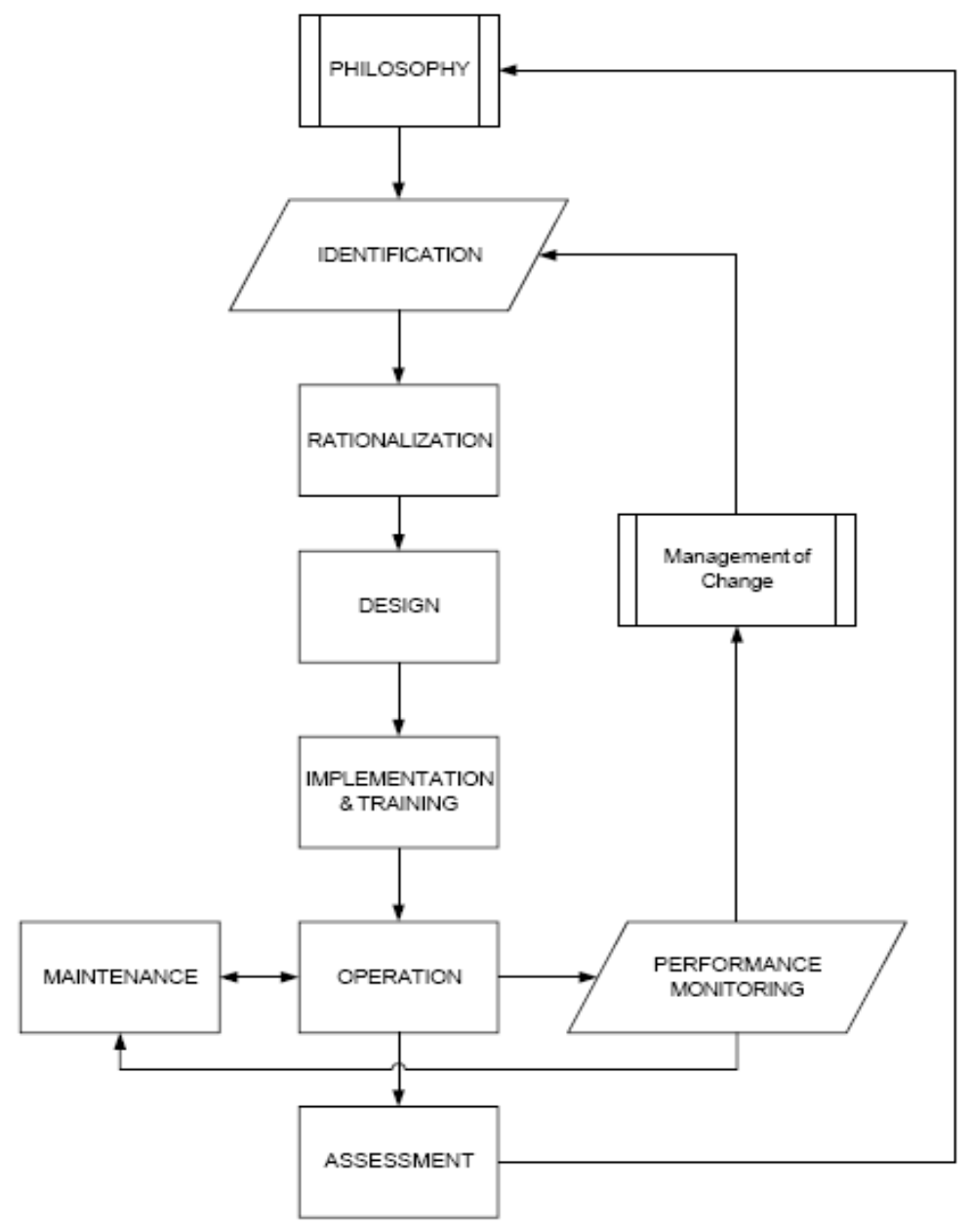

Figure 1- Alarm Management Lifecycle

\subsubsection{Alarm Philosophy}

Many authors, Bass (2007), Dunn \& Sands (2005), EEMUA (1999), ISA (2008), and API 
(2009) discuss what components should be included in the alarm philosophy. Key components of the alarm system philosophy document compiled from the four aforementioned authors are listed below:

- Definition of the alarm and purpose of the system

- Specify key design principles/goals of the alarm system (purpose is to guide operator to required action)

- Define a lifecycle approach for alarm management with feedback loops for continuous improvement. The ISA 18.02 document provides a good base or starting point to developing a site specific alarm management lifecycle

- Provide an operating framework for each alarm management lifecycle component

- Clearly identify the roles and responsibilities of the operator for each operating state, and roles/responsibilities related to $\&$ in response to alarms

- Rationalization processes for alarms, i.e. creating or removing alarms

- Maintenance procedures and monitoring requirements for the alarm system, i.e. testing of alarms periodically

- How alarms will be prioritized and classified (economic, safety, environmental), i.e. methodology describing how alarms will be prioritized and classified. Also, each class and priority level should be defined

- Management of change procedures

- Alarm audit requirements and processes

- Performance monitoring techniques and metrics (identify an appropriate benchmark)

- How alarms will be presented to the operator, acknowledged, and what is the defined response 
- Operating characteristics unique to an operating company's site or facility

- Comprehensive overview of the alarm system suppression techniques/processes

- Alarm system's relationship to other relevant site procedures

- Operator Training

\subsubsection{Identification}

The identification stage in the lifecycle should facilitate a methodology for recognizing the need to alarm, which will later be thoroughly evaluated and analyzed in the rationalization stage (Dunn and Sands 2005). The intention of identification is not to conduct a formal analysis of each new alarm only to justify approving it, in place of arbitrarily creating alarms. EEMUA (1999) states that "every alarm should be justified, properly engineered, and be consistent with the overall alarm philosophy \& plant risk assessment." This stage is particularly important due to government regulation specifically requiring employers to "make suitable and sufficient assessment of risk" (EEMUA 1999).

Request for alarms can originate from process hazards analysis, safety requirement specifications, recommendations from an incident investigation, new industry best practices, operator feedback, and/or Process and Instrumentation Display (P\&ID) development or operating procedure reviews (ISA 2008). General guidelines to consider when identifying possible alarms during the risk assessment is to focus on risks or hazards which an alarm would greatly reduce the potential for environmental, safety, or economic loss (EEMUA 1999).

\subsubsection{Rationalization}

Rationalization is a means of thoroughly analyzing each potential alarm against a set of standardized criteria in the alarm philosophy (Dunn and Sands 2005). The goal of the 
rationalization stage is to only create those alarms that will add value to the operator and not contribute to an alarm overload situation. It should be intuitive that if alarms are not evaluated according to a set of standardized criteria listed in the alarm philosophy (at the very least a set of standardized criteria) the creation of many unnecessary and unjustified alarms will possibly be the result. Some considerations to emphasize when rationalizing an alarm are its purpose, the severity of risk, frequency of possible risk, prioritization, operator response, alarm settings, suppression techniques, and management control (EEMUA 1999).

\subsubsection{Design of Alarms}

The design process focuses on the configuration of alarms, design of the human machine interface, and any advanced/artificial intelligence suppression techniques (advanced alarming techniques) based on the alarm requirements identified during the rationalization stage (ISA 2008). Obviously, once the alarm is in the design phase the key design principles in the alarm philosophy should be used to configure the alarm (EEMUA 1999). Consistently applying the key design principles to each alarm will help ensure optimum alarm operation when an alarm is put online and this effort should also reduce the potential of the alarm to contribute to alarm floods. Designers would ideally incorporate human factors engineering into the HMI and GUI to help aid an operator detect abnormal situations and then aid an operator to respond accordingly. This information may not always be appropriate to include in the alarm philosophy document because of the extensive amount of technical information, however it may be a good practice to include general guidelines (Dunn and Sands 2005). Moreover, if a site or facility has highly customized HMI or GUI design standards to compliment the current alarm system it may prove advantageous to incorporate this into the alarm philosophy document. Moreover, the American Petroleum Institute's 1165 standard on display design provides design engineers useful insight 
about current industry best practices when designing an HCI/HMI or GUI.

\subsubsection{Implementation}

Implementation focuses on installing the new alarm in the alarm system and making sure the system is functioning properly to proceed with testing (Dunn and Sands 2005). The ISA 18.02 standard outlines the requirements to install an alarm/(alarm system) or modify an existing alarm or alarm system. These requirements include training for operators (initial and refresher), testing and validation, and documentation requirements. Objectives of this stage are to troubleshoot and identify design flaws, and then correct them before the new alarm becomes fully operational. Moreover, this testing and operator training stage could benefit from a corporate culture that is conducive to constructive feedback because experienced operators often have valuable information that can add significant justification and value to an alarm (Mattiasson 1999).

\subsubsection{Operation}

Dunn \& Sands (2005) define the operation stage as the point at which abnormal situations are able to be presented to the operator during regular operational monitoring and control. At this stage a new alarm has become fully operational and able to provide critical feedback to the operator on the condition of the unit, process, pipeline, or plant (ISA 2008). Three final stages combine to form a feedback loop for continuous improvement: (1) Maintenance; (2) Performance monitoring; and (3) Assessment. Performance monitoring will be implemented after the alarm becomes operational and will continue on a more frequent basis than the assessment stage (ISA 2008). In this part of the feedback loop key performance indicators should be selected (Errington, DeMaere et al. 2004). Bass (2007) indicates a low alarm rate is the best 
performance indicator for an alarm management program. Additional metrics used in the performance evaluation are standing \& stale alarm analysis, average \& peak alarm rate analysis, and time in an abnormal operating state, i.e. greater than ten alarms in a ten minute interval (Errington, DeMaere et al. 2004).

\subsubsection{Lifecycle Loops (Maintenance, Performance Monitoring, and MOC)}

During the maintenance stage the alarm sensor device is serviced according to its individualized maintenance schedule (Dunn and Sands 2005). The goal here is to help ensure the accuracy of the measurement device in the field and make sure it is calibrated properly with the alarm system. The next lifecycle loop to be implemented is management of change (MOC). This process is dynamic and is used as needed allowing an alarm to be evaluated after some period of time after it has been in operation (Dunn and Sands 2005). This stage enables one of the continuous improvement opportunities that have been built into this alarm management process. The management of change procedures should be clearly defined in the philosophy document and a good practice for decision management is structuring changes according to priority of the alarms (EEMUA 1999). For example, low priority alarms may not require the level of scrutiny that a critical or safety alarm requires.

\subsubsection{Assessment}

Finally, the assessment stage of the lifecycle deals with analyzing each alarm to ensure it accurately reflects the standards set forth in the alarm philosophy document (Dunn and Sands 2005). Assessments, often referred to as alarm audits or rationalizations, are most often conducted when a site's management recognize the alarm system's usefulness has deteriorated to the point where it is no longer efficient or effective at alerting operators of abnormal situations 
(Mostia Jr 2003). A more proactive solution than postponing the assessment process until operations are significantly affected is to complete the process on a more consistent basis. This should improve the quality of the assessment process because the task load would probably be substantially less, allowing a project team to focus their resources on a fewer number of poorly configured alarms/implemented alarms.

Also, the assessment process may not always result in a reduced number of alarms. Remember, the purpose of the assessment process is to make sure the alarm system meets the requirements in the alarm philosophy document. For instance, if a deficiency is recognized during the assessment process an alarm should be identified, scrutinized in the rationalization stage, and if that alarm is found to add value to the system it should be designed \& implemented. The point here is that if an alarm will add material value to the system it should be included. A good example of this situation is demonstrated in a study conducted by the ASM Consortium. A chemical plant performed an alarm rationalization and focused their efforts on worst actors in their alarm system. After the process was completed the site realized a $20 \%$ increase in the number of configured alarms (Reising and Montgomery 2005). However, the same plant's average alarm rate decreased by about $33 \%$. Over a three and one-half year period this plant was able to achieve a cumulative reduction in the average alarm rate of $94 \%$.

\subsection{Observed Alarm Performance vs. EMMUA No. 191 Standard of Performance}

\subsubsection{Analysis of the Results}

Widely known in industries with operator control rooms is the EEMUA No. 191 alarm system performance standards (Appendix 2). Some operating companies express that the EEMUA standard is geared towards process plants and therefore assume the standard does not 
reflect appropriate benchmarks for the pipeline community. In support of this, there is little published empirical research regarding specific best practices for pipeline control room operators relative to other topics studied in the petroleum industry. However, the Engineering Equipment Materials and Users Association (EEMUA) No.191 authors imply that research conducted in the process industry or elsewhere in a control room setting, (e.g. a refinery or similar control room environments), can be used to improve human factors design and benchmark performance in the pipeline industry, as well as other industries.

Moreover, research conducted by the ASM consortium suggests that the EEMUA standards are not entirely unachievable (Reising and Montgomery 2005). The ASM group conducted a study including 37 operator consoles and collected statistics on monthly average alarm rates \& monthly peak average alarm rates following major plant disruptions. The monthly average alarm rate was calculated to be 2.3 and median value of 1.77 alarms per ten minute period for normal operations, while the Health \& Safety Executive alarm study reported 5 alarms per ten minute period (Reising and Montgomery 2005). For 95\% of the consoles included in the study the average monthly peak alarm rate reported was 31-50 alarms per ten minute interval. For a more detailed description and analysis of the ASM study refer to (Reising and Montgomery 2005).

\subsubsection{Interpretations}

The results of the ASM study demonstrated that during normal operations the EEMUA standards, based on a consensus of industry experience, appear to be attainable today in the near future. Unfortunately, the peak alarm rates during abnormal situations continue to present challenges to operating companies when compared against the EEMUA No. 191 standard for alarm system performance. The EEMUA No. 191 standard states there should be no more than 
one alarm per one minute period during a plant upset, or stated differently no more than ten alarms in the first ten minutes of a plant upset (EEMUA 1999).

\subsection{HMI Studies}

There is little published research empirically evaluating different alarm rates and display methodologies on pipeline operator performance. A study has been conducted which utilizes Keystroke-Level Modeling and Markov Modeling to assess the observed performance of human operators against the standards currently adopted by the industry (Reising, Downs et al. 2004). The methodology used for the Keystroke-level Modeling included using Goals, Methods, Operators, and Selection Rules (GOMS) analysis to create a framework of elemental human operator tasks for a "prototypical" response to an alarm. These elemental tasks were then assigned "psychological-based time constants." Several validating assumptions regarding the aforementioned GOMS task framework and alarm system time constants and other parameters, (e.g. system lag time, event size), were identified. The methodology used for the Markov Modeling focused on estimating the time required to respond per alarm generated. This method included recording video of five experienced operators while they completed their annual simulator training. Each operator completed each alarm scenario on a high fidelity simulator simulating their respective units. The training session consisted of four to five operating scenarios ranging from a valve failing in the open position to a turbine trip. Communications with field operators and console operators were simulated by the unit trainer via a radio. Using the video recordings and the GOMS elemental task framework the authors constructed a time per element task document for each scenario and operator.

An interesting finding using Keystroke-Level Modeling is that given a burst of ten alarms the time required of an operator to complete the high level goals in the GOMS framework is 
thirty four minutes and four seconds (Reising, Downs et al. 2004). The time required to respond to just one alarm was found to be three minutes and twenty two seconds. When compared to the EEMUA No. 191 standard (no more than ten alarms in the first ten minutes following a process upset) a person realizes that even a relatively small number of alarms such as ten can initiate a time consuming alarm response process. However, often times an operator must work quickly to resolve an abnormal situation before the process becomes unstable and causes product loss, property damage, or injury. So, this study shows that reducing the number of alarms presented to an operator may have a significant positive effect on reducing the likelihood an incident will escalate in severity. Further, the leading contributor to higher response times when responding to alarms was found to be the time required to assess new alarms (Reising, Downs et al. 2004). This finding also supports the notion that fewer alarms presented to an operator will result in quicker resolutions of abnormal situations. The second study method, Markov Method, found the average time required of the five operators studied to completely handle one alarm was found to be 49.1 seconds (Reising, Downs et al. 2004).

In another study conducted involving 21 console operators performing simulated operating scenarios on traditional and new human-centered design high fidelity training simulators results showed significant gains in operating performance can be realized by implementing a human-centered design interface (Errington, Reising et al. 2005). The experimental method included identifying two high fidelity training simulators. One of which was just recently designed implementing human-centered design and another that was representative of a more traditional control interface. Both interfaces utilized a Honeywell Total Plant System control system. Eleven operators were selected to perform the experiment on the new human-centered interface and ten were selected for the traditional interface. All operating 
scenarios were modeled from past process upsets at each respective plant and each operator completed the experiment interacting with an interface that accurately represented the interface currently online in the respective plants. It should be noted that only data from four of the eight operating scenarios were used in analyzing the experimental data and efforts were taken to design the experimental operating scenarios to make use of the beneficial features when using the human-centered design interface.

Results of the study yielded the finding that operators who used the human-centered design interface responded to an abnormal situation 7.5 minutes (41\%) faster on average than operators using the traditional interface (Errington, Reising et al. 2005). It was also observed that the response time variance between operators using the two interfaces was reduced when using the human-centered design. Further, it was observed that early event detection reported by operators using the human-centered design interface was found to be $47.7 \%$ on average and early event detection reported by operators using the traditional interface was calculated to be $10 \%$ on average (Errington, Reising et al. 2005). Finally, results observed showed that operators using the human-centered design interface completed operating scenarios $95.5 \%$ on average and operators using the traditional interface yielded a result of $70 \%$ completion on average (Errington, Reising et al. 2005).

\subsection{Roles and Responsibilities of the Operator}

The proposed rule issued by PHMSA requires each operating company to clearly define and document the roles and responsibilities of control room operators, explaining that such documentation should define an operator's authority and expectation of the operator.

EEMUA No. 191 defines the roles and responsibilities for an operator in three operating

states. They include (1) Normal; (2) Upset; and (3) Shut-down. These roles should be clearly 
defined in the philosophy document and broken down into subsections stating the role for each operating state of the system and define the required actions for each state, (e.g. normal, upset, and shutdown) (EEMUA 1999). Another plant state which could be defined is the planned offnormal situation (Errington, DeMaere et al. 2004). A table using data compiled from Errington et al. (2004) and EEMUA (1999) outlining the roles and responsibilities of the operator for each state is detailed below (Table 2).

Table 2 - Roles and Responsibilities of the Console Operator

\begin{tabular}{l|l|l}
\hline Operating State & Operator's Role & Alarm Information Needed \\
\hline Normal & $\begin{array}{l}\text { Monitoring, optimization, coordination } \\
\text { of maintenance }\end{array}$ & $\begin{array}{l}\text { Alert of minor operating adjustments } \\
\text { required }\end{array}$ \\
\hline Planned Off-Normal & $\begin{array}{l}\text { Manage intended operation and } \\
\text { coordinate changes to the planned off- } \\
\text { normal situation }\end{array}$ & $\begin{array}{l}\text { Alert operator intended operation is } \\
\text { deviating from planned or required } \\
\text { responses }\end{array}$ \\
\hline Abnormal Situation & $\begin{array}{l}\text { Manage the alarm response system } \\
\text { manually where appropriate }\end{array}$ & $\begin{array}{l}\text { Prioritize and clearly present alarms needed } \\
\text { to return operation to a normal state }\end{array}$ \\
\hline Shut-down & Ensure shutdown proceeds safely & $\begin{array}{l}\text { Prioritize critical and safety alarms which } \\
\text { require action }\end{array}$ \\
\hline
\end{tabular}

\subsection{Summary of Literature Review}

The topic of alarm management is of great importance to the pipeline industry, as well as many other industries which operate control rooms. There is also great diversity in regards to the practice of design principles, management philosophies, and equipment procurement. Organizations like EEMUA, API, ASM Consortium, H\&SE, ISA, and others have dedicated themselves to the standardization of processes and technologies across industries that routinely transport/process large amounts of gas or hazardous liquids. Many successes have been realized when a site's management show a genuine commitment to an alarm management lifecycle to improve the performance of the alarm system. For example, NOVA Chemicals realized great success when an alarm assessment and rationalization was completed at one of their plants, and 
the company also expressed the most significant contributing factor to their success was consistently following the alarm management lifecycle (Errington, DeMaere et al. 2004). Another success story is exemplified by Xcel Energy which reduced the alarm rate per shift from several hundred to only about 8 , and during upsets a trip would typically produce no more than 20 alarms (Bass 2007). It should be noted that Xcel Energy commissioned a team of experts who worked about 10 hours each week for a two year period to obtain that level of performance. Good alarm system performance has been demonstrated to be achievable, however a company must be committed to a continually improving the system through a lifecycle approach. 


\section{CHAPTER 3. EXPERIMENTAL METHOD AND PROCEDURE}

\subsection{Experimental Design and Layout}

The experimental model used for this study was a repeated measures design where all participants were subjected to the same conditions. Each participant was trained in an effort to orient participants to the type of situations they would experience during supervision and management of the simulated pipeline system. More detail regarding participant training can be found in the Training and Selection section 3.3 below. For the main experiment participants completed ten separate experiments lasting ten minutes each. Five experiments were completed by each participant utilizing an alarm window that displays alarms in order of occurrence (chronological) and distinguishing the alarms by priority using color, i.e. three priority levels were used: Red-High, Yellow-Caution, and White-Low. The remaining five experiments completed by participants were done using a different alarm window which displays alarms by grouping them categorically for each priority, although chronologically ordered within each category.

Since this study attempted to empirically determine an alarm rate standard the alarm rate/interval during each experiment was evenly distributed given any number of alarms. For example, for an experiment that would present 20 alarms in ten minutes to a participant, one alarm would display every 30 seconds. The alarm rates chosen for this study were derived from the Engineering Equipment \& Users’ Association standard publication No. 191.

The experimental scenarios completed by participants were randomized. Specifically, the order in which participants completed the five alarm rate experiments using the chronological alarm display and the five alarm rate experiments using the categorized display were randomized between participants. Also, the order in which participants completed the experiment starting 
with a particular alarm display was randomized between participants. Tables displaying the sequences in which participants completed experiments can be found in Appendix 3.

\subsection{Participants}

The participants in this study consisted of undergraduate and graduate students at Louisiana State University. The number of participants to complete the experiment was determined by a statistical power test as subjects completed the experiment. Participants completed the training, qualification testing/assessments, and the two experiments designed to measure specific human performance variables when supervising and operating a high fidelity pipeline simulator. After completing the experiment participants were asked to complete a subjective usability questionnaire; summary data for the questionnaire can be found in the Results section and Appendix 7.

\subsection{Participant Training and Selection}

To help reduce differences among participants attributed to other factors other than those experimentally manipulated all participants completed a training presentation, demonstration/familiarization session, a multiple choice quiz, and training qualification assessment. The training presentation can be found in Appendix 4 and the quiz in Appendix 6 . This battery of pre-experiment training and testing was developed to help ensure only those participants who are able to successfully execute tasks representative to those during the actual experiment would be allowed to complete the experiment. Each participant was trained and oriented via a power point presentation presented by the experimenter (Appendix 4). Afterwards, any questions a participant had were then answered and the participants were shown a demonstration of the type of system they would supervise and manage to familiarize them with 
executing tasks representative of those during the actual experiment.

This training presentation provided each participant with a general overview of the actual pipeline they would operate upon successful completion of training \& qualification and for this particular study it attempted to teach each participant the fundamental principles of abnormal situation assessment and responses which were required for each type of abnormal event simulated in this experiment (e.g. leak/pressure relief event). The principles emphasized were covered in the training presentation and any questions or ambiguities perceived by a participant were answered or clarified verbally and with illustrations/demonstration where appropriate.

\subsection{Equipment and Software}

Advantica's Stoner Pipeline Simulator (SPS) software was used to develop a pipeline model which calculates the fluid hydraulics and transients occurring in the simulated pipeline; simply put SPS is the calculation engine for the simulated pipeline in this study. SPS is widely used in the pipeline community for engineering analysis. Schematic, Advantica's interface design module for SPS, in conjunction with Microsoft Visual Studio.NET 2008, was used to develop the graphical user interface (GUI) for the pipeline model that was developed with SPS. These screens were analogous to the SCADA screens used for online systems. SCADA systems are defined by PHMSA (2008) as serving a principal function to alarm or notify a control room operator of abnormal process deviations, (e.g. pressure, flow, and temperature). A standalone Visual Basic program was developed to present alarms to participants. Our Visual Basic alarm presentation program allowed the manipulation of essential independent variables in this experiment, i.e. alarm category colors and different display methods. Sample pictures of the user interface are provided in Figures 2, 3, and 4.

The interface design for the study utilized four computer monitors, one 19 inch and three 


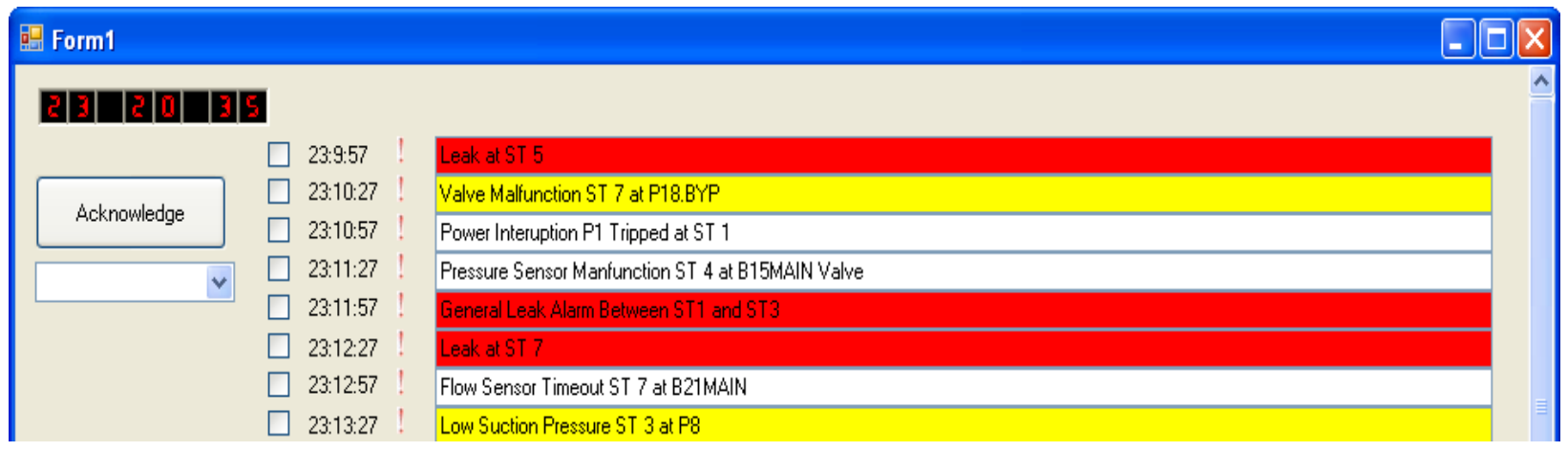

\section{Figure 2 - Example Alarm List Display}

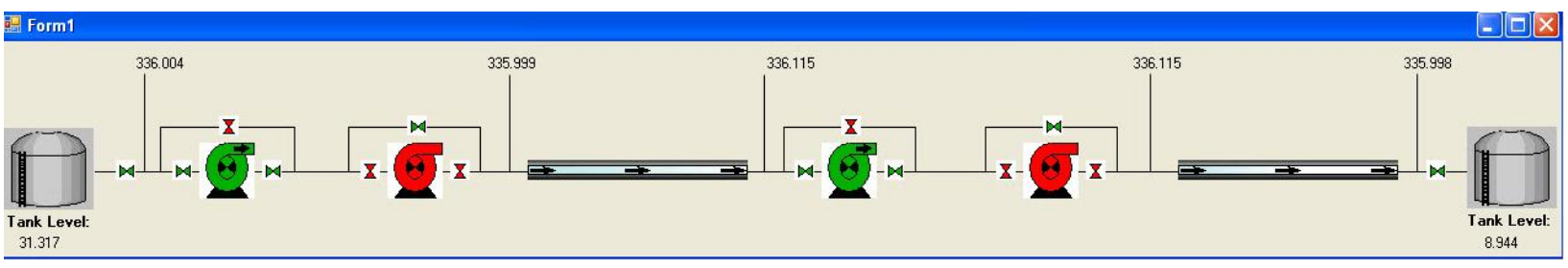

Figure 3 - User Interface Used for Qualifying Participants

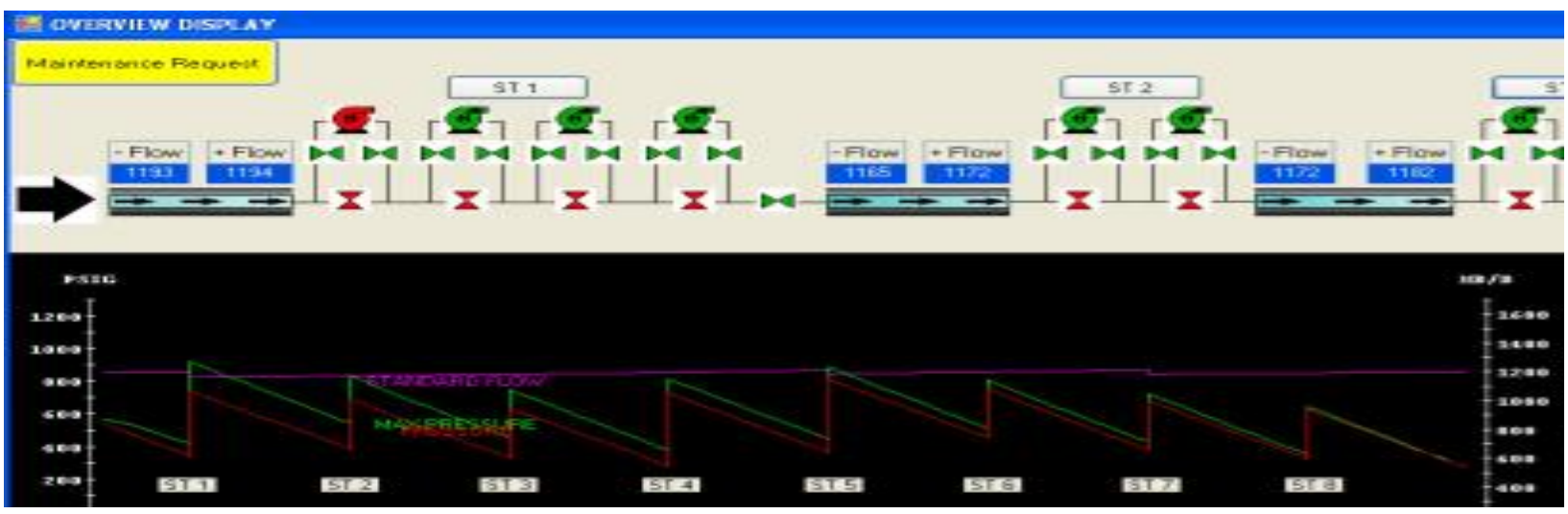

Figure 4 - Partial Snapshot of Overview Display Used During Actual Experiment

17 inch monitors. The 19 inch monitor was used to display the participant qualifying and experiment overview displays. Two 17 inch monitors were dedicated to displaying detailed station displays of the simulated pipeline system. The remaining 17 inch monitor was used to display the alarm window and maintenance request form for the experiments. The additional screens were setup as an extension of the computer's desktop so one keyboard and mouse could control all system functions. A picture of the hardware setup is provided in Figure 5.

To capture each participant's observed performance and responses during each 


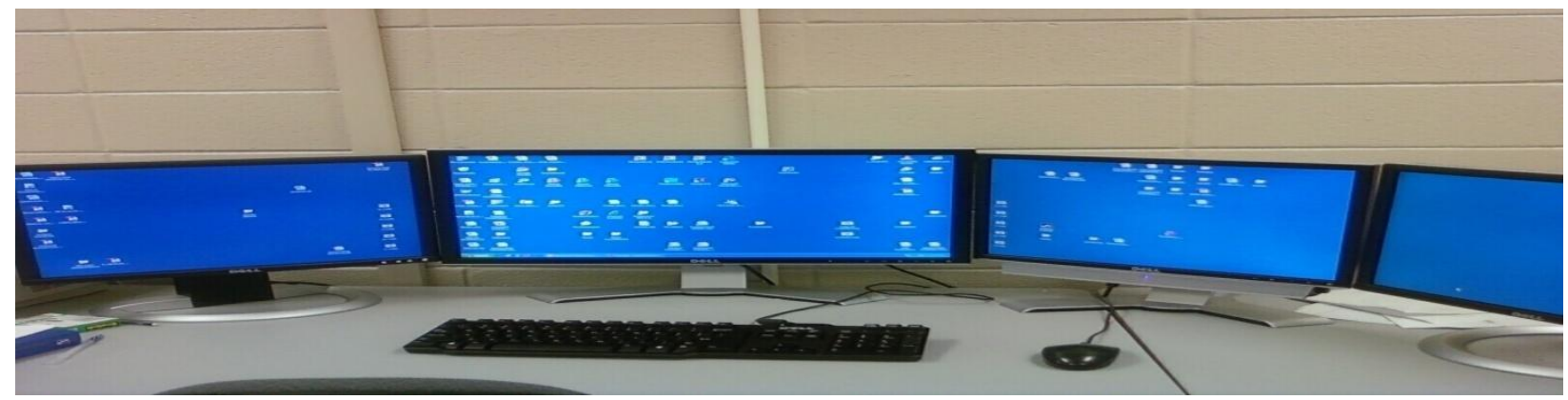

Figure 5 - Picture of Hardware used by Participants

experimental scenario, MORAE (video capture software) was installed on the same computer as that used by participants for their training and experiments. This data was analyzed manually after each participant finished all phases of the study to collect response times and scenario performance.

\subsection{Overview of Abnormal Events Simulated}

For this experiment an essential objective was to measure operator performance given different alarm rates and alarm display methodologies. Given that this was the goal it was decided that each alarm would require an operator response which consist of three elemental subtasks. These subtasks are (1) Identify the abnormal situation; (2) Assess the abnormal situation; and (3) Respond to the abnormal situation. The decision to exclude erroneous alarms (e.g. nuisance alarms, false alarms, etc...) during all of these experiments was based on the assumption that these alarms would not add any significant value when interpreting operator performance data as measured in this experiment. The reasoning for using this simplifying assumption, for this experiment, is that there are a very limited number of published empirical studies evaluating operator performance given different alarm rates and display types. So, it was decided that an idealized simulation scenario evaluating alarm rates would yield the most useful results, with the goal of evaluating and developing "condition specific" studies at a later date. 
Further, since this study was directly attempting to empirically evaluate the impact alarm rates and alarm display methodologies has on operator performance, the addition of erroneous alarms (e.g. nuisance alarms, false alarms, etc...) was believed to not contribute relevant data when analyzing performance measures such as response time and error rate, and would only add "noise" to the data. Future studies may attempt to further evaluate the topic of alarm floods which include some number of non-value added (erroneous) alarms since there have only been a small number of experimental studies focusing on the alarm rate and display methodology topic. A list of example events that were randomly presented to participants is provided below.

- Pressure Relief/Leak Events

- Power Failures

- Equipment Malfunctions

- Equipment Failures

\subsection{Experimental Variables and Their Measures}

A discussion of the experimental variables in this experiment and their measures are provided below. Figure 6 graphically presents an overview of the experimental variables and their measures. The independent variables were the experimental alarm rates (Table 6) and the two types of alarm window displays chronological (Figure 8) and categorical (Figure 9). The dependent variables in this experiment was the time taken to acknowledge each alarm, response time to initiate corrective action, fraction of abnormal situations successfully dealt with, and accuracy of response.

\subsubsection{Dependent Variables}

Time Taken to Acknowledge Each Alarm - This is simply the time elapsed after an alarm 


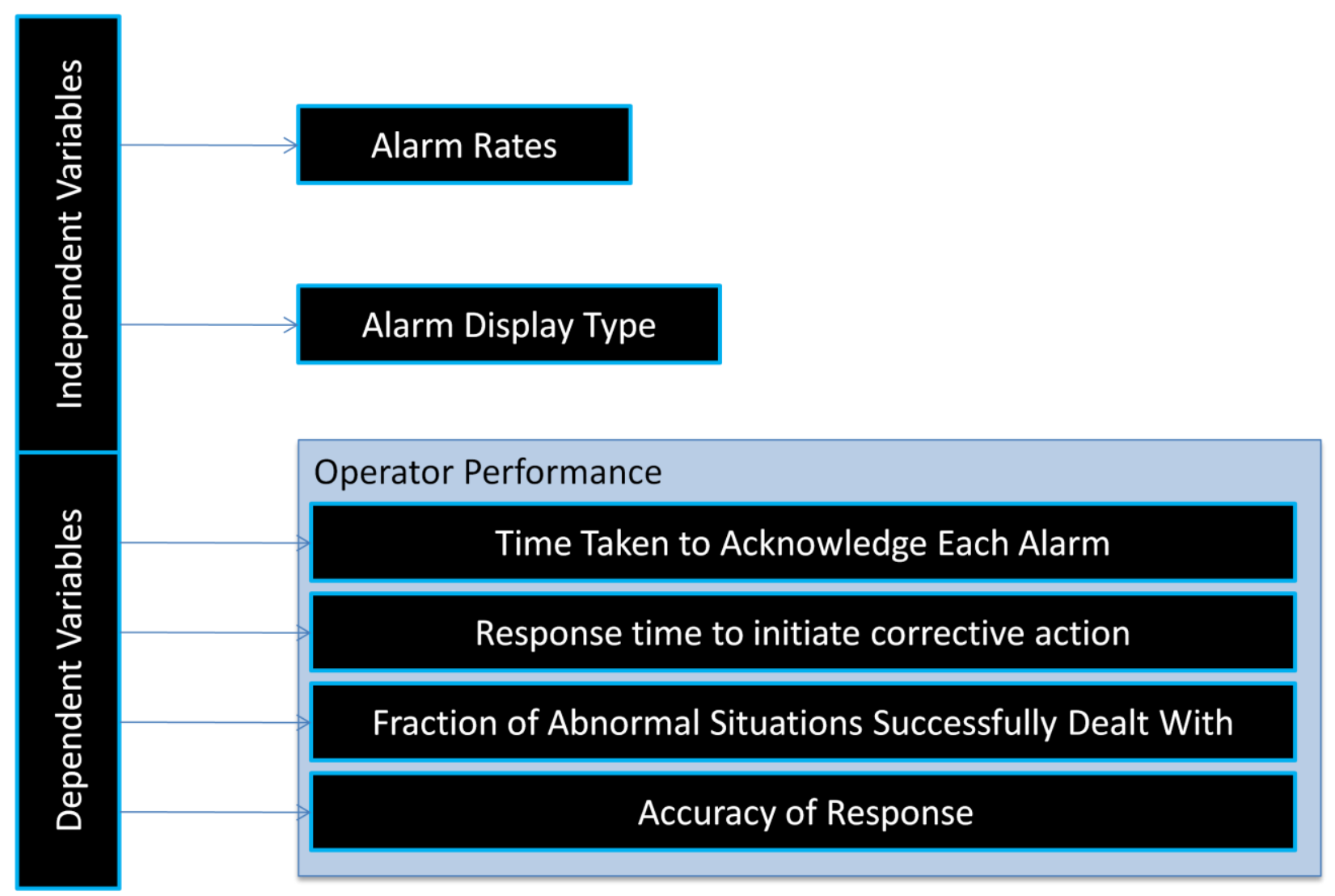

Figure 6 - Overview of Experimental Variables and Measures of Operator Performance is displayed until that alarm is acknowledged by the participant.

- Response Time to Each Alarm - Response time can be broken down into three general sub-measures (1) Acknowledgement; (2) Analyze; and (3) Act. This framework is adapted from a study conducted by Reising et al. (2004). Also, when an operator is handling alarms, by GOMS analysis, there are four distinct steps an operator must complete to respond to any given alarm, these are (1) Acknowledge; (2) Analyze; (3) Act; and (4) Interpret effect of action (Reising, Downs et al. 2004). For this experiment, the time taken during the acknowledgement stage is measured as the time elapsed after an alarm is displayed until that alarm is acknowledged by the participant. The time taken to analyze an alarm and the time taken to determine the effect of action was not considered 
directly for this experiment. The time taken to act on an alarm is measured as the time elapsed after an alarm is displayed until action is taken.

- Fraction of Abnormal Situations Successfully Dealt With - A point system was defined to practically measure this variable. The point system is defined by 0 - Unsuccessful and 1 - Successful. "Successful" is defined here in a very literal sense as the participant executes the correct action for a given alarm. For simplicity, the correct action (defined by the respective abnormal event simulated) did not have to be executed in the correct order to be awarded points for this measure.

- Accuracy of Response - A point system was defined to practically measure this variable. The total number of points possible was calculated based on the minimum number of actions to successfully handle all abnormal situations for each alarm, for each unique experiment. Participants start the experiment with zero points and were awarded points when they took the appropriate action for each alarm. For example, one point could be awarded for submitting a maintenance request for a pump failure, one point could be awarded for shutting down the correct pump during a leak event, or one point could be awarded for opening/closing a block valve that malfunctioned. Every elemental defined action was worth one point. The maximum points a participant could achieve was 38 (20 Alarms - 10 Min.), 20 (10 Alarms - 10 Min.), 10 (5 Alarms - 10 Min.), 4 (2 Alarms - 10 Min.), and 2 (1 Alarms - 10 Min.). Unlike the Fraction of Abnormal Situations Successfully Dealt With measure, the Accuracy of Response measure evaluates a participant's ability to execute corrective action in the correct sequence. This measure can be thought of as a participant's error rate. A grading example is provided in Table 3 below. 
Table 3 - Example participant Grading for Accuracy of Response and Successful Completion

\begin{tabular}{l|l|l|l|l|l|l|l|l|l}
\hline \multicolumn{2}{c|}{ Accuracy of Response } & \multicolumn{2}{l}{ Successfully Handled Abnormal Situation } \\
Required Action In \\
Order of Occurance
\end{tabular}

\subsubsection{Independent Variables}

- Alarm Rates - The alarm rates for this experiment were kept constant. Please refer to Table 4 for the EEMUA No. 191 average alarm rate standard, Table 5 for the Draft ISA average alarm rate standard, and Table 6 for the alarm rates used for this experiment. The alarm priority distribution is presented in Figure 7.

Table 4 - EEMUA No. 191 Benchmark Average Alarm Rate Standard

\begin{tabular}{c|c}
\hline $\begin{array}{c}\text { Long Term Average Alarm Rate in Steady } \\
\text { Operation }\end{array}$ & Acceptability \\
\hline$>1$ alarm per minute & Very likely to be unacceptable \\
\hline 1 alarm per two minute & Likely to be excessively demanding \\
\hline 1 alarm per five minutes & Manageable \\
\hline$<1$ one alarm per ten minutes & Very likely to be acceptable \\
\hline
\end{tabular}

Table 5 - Draft ISA 18.02 Average Alarm Rate Standard

\begin{tabular}{l|l}
\hline Very Likely to be Acceptable & Maximum Manageable \\
\hline$\sim 150$ Alarms per day & $\sim 300$ Alarms per day \\
\hline$\sim 6$ Alarms per hour (average) & $\sim 12$ Alarms per hour (average) \\
\hline$\sim 1$ Alarms per 10 minutes (average) & $\sim 2$ Alarms per 10 minutes (average) \\
\hline
\end{tabular}

- Alarm Windows - There were two types of alarm windows used for this experiment. One presented alarms chronologically (Figure 8) and the other presented them by category (Figure 9). 
Table 6 - Alarm Rates Used For Experiments

\begin{tabular}{c|l}
\hline 20 in First 10 Minutes & Chronological and Categorized Alarm display \\
\hline 10 in First 10 Minutes & Chronological and Categorized Alarm display \\
\hline 5 in First 10 Minutes & Chronological and Categorized Alarm display \\
\hline 2 in First 10 Minutes & Chronological and Categorized Alarm display \\
\hline 1 in First 10 Minutes & Chronological and Categorized Alarm display \\
\hline
\end{tabular}

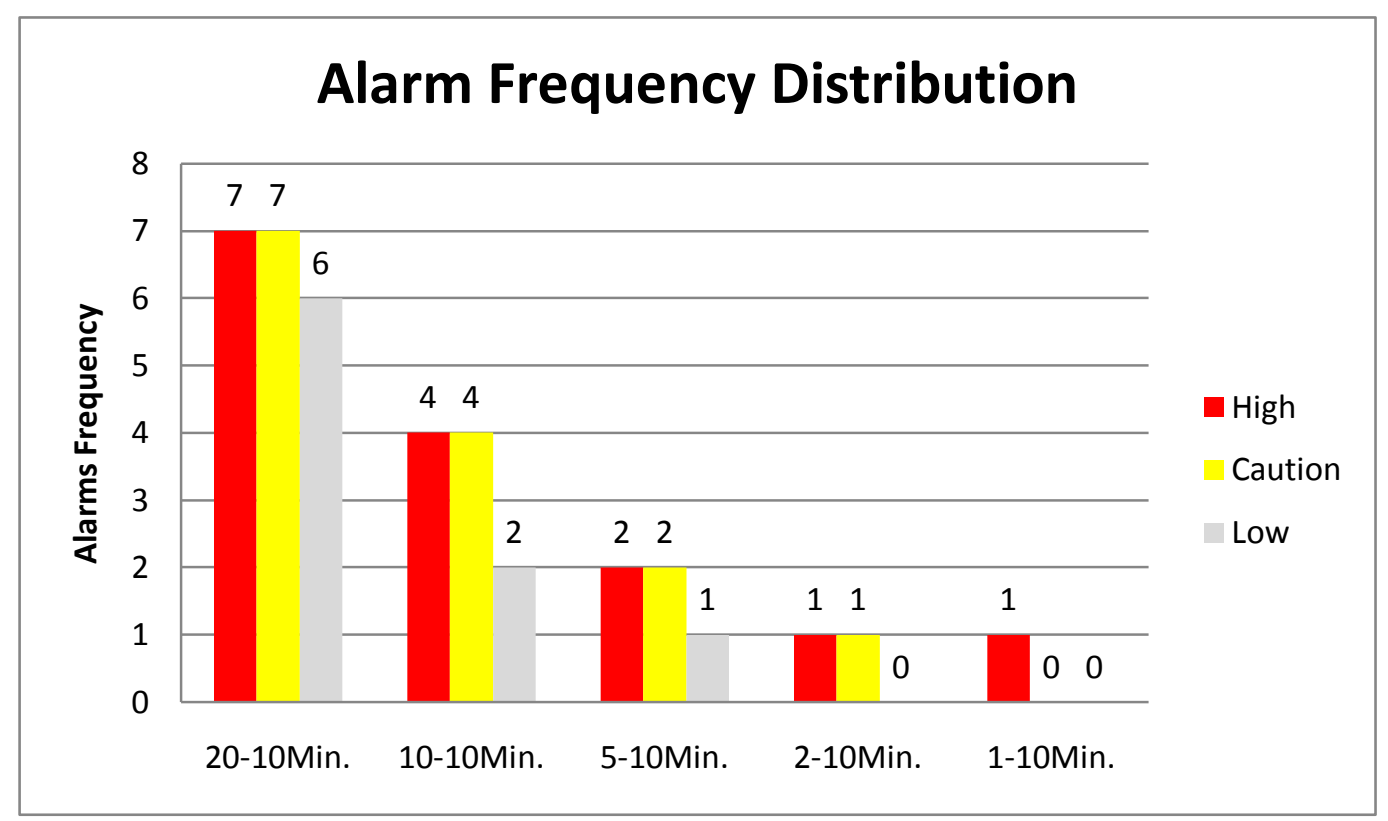

Figure 7 - Alarm Frequency Distribution

\subsection{Experimental Design Procedure}

The experimental procedure begins with the participant completing a demographic survey (computer based). This survey included questions regarding generalized demographic information (e.g. major, student classification, GPA, etc.), a participants computer literacy, and a question asking if they have ever used Stoner's software (used to develop and complete Experiments utilized in this study). The demographic survey can be found in Appendix 5. Participants with any past experience using Stoner software were eliminated. Participants were then trained to navigate the user interface and become familiarized with standard operating 


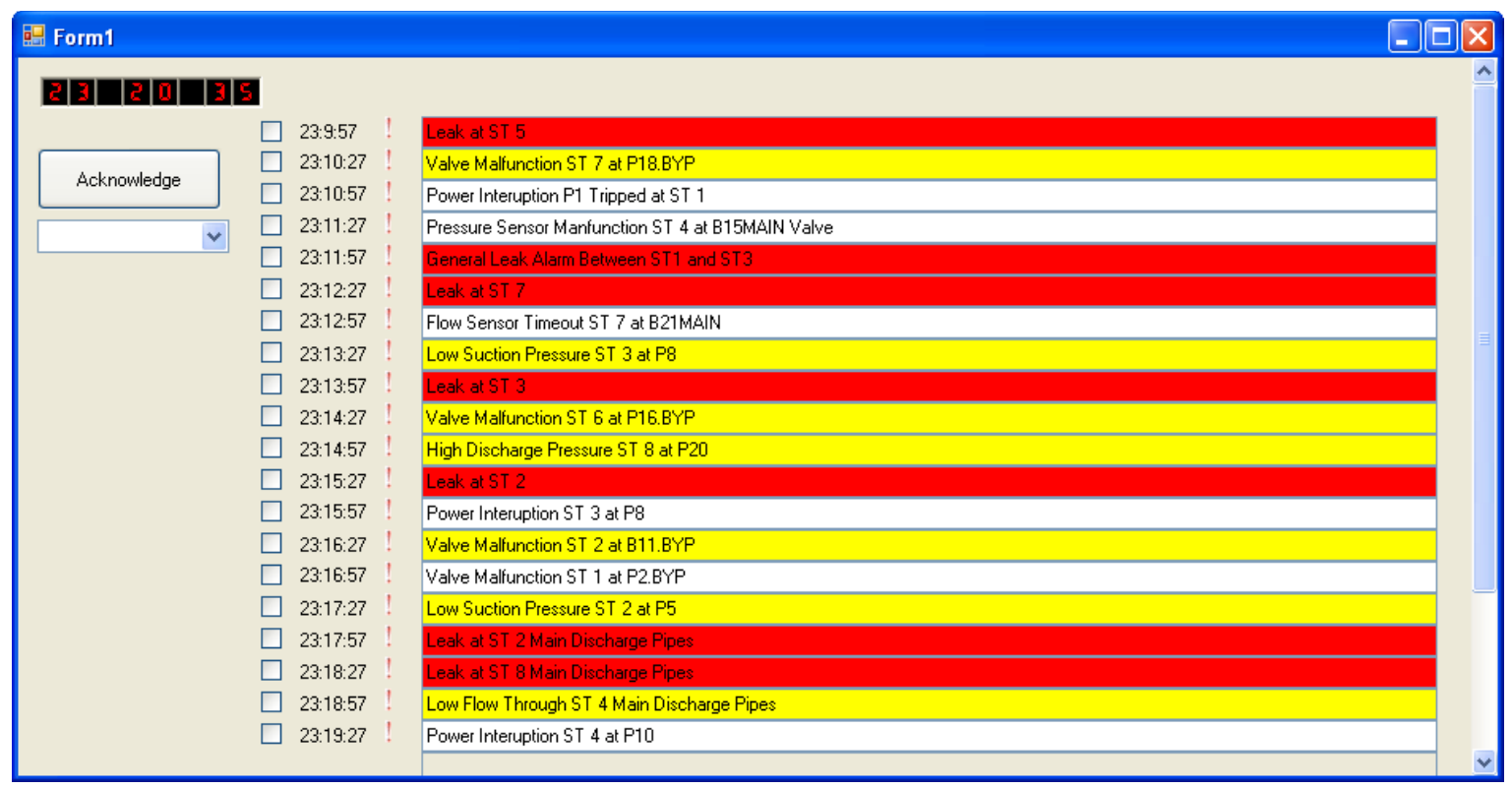

Figure 8 - Chronological Alarm Display

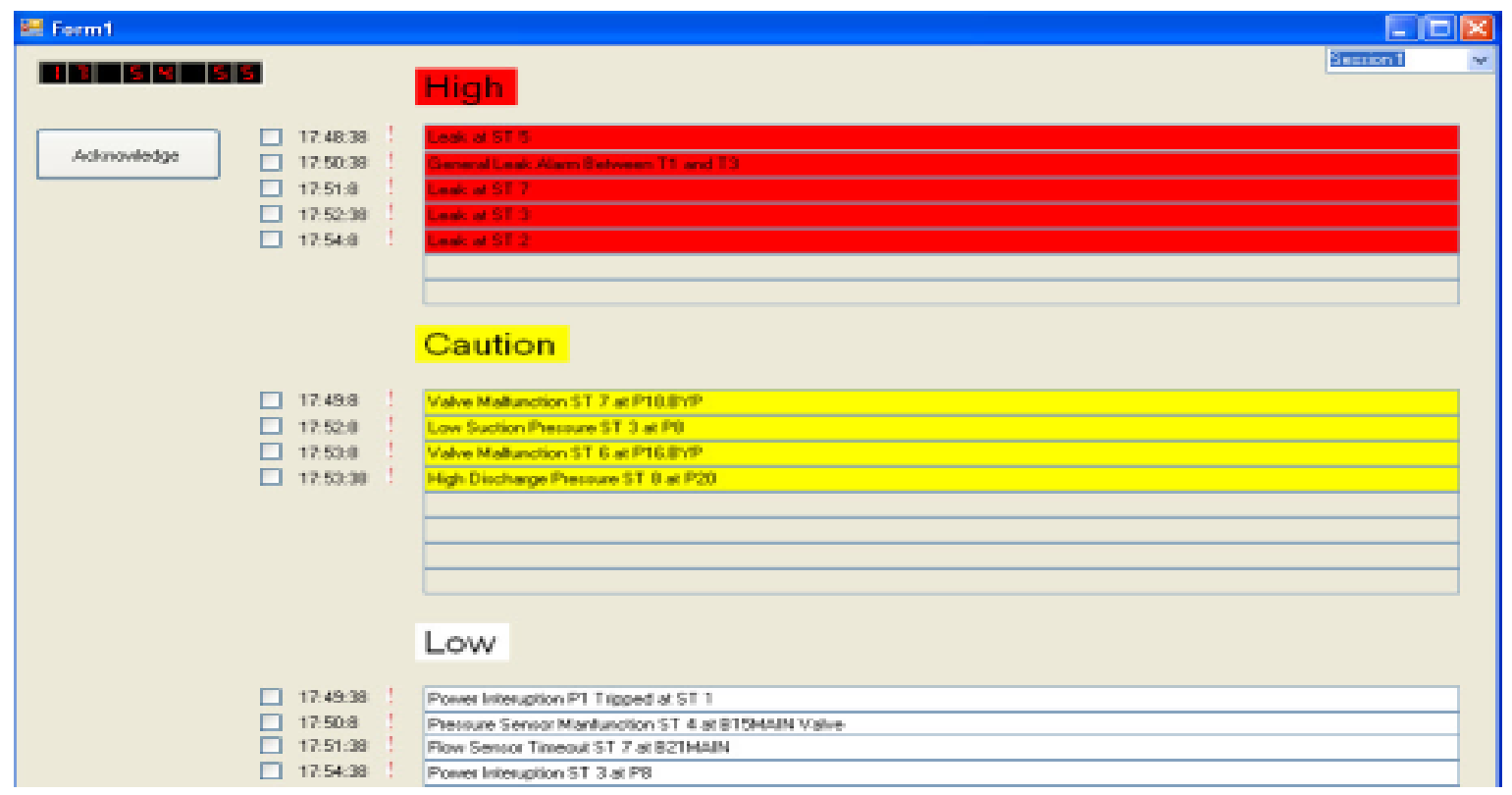

Figure 9 - Categorized Alarm Display

procedures via a power point presentation and demonstration model. Last, participants were then administered a general knowledge quiz testing their ability to complete elemental tasks involved with the experiment. A copy of this quiz can be found in Appendix 6.

Upon passing the general knowledge quiz participants were then administered the qualification assessment (overview display for the qualification assessment can be found in 
Figure 3). The qualification assessment tested each participant's ability to correctly handle abnormal situations representative of those to be experienced during the experiment. Upon successful completion of the qualification assessment participants proceeded to complete the first part of the experiment. Finally, during day two a brief round of refresher training was provided to each participant to help ensure the skills taught during the first day were retained for the second portion of the experiment. After completing all experiments each participant was administered a subjective usability questionnaire evaluating their experiences during both days of the experiment. A copy of this questionnaire can be found in Appendix 7. A flow chart of the experimental procedure is presented in Figure 10.

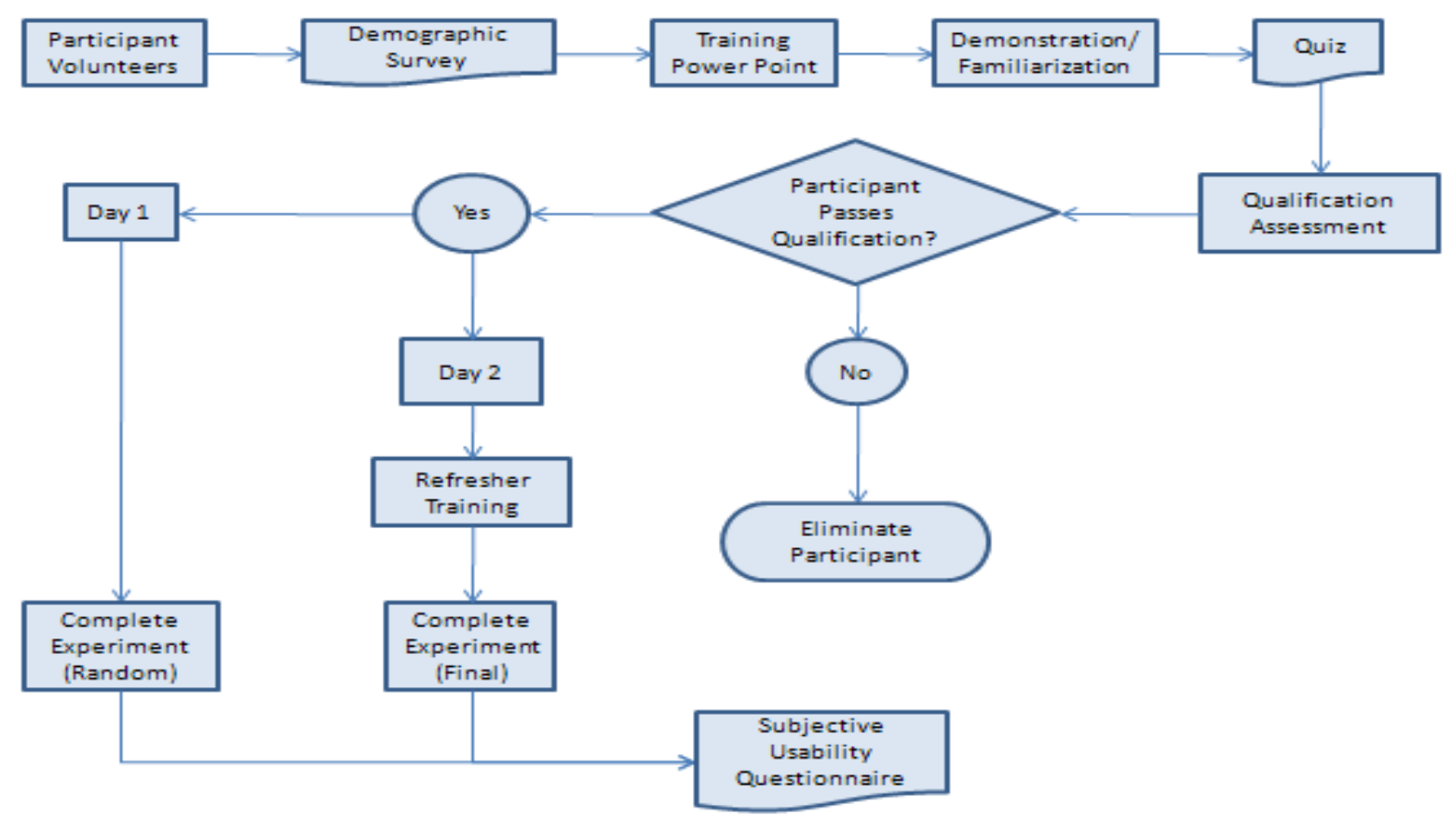

Figure 10 - Experimental Procedure Flow Chart. 


\section{CHAPTER 4. RESULTS AND DISCUSSION}

\subsection{Experimental Model and Statistical Reporting Conventions}

Within subject design (A x I x P), the model would be:

$f=\mathrm{m}+\mathrm{A}+\mathrm{I}+\mathrm{P}+\mathrm{AI}+\mathrm{AP}+\mathrm{IP}+\mathrm{AIP}+\mathrm{e}$

Where:

$A=$ the effect of your first Independent Variable (Alarm Rate)

$\mathrm{I}=$ the effect of your second Independent Variable (Interface Type)

$\mathrm{P}=$ the participant effect (The Repetitions)

$f=$ dependent measures (Reaction time, Accuracy, Acknowledge time)

$\mathrm{m}=$ the population mean

$\mathrm{AI}=$ the interaction of "A" and "I"

$\mathrm{AP}=$ the interaction of "A" and "P"

$\mathrm{IP}=$ the interaction of "I" and "P"

AIP = the interaction of "A," "I" and "P"

$\mathrm{e}=$ error

- The P-Value will always be reported as P-Value = \#.

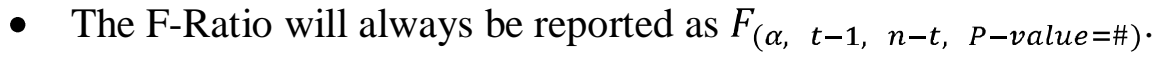

- All analysis of variance (ANOVA) tests were completed using a 0.05 level of significance.

\subsection{Hypothesis 1}

Null Hypothesis 1: No differences exist in participant accuracy of response given different alarm rates.

Alternative Hypothesis 1: Differences exist in participant accuracy of response given 
different alarm rates.

$\begin{array}{ll}\text { Dependent Variable } & : \text { Accuracy of Response } \\ \text { Independent Variable } & : \text { Alarm Rates }\end{array}$

\subsubsection{Differences in Accuracy of Response (All Alarms)}

The results of an ANOVA testing for differences in accuracy of response (including all alarms) between the five different alarm rate experiments yielded a significant effect. Thus, there is sufficient evidence at the 0.05 level of significance to conclude that differences do exist in an operator's performance at different alarm rates. $\left(F=12.015_{(0.05,4,2346, P-\text { Value }=0.0001)}\right)$.

To determine which alarm rates showed difference, a Tukey's means test was performed. The results showed that for the 20 Alarms in 10 Min. experiment there was a significant difference compared to all other experimental alarm rates used. See Appendix 8 for a summary of the AVONA, Effects Test, and Tukey's Means Test.

\subsubsection{Differences in Accuracy of Response (Low Priority Alarms)}

Response accuracy for low priority alarms at different alarm rates was observed to be significant. The results of an ANOVA testing for differences in accuracy of response for different alarm rates given low priority alarms yielded a significant effect. Thus, there is sufficient evidence at the 0.05 level of significance to conclude that differences do exist in an operator's performance for different alarm rates given low priority alarms. $\left.\left(F=17.995_{(0.05,2,552, P-\text { Value }}=0.0001\right)\right)$.

To determine which alarm rates showed difference, a Tukey's means test was performed. The results showed that for the 20 Alarms in 10 Min. experiment there was a significant difference compared to all other experimental alarm rates used. See Appendix 9 for a summary 
of the AVONA, Effects Test, and Tukey's Means Test.

\subsection{Hypothesis 2}

Null Hypothesis 2: Participant response time to each alarm by category does not differ between each alarm display used by participants.

Alternative Hypothesis 2: Participant response time to each alarm by category differs between each alarm display used by participants.

Dependent Variable : Participant Response Time

Independent Variable $\quad$ : Alarm Display Window (Category or Chronological)

\subsubsection{Differences in Response Time (Low Priority Alarms)}

The results of an ANOVA testing for differences in participant response times (including only Low priority alarms) yielded a significant effect. Thus, there is sufficient evidence at the 0.05 level of significance to conclude that differences do exist in an operator's response time to Low priority alarms. $\left(F=42.522_{(0.05,2,539, P-\text { Value }}=0.0001\right)$.

To determine which alarm rates showed difference, a Tukey's means test was performed. The results showed that for the 20 Alarms in 10 Min. experiment there was a significant difference in participant reaction time (for Low priority alarms only) between all other experimental alarm rates used. Specifically, the mean response time (in seconds) observed for each alarm rate experiment (by alarm rate for Low priority alarms only) are as follows 162 (20 Alarms in 10 Min.), 33 (5 Alarms in 10 Min.), and 19 (10 Alarms in 10 Min.). See Appendix 10 for a summary of the AVONA, Effects Test, and Tukey’s Means Test.

\subsubsection{Differences in Response Time (Caution Priority Alarms)}

The results of an ANOVA testing for differences in participant response times (including only 
Caution priority alarms) yielded a significant effect. Thus, there is sufficient evidence at the 0.05 level of significance to conclude that differences do exist in an operator's response time to Caution priority alarms. $\left.\left(F=16.578_{(0.05,3,852, P-\text { Value }}=0.0001\right)\right)$.

To determine which alarm rates showed difference, a Tukey's means test was performed. The results showed that for the 20 Alarms in 10 Min. experiment there was a significant difference in participant reaction time (for Caution priority alarms only) between all other experimental alarm rates used. Specifically, the mean response time (in seconds) observed for each alarm rate experiment (by alarm rate for Caution priority alarms only) are as follows 64 (20 Alarms in 10 Min.), 33 (10 Alarms in 10 Min.), 31 (5 Alarms in 10 Min.), and 22 (2 Alarms in 10 Min.). See Appendix 11 for a summary of the AVONA, Effects Test, and Tukey's Means Test.

\subsubsection{Differences in Response Time (High Priority Alarms)}

The results of an ANOVA testing for differences in participant response times (including only High priority alarms) yielded a significant effect. Thus, there is sufficient evidence at the 0.05 level of significance to conclude that differences do exist in an operator's response time to High priority alarms. The Effects Tests showed that the Main Effect (alarm rate) was significant having a $\left.F=9.284_{(0.05,4,906, P-\text { Value }}=0.0001\right)$ and the Interaction Category \& Chronological Alarm Display was significant having $\left.F=4.024_{(0.05,1,906, P-\text { Value }}=0.0001\right)$.

To determine which alarm rates showed difference, a Tukey's means test was performed. The results showed that for the 20 Alarms in 10 Min. experiment there was a significant difference in participant reaction time (only for High priority alarms) between all other experimental alarm rates used. Specifically, the mean response time (in seconds) observed for each alarm rate experiment (by alarm rate for High priority alarms only) are as follows 64 (20 
Alarms in 10 Min.), 41 (5 Alarms in 10 Min.), 37 (10 Alarms in 10 Min.), 37 (2 Alarms in 10 Min.), and 27 (1 Alarms in 10 Min.). See Appendix 12 for a summary of the AVONA, Effects Test, and Tukey's Means Test.

Another Tukey's Means Test was performed to determine where differences exist in participant response times when using the Category \& Chronological Alarm Displays (for High priority alarms only). The results showed that there was a significant difference in participant reaction time (only for High priority alarms) between the Category \& Chronological Alarm Displays. Specifically, the mean response time (by Alarm Display Type for High priority alarms only) observed when using the Chronological Alarm Display was 47 seconds and the mean response time when using the Categorical Alarm Display was 35 seconds. See Appendix 12 for a summary of the AVONA, Effects Test, and Tukey's Means Test.

\subsection{Hypothesis 3}

Null Hypothesis 3: Participant response time to alarms will not increase as the alarm rate is increased.

Alternative Hypothesis 3: Participant response time to alarms will increase as the alarm rate is increased.

$\begin{array}{ll}\text { Dependent Variable } & \text { : Participant Response Time } \\ \text { Independent Variable } & \text { : Alarm Rate }\end{array}$

\subsubsection{Differences in Response Time (All Alarms)}

The results of an ANOVA testing for differences in participant response times (including all alarms) yielded a significant effect. Thus, there is sufficient evidence at the 0.05 level of significance to conclude that differences do exist in an operator's response time to alarms. The 
Effects Tests showed that the Main Effect (alarm rate) was significant, having $\left.F=47.908_{(0.05,4,2311, P-\text { Value }}=0.0001\right)$ and the Interaction of Alarm Rate \& Alarm Display Type (Category/Chronological) was significant, having $\left.F=3.08_{(0.05,4,2311, P-\text { Value }}=0.0001\right)$.

To determine which alarm rates showed difference, a Tukey's means test was performed. The results showed that for the 20 Alarms in 10 Min. experiment there was a significant difference in participant reaction time between all other experimental alarm rates used. Specifically, the mean response time (in seconds) observed for each alarm rate experiment (by alarm rate only) are as follows 93 (20 Alarms in 10 Min.), 35 (5 Alarms in 10 Min.), 32 (10 Alarms in 10 Min.), 29 (2 Alarms in 10 Min.), and 27 (1 Alarms in 10 Min.). Performing an expanded Tukey's Means test for the interaction between Alarm Rate \& Alarm Display Type results showed that for the 20 Alarms in 10 Min. experiment there was a significant difference in participant reaction time between the categorical alarm window and chronological alarm window. Specifically, the mean response times (in seconds) observed for each experiment are as follows 112 (20 Alarms in 10 Min. - Chronological Alarm Display) and 74 (20 Alarms in 10 Min. - Categorical Alarm Display). See Appendix 13 for a summary of the AVONA, Effects Test, and Tukey's Means Test.

\subsection{Further Observations}

\subsubsection{Differences in Acknowledgement Time (All Alarms)}

The results of an ANOVA testing for differences in participant acknowledgement times (including all alarms) yielded a significant effect. Where, the independent variables were Alarm Rate \& Display Type and the dependent variable was participant acknowledgement times. Thus, there is sufficient evidence at the 0.05 level of significance to conclude that differences do exist 
in an operator's acknowledgement time to alarms. The Effects Tests showed that the Main Effect (alarm rate) was significant, having $\left.F=55.693_{(0.05,4,2340, P-\text { Value }}=0.0001\right)$ and the Interaction of Alarm Rate \& Alarm Display Type (Category/Chronological) was significant, having $F=$ $8.887(0.05,4,2340, P-$ Value $=0.0001)$.

To determine which alarm rates showed difference, a Tukey's means test was performed. The results showed that for the 20 Alarms in 10 Min. experiment there was a significant difference in participant acknowledgement time between all other experimental alarm rates used. Specifically, the mean acknowledgement time (in seconds) observed for each alarm rate experiment (by alarm rate only) are as follows 93 (20 Alarms in 10 Min.), 35 (5 Alarms in 10 Min.), 32 (10 Alarms in 10 Min.), 29 (2 Alarms in 10 Min.), and 27 (1 Alarms in 10 Min.). Running an expanded Tukey's Means test for the interaction between Alarm Rate \& Alarm Display Type results showed that for the 20 Alarms in 10 Min. experiment there was a significant difference in participant acknowledgement time between the categorical alarm window and chronological alarm window. Specifically, the mean acknowledgement times (in seconds) observed for each experiment are as follows 115 (20 Alarms in 10 Min. Chronological Alarm Display) and 63 (20 Alarms in 10 Min. - Categorical Alarm Display). See Appendix 14 for a summary of the AVONA, Effects Test, and Tukey's Means Test.

\subsubsection{Differences in Acknowledgement Time (Low Priority Alarms)}

The results of an ANOVA testing for differences in participant acknowledgement times (including only Low priority Alarms) yielded a significant effect. Thus, there is sufficient evidence at the 0.05 level of significance to conclude that differences do exist in an operator's acknowledgement time for Low priority alarms. The Effects Tests showed that the Main Effect

(alarm rate) was significant, having $F=40.776_{(0.05,2,551, P-\text { Value }=0.0001)}$ and the Interaction of 
Alarm Rate \& Alarm Display Type (Category/Chronological) was significant, having $F=$ $\left.4.103_{(0.05,2,551, P-\text { Value }}=0.0001\right) \cdot$

To determine which alarm rates showed difference, a Tukey's means test was performed. The interaction between Alarm Rate \& Alarm Display Type results showed that for the 20 Alarms in 10 Min. experiment there was a significant difference in participant acknowledgement time for Low priority alarms between the categorical alarm window and chronological alarm window. Specifically, the mean acknowledgement times (in seconds) observed for each experiment, for Low priority alarms only, are as follows 191 (20 Alarms in 10 Min. Chronological Alarm Display) and 116 (20 Alarms in 10 Min. - Categorical Alarm Display). See Appendix 15 for a summary of the AVONA, Effects Test, and Tukey’s Means Test.

\subsubsection{Differences in Acknowledgement Time (Caution Priority Alarms)}

The results of an ANOVA testing for differences in participant acknowledgement times (including only Caution priority Alarms) yielded a significant effect. Thus, there is sufficient evidence at the 0.05 level of significance to conclude that differences do exist in an operator's acknowledgement time for Caution priority alarms. The Effects Tests showed that the Main

Effect (alarm rate) was significant, having $F=29.67_{(0.05,3,858, \mathrm{P}-\text { Value }=0.0001)}$ and the Interaction of Alarm Rate \& Alarm Display Type (Category/Chronological) was significant, having $\left.F=7.644_{(0.05,3,858, \mathrm{P}-\text { Value }}=0.0001\right)$.

To determine which alarm rates showed difference, a Tukey's means test was performed. The results for the interaction between Alarm Rate \& Alarm Display Type showed that for the 20 Alarms in 10 Min. experiment there was a significant difference in participant acknowledgement time for Caution priority alarms only using the chronological alarm window. Specifically, the mean acknowledgement times (in seconds) observed for each 20 Alarms in 10 Min. experiment 
for Caution priority alarms only are as follows 107 (20 Alarms in 10 Min. - Chronological Alarm Display) and 52 (20 Alarms in 10 Min. - Categorical Alarm Display). See Appendix 16 for a summary of the AVONA, Effects Test, and Tukey's Means Test.

\subsubsection{Differences in Acknowledgement Time (High Priority Alarms)}

The results of an ANOVA testing for differences in participant acknowledgement times (including only High priority Alarms) yielded a significant effect. Thus, there is sufficient evidence at the 0.05 level of significance to conclude that differences do exist in an operator's acknowledgement time for High priority alarms. The Effects Tests showed that the Main Effect (alarm rate) was significant, having $\left.F=8.83_{(0.05,4,917, P-\text { Value }}=0.0001\right)$, the Effect Categorical vs. Chronological was significant having $\left.F=4.132_{(0.05,1,917, P-\text { Value }}=0.0424\right)$, and the Interaction of Alarm Rate \& Alarm Display Type (Category/Chronological) was significant, having $F=3.309_{(0.05,4,917, P-\text { Value }=0.0105)}$.

To determine which alarm rates showed difference, a Tukey's means test was performed. The results for the interaction between Alarm Rate \& Alarm Display Type showed that for the 20 Alarms - 10 Min. experiment there was a significant difference in participant acknowledgement time for High priority alarms only using the chronological alarm window. Specifically, the mean acknowledgement times (in seconds) observed for each 20 Alarms in 10 Min. experiment for High priority alarms only are as follows 58 (20 Alarms in 10 Min. - Chronological Alarm Display) and 29 (20 Alarms in 10 Min. - Categorical Alarm Display). Also, significance was observed for the 2 Alarms in 10 Min. experiment for chronological \& categorical. The results observed (in seconds) are as follows 38 (2 Alarms in 10 Min. - Chronological Alarm Display) and 38 (2 Alarms in 10 Min. - Categorical Alarm Display). See Appendix 17 for a summary of the AVONA, Effects Test, and Tukey's Means Test. 


\subsection{Subjective Usability Questionnaire}

A total of 34 participants completed the subjective usability questionnaire. A complete table of participant answers and summary data can be found in Appendix 7. Of those surveyed, 79\% (27/34) of participants preferred using the Categorical Alarm Display and 21\% preferred using the Chronological Alarm display. The average response (including all questions and participants surveyed) was 1.6.

\subsection{Experiment Summary Statistics}

See Table 9 for a summary of the hypotheses, with each answered. See Figures 11 and 12 and Tables 7 and 8 below for important results observed during this experiment. A total of 39 participants volunteered for this study. 31 participants were included in the data analysis in Chapter 4. Participants whose participant number is highlighted in yellow in Appendix 3 were included in the data analysis in Chapter 4. The first 4 participants were part of the pilot study which evaluated the experimental method; participants who were part of the pilot study were not included in the final data analysis in Chapter 4. Two participants failed the qualification assessment (passing was $\geq 50 \%$ and failing was $<50 \%$ ), this is where each participant qualified using a scaled down version of the actual experiment (100\% is 4/4). All participants passed the multiple choice quiz (Appendix 6); passing was $\geq 4 / 6$ and failing was $<4 / 6$. There was incomplete data on participant 36. Of the participants included in the final data analysis in Chapter 4, 16 participants started the experiment using the categorical alarm window first and 15 participants started the experiment using the chronological alarm window. See Appendix 3 for a summary of general participant experiment statistics and demographic data collected. Please see Appendix 18 for Descriptive Statistics observed during this experiment. 


\subsection{Discussion and Future Research Recommendations}

The most noticeable distinction between this study and all but one previously discussed in the literature review is that this study set out with a goal to empirically evaluate the human

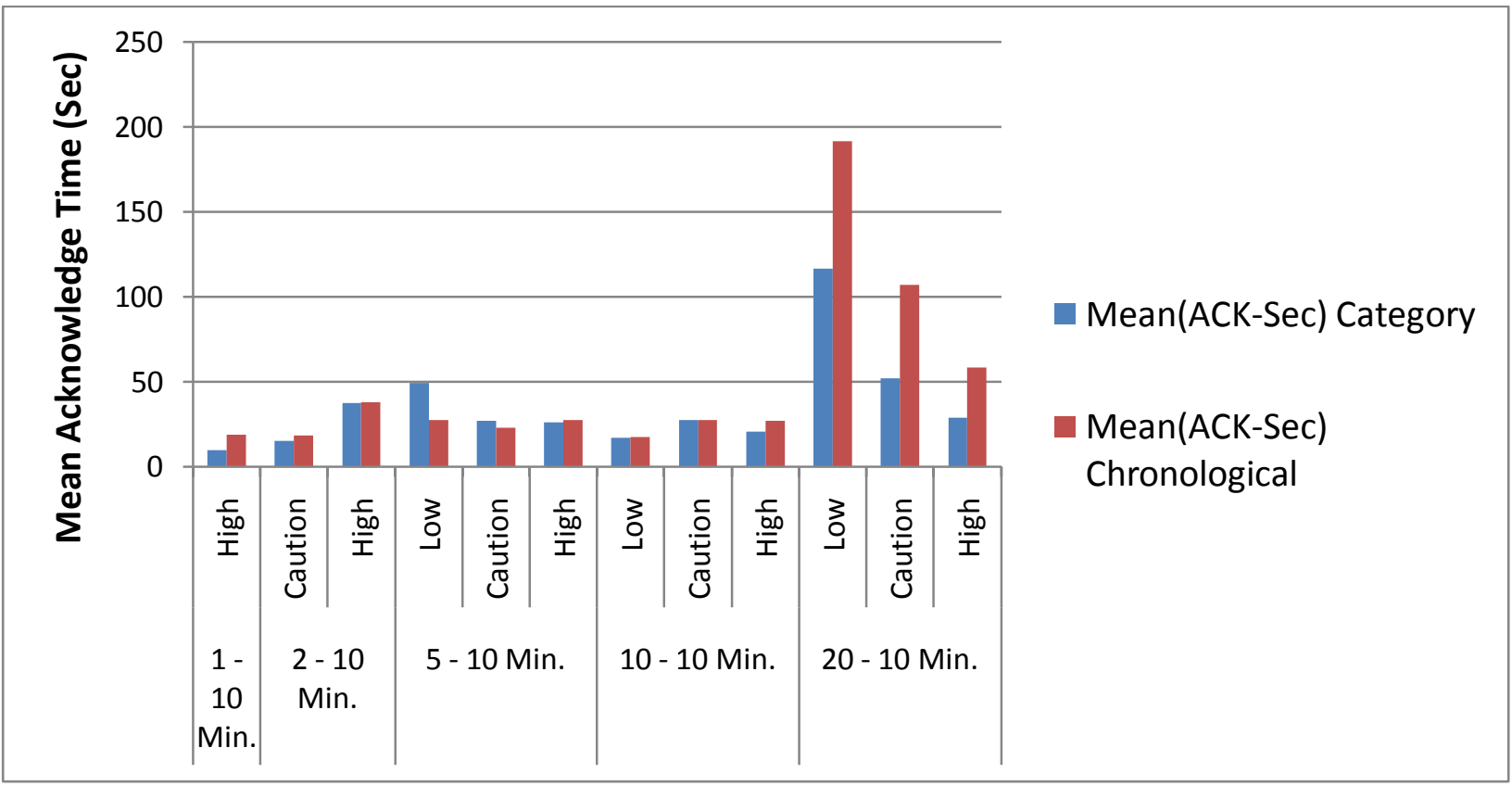

Figure 11 - Mean Acknowledgement Time

limitation with respect to alarm rates for liquid pipeline control room operators. While the studies evaluating observed alarm rates during actual operation or different display methodologies are completely valid and practical there still was still a void in the research with respect to empirically evaluating alarm rate standards.

Future alarm management studies could focus on further developing and evaluating an empirical alarm rate standard. Topics for this scope of research could target maximum allowable number of alarms an operator can theoretically handle over some time interval, how long a given alarm rate can be sustained by an operator before performance begins to decrease significantly, and this last topic, but certainly not the only, can be described as a "performance measure as a function of time" curve which could prove useful to companies developing new systems, 
improving existing systems, and/or benchmark current system performance. "Performance

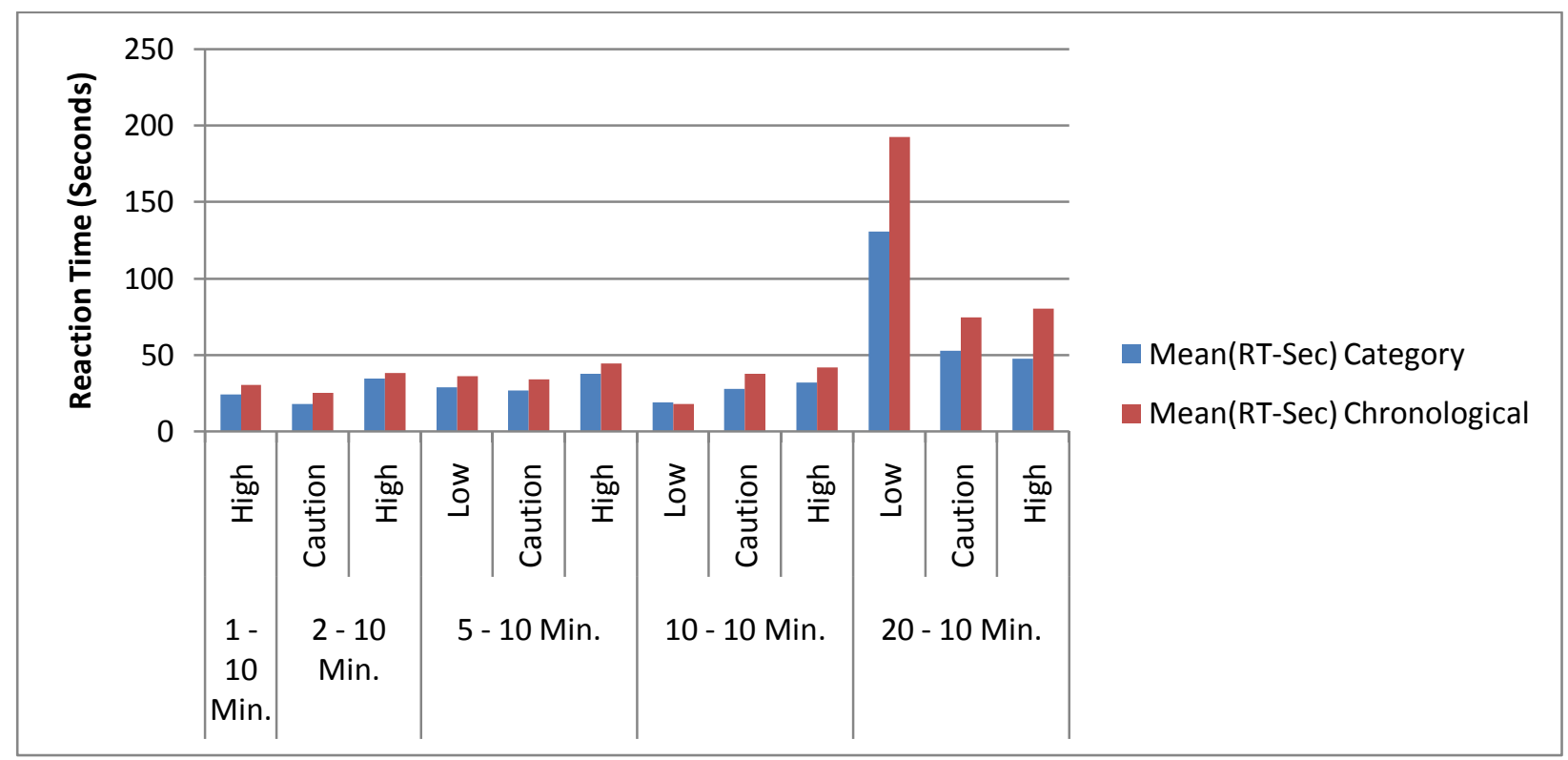

Figure 12 - Mean Reaction Time

Table 7 - Acknowledgement Time Summary Statistics

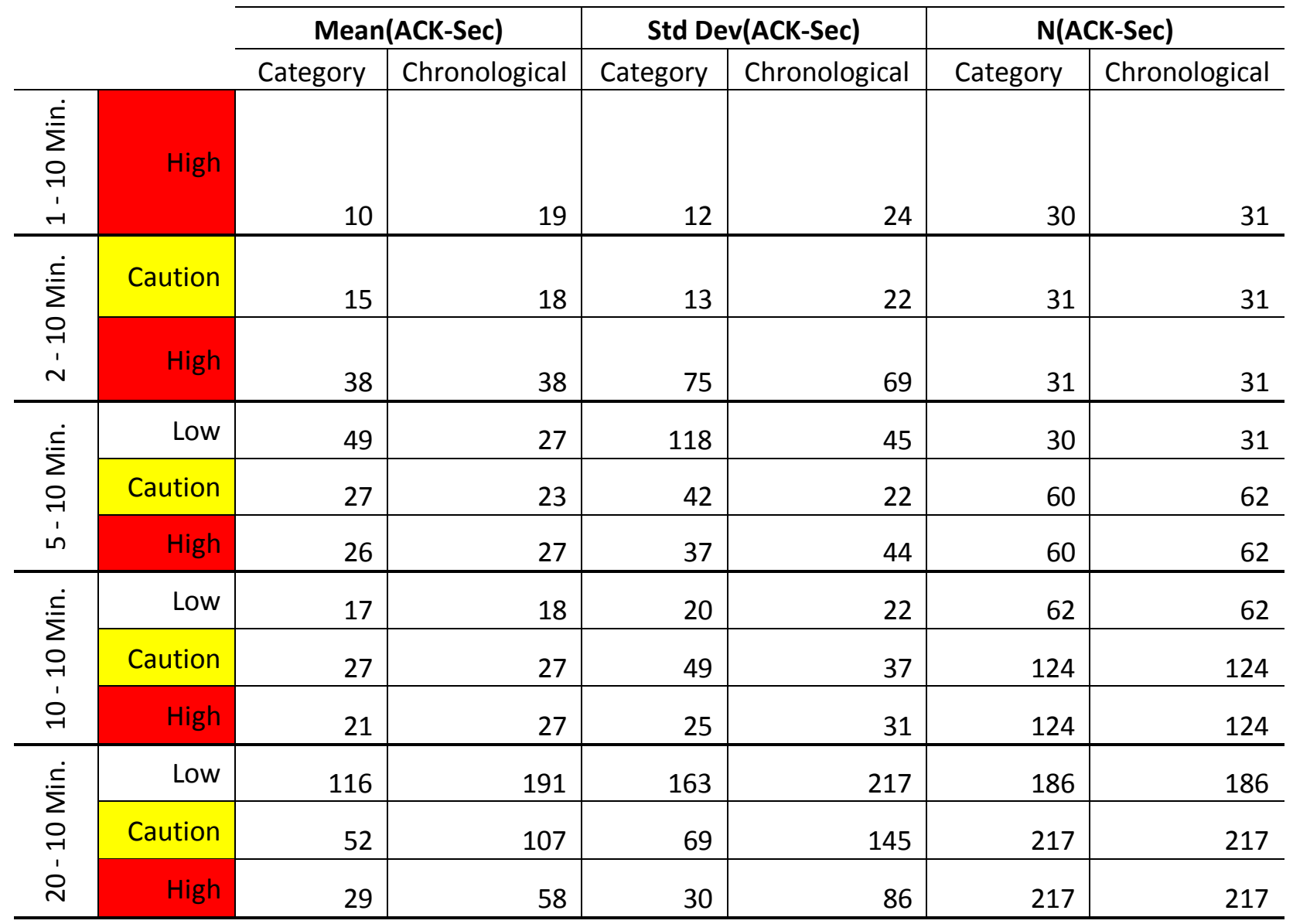


Table 8- - Reaction Time Summary Statistics

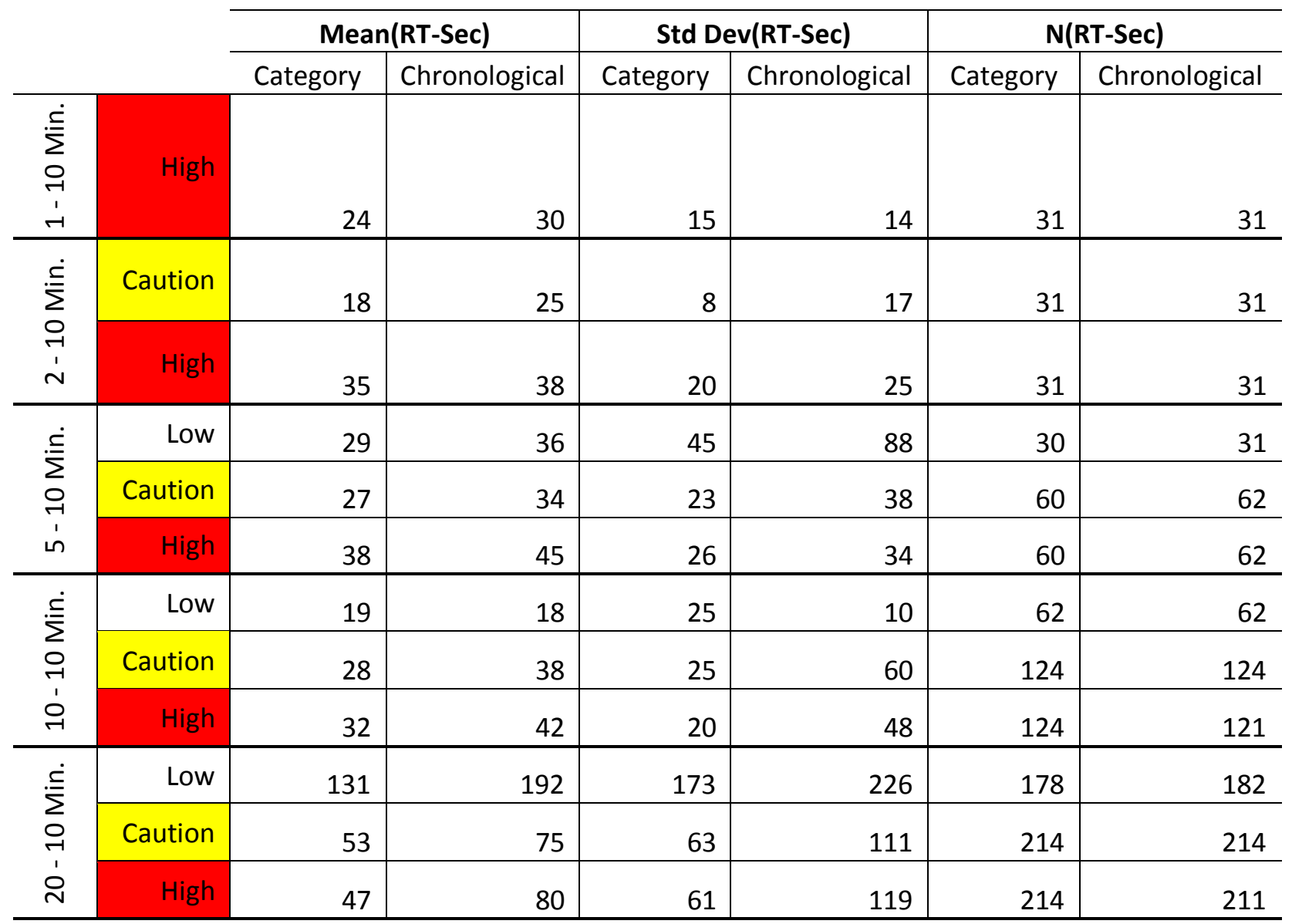

measures" defined here could be response times, accuracy of response, successful completion, and/or acknowledgement time (these performance measures would be literally studied as a function of time). Some other areas of study could include operator distractions, time of day effects, affect of nuisance alarms on operator performance, and operator stress experiments.

There are two note worthy limitations to this study that should not be overlooked including (1) students were the participants as opposed to actual operators and (2) the full complexity of the simulation was not comparable to real-world SCADA systems. These limitations must be understood in interpreting the results of this work and its application to the industry. Further work is needed before the results can be implemented within industry. 
Table 9 - Summary of Null Hypotheses

\begin{tabular}{l|l|l|l}
\hline & Description & Observation & Conclusion \\
\hline Hypothesis 1 & $\begin{array}{l}\text { No differences exist in } \\
\text { participant accuracy of } \\
\text { response given different } \\
\text { alarm rates }\end{array}$ & Rejected & Differences Exist \\
\hline Hypothesis 2 & $\begin{array}{l}\text { Participant response } \\
\text { time to each alarm by } \\
\text { category does not differ } \\
\text { between each alarm } \\
\text { display used by } \\
\text { participants }\end{array}$ & Rejected & Differences Exist \\
\hline Hypothesis 3 & $\begin{array}{l}\text { Participant response } \\
\text { time to alarms will not } \\
\text { increase as the alarm } \\
\text { rate is increased }\end{array}$ & Rejected & $\begin{array}{l}\text { Response time does } \\
\text { increase }\end{array}$ \\
\hline
\end{tabular}

Empirically evaluating the effect of alarm rates and different display types has provided a baseline of how many alarms a liquid pipeline control room operator can handle. Although, this study focused specifically on liquid pipeline simulation experiments one could also potentially apply the findings to refinery console operators or control room operators of gas pipelines to improve human factors design and benchmark performance.

Recommendations for continued research for alarm management in liquid pipeline control rooms are provided for areas.

I. Further developing and evaluating an empirical alarm rate standard. Areas of focus would include the following:

a. Study operator performance strictly as a function of time. This would allow researchers or companies to see how operator performance is influenced by fatigue over time.

b. Maximum allowable number of alarms an operator could theoretically 
handle over some time interval.

c. Time a given alarm rate or dynamic alarm rate can be sustained before selected performance measures begin to decrease materially.

d. Operator distractions - Communication, Logging, and other distractions.

e. Time of day effects - Operator performance could be studied taking into account the nature of shift-work.

f. Effect of nuisance alarms - The effect of nuisance alarms could be studied to evaluate how to these alarms effect operator performance.

g. Operator stress effects - Specific "stressor" experiments could be developed to evaluate the impact on operator performance. 


\section{REFERENCES}

American Petroleum Institute (API). (2009). API RP 1167: Recommended Practice for Pipeline Control Room Alarm Management (Vol. FIRST EDITION).

API (2007). API - RP 1165 - 2007, Recommended Practice for Pipeline SCADA Displays, API - American Petroleum Institute, API Publishing Services 1220 L Street, N.W., Washington, D.C. 20005, United States.

Bass, J. (2007). "Xcel Energy Implements an Alarm Management Strategy." Power Engineering 111(11): 196-204.

Bullemer, P. and I. Nimmo (1998). "Tackle abnormal situation management with better training." Chemical Engineering Progress 94(1): 43.

Bullemer, P. T. and I. Nimmo (1994). Understanding and supporting abnormal situation management in industrial process control environments: a new approach to training, San Antonio, TX, USA, IEEE, Piscataway, NJ, USA.

Butikofer, R.E. Safety Digest of Lessons Learned, API Publications 758. American Petroleum Institute, Washington DC, 1986

Dunn, D. G. and N. P. Sands (2005). ISA-SP18 - Alarm systems management and design guide, Chicago, IL, United States, ISA - Instrumentation, Systems, and Automation Society, Research Triangle Park, NC 27709, United States.

EEMUA (1999). Alarm systems : a guide to design, management and procurement. London, Engineering Equipment and Materials Users Association.

EEMUA (2002). Process Plant Control Desks Utilising Human-Computer Interfaces. London, Engineering Equipment and Materials Users Association

Errington, J., T. DeMaere, Reising, D. (2004). After the alarm rationalization - Managing the DCS alarm system, New Orleans, LA, United States, American Institute of Chemical Engineers, New York, United States.

Errington, J., D. V. Reising, Harris, K. (2006). "ASM outperforms traditional interface." Chemical Processing 69(3): 55-58.

Errington, J., D. V. C. Reising, Bullemer, P, Demaere, T., Coppard, D., Doe, K., Bloom, C. (2005). "Establishing Human Performance Improvements and Economic Benefit for a Human-Centered Operator Interface: An Industrial Evaluation." Human Factors and Ergonomics Society Annual Meeting Proceedings 49: 2036-2040.

Goldstien, I.L. (1986). Training in Organizations: Needs Assessment, Development, and Evaluation. Monterery, CA: Brooks/Cole. 
ISA (2008). ISA - 18.02 - 2008, Management of Alarm Systems for the Process Industries, ISA - Instrumentation, Systems, and Automation Society, Research Triangle Park, NC 27709, United States.

Mattiasson, C. T. (1999). "Alarm system from the operator's perspective." IEE Conference Publication(463): 217-221.

Mostia Jr, W. L. B. (2003). "How to perform alarm rationalization." Control (Chicago, Ill) 16(7): 45-47.

MPR Associates, I. and B. N. Laboratory (2004). Human Factors Guidance for Control Room and Digital Human-System Interface Design and Modification, Guidelines for Planning, Specification, Design, Licensing, Implementation, Training, Operation and Maintenance. United States: 1136p.

Nimmo, I. (1995). Abnormal situation management, New Orleans, LA, USA, Instrument Society of America, Research Triangle Park, NC, USA.

Nimmo, I. (2002). "It's time to consider human factors in alarm management." Chemical Engineering Progress 98(11): 30-38.

Pipeline and Hazardous Materials Safety Administration (PHMSA), D. O. T. (2008). Pipeline Safety: Control Room Management/Human Factors; Proposed Rule. Federal Register/Vol. 73, No. 178. 49 CFR Parts 192, 193, and 195.

Rasmussen, B. (1989). "CHEMICAL PROCESS HAZARD IDENTIFICATION." Reliability Engineering \& System Safety 24(1): 11-20.

Reising, D. V. C., J. L. Downs, Danni, B. (2004). "Human Performance Models for Response to Alarm Notifications in the Process Industries: An Industrial Case Study." Human Factors and Ergonomics Society Annual Meeting Proceedings 48: 1189-1193.

Reising, D. V. C. and T. Montgomery (2005). Achieving effective alarm system performance: Results of ASM [registered trademark] consortium benchmarking against the EEMUA guide for alarm systems, Atlanta, GA, United States, American Institute of Chemical Engineers, New York, NY 10016-5991, United States.

Shahriari, M., A. Shee, Ortengren, R. (2006). "The development of critical criteria to improve the alarm system in the process industry." Human Factors and Ergonomics in Manufacturing 16(3): 321-337.

Smith, K. D. and B. A. Walker (2001). "Optimum console design promotes control room efficiency. (Cover story)." Hydrocarbon Processing 80(9): 163.

Walker, B. A., K. D. Smith, Kekich, M. D. (2003). "Limiting shift-work fatigue in process control." Chemical Engineering Progress 99(4): 54-57. 
Watts-Perotti, J. and D. D. Woods (1999). "How Experienced Users Avoid Getting Lost in Large Display Networks." International Journal of Human-Computer Interaction 11(4): 269299.

Woods, D.D. (1984). Visual Momentum - A Concept to Improve the Cognitive Coupling of Person and Computer. [Article]. International Journal of Man-Machine Studies, 21(3). 229-244. 


\section{APPENDIX 1 - TABLE IDENTIFYING MEANING OF COLORS}

Page 526 of (MPR Associates and Laboratory 2004), table on meaning of colors.

\begin{tabular}{|c|c|}
\hline Color & Typlcal Meaning \\
\hline Red & $\begin{array}{ll}\text { - } & \text { Fire protection equipment and apparatus } \\
\text { - } & \text { Danger } \\
\text { - } & \text { Stop or Trip (for a control) } \\
\text { - } & \text { Valve Open } \\
\text { - } & \text { Breaker Closed } \\
\text { - } & \text { Alarm of HIgh Prlortty } \\
\text { - } & \text { Abnormal Condition } \\
\end{array}$ \\
\hline Orange & $\begin{array}{l}\text { - Dangerous parts of machinery or equipment, such as open breaker } \\
\text { boxes } \\
\text { - Alarms of Intermedlate priority }\end{array}$ \\
\hline Yellow & $\begin{array}{ll}\text { - } & \text { Physical hazards, such as falling or tripping } \\
\text { - } & \text { Caution } \\
\text { - } & \text { Alarm of Intermedlate Priority } \\
\text { - } & \text { Innormal Condition } \\
\text { - } & \text { In standby } \\
\text { - } & \text { Not in desired postESFAS Inittation status } \\
\end{array}$ \\
\hline Green & $\begin{array}{ll}\text { - } & \text { Personnel Health or Safety } \\
\text { - } & \text { Location of flist ald equipment } \\
\text { - } & \text { Not Running or "OFF" } \\
\text { - } & \text { Valve Closed } \\
\text { - } & \text { Breaker Open } \\
\text { - } & \text { Normal Condition } \\
\text { - } & \text { Alarm Cleared } \\
\end{array}$ \\
\hline Blue & 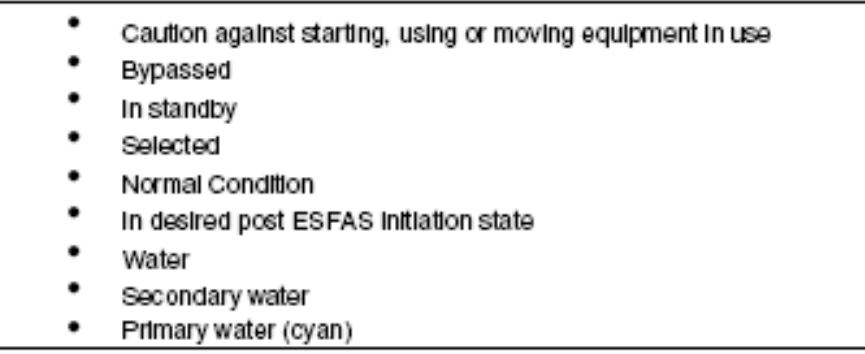 \\
\hline Magenta & $\begin{array}{l}\text { - Radlation hazards (used in combination with yellow) } \\
\text { - Abnormal Condition }\end{array}$ \\
\hline Black anc/or White & 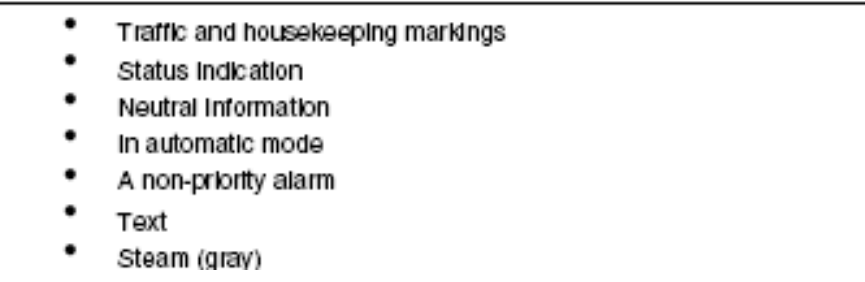 \\
\hline
\end{tabular}




\section{APPENDIX 2 - EEMUA NO. 191 BENCHMARK AVERAGE ALARM RATE STANDARD}

Alarm system performance benchmark standards developed by (EEMUA 1999).

\begin{tabular}{c|c}
\hline $\begin{array}{c}\text { Long Term Average Alarm Rate in } \\
\text { Steady Operation }\end{array}$ & Acceptability \\
\hline$>1$ alarm per minute & Very likely to be unacceptable \\
\hline 1 alarm per two minute & Likely to be excessively demanding \\
\hline 1 alarm per five minutes & Manageable \\
\hline$<1$ one alarm per ten minutes & Very likely to be acceptable \\
\hline
\end{tabular}


APPENDIX 3 - TABLE SHOWING ORDER OF EXPERIMENTS, WHICH DISPLAY USED FIRST, AND DEMOGRAPHIC INFORMATION

\begin{tabular}{|c|c|c|c|c|c|c|c|c|c|c|c|}
\hline 1---------- & 5 & 2 & 1 & 3 & 4 & ---------- & 4 & 1 & 5 & 2 & 3 \\
\hline 2--------- & 2 & 3 & 1 & 5 & 4 & ----------- & 5 & 3 & 2 & 4 & 1 \\
\hline 3--------- & 4 & 1 & 2 & 5 & 3 & ------------ & 2 & 1 & 3 & 5 & 4 \\
\hline 4------ & 1 & 5 & 3 & 4 & 2 & --.-- & 2 & 4 & 1 & 3 & 5 \\
\hline 5---------- & 4 & 3 & 2 & 5 & 1 & ------------ & 1 & 4 & 5 & 2 & 3 \\
\hline 6---------- & 4 & 5 & 3 & 2 & 1 & ------------- & 2 & 5 & 1 & 3 & 4 \\
\hline 7--------- & 4 & 1 & 5 & 2 & 3 & ---------- & 5 & 4 & 2 & 3 & 1 \\
\hline 8---------- & 2 & 4 & 1 & 3 & 5 & ------------- & 2 & 3 & 4 & 1 & 5 \\
\hline 9---------- & 3 & 4 & 1 & 2 & 5 & ------------ & 1 & 4 & 2 & 5 & 3 \\
\hline 10--------- & 5 & 3 & 4 & 2 & 1 & ------------- & 3 & 2 & 5 & 4 & 1 \\
\hline 11--------- & 1 & 5 & 4 & 3 & 2 & -------------- & 4 & 3 & 2 & 5 & 1 \\
\hline 12--------- & 1 & 4 & 3 & 5 & 2 & ------------- & 3 & 5 & 1 & 4 & 2 \\
\hline 13--------- & 3 & 4 & 1 & 5 & 2 & - & 4 & 2 & 5 & 1 & 3 \\
\hline 14--------- & 1 & 4 & 3 & 2 & 5 & ------------- & 1 & 4 & 3 & 5 & 2 \\
\hline 15---------- & 4 & 5 & 1 & 2 & 3 & ------------- & 5 & 1 & 3 & 4 & 2 \\
\hline 16--------- & 5 & 4 & 2 & 3 & 1 & ------------ & 5 & 1 & 2 & 4 & 3 \\
\hline 17--------- & 3 & 1 & 2 & 4 & 5 & ------------- & 4 & 5 & 2 & 1 & 3 \\
\hline 18---------- & 4 & 3 & 5 & 1 & 2 & -------------- & 4 & 1 & 2 & 5 & 3 \\
\hline 19--------- & 4 & 3 & 1 & 5 & 2 & ------------- & 1 & 2 & 5 & 3 & 4 \\
\hline 20---------- & 3 & 2 & 1 & 5 & 4 & ------------ & 5 & 1 & 3 & 4 & 2 \\
\hline 21------- & 2 & 1 & 4 & 5 & 3 & ----------- & 4 & 5 & 3 & 1 & 2 \\
\hline 22--------- & 1 & 2 & 3 & 5 & 4 & ------------- & 4 & 3 & 5 & 2 & 1 \\
\hline 23--------- & 5 & 1 & 2 & 4 & 3 & ------------ & 5 & 1 & 3 & 2 & 4 \\
\hline 24-------- & 5 & 4 & 2 & 1 & 3 & -----------. & 3 & 4 & 2 & 1 & 5 \\
\hline 25---------- & 2 & 4 & 3 & 5 & 1 & ------------- & 5 & 2 & 4 & 3 & 1 \\
\hline 26--------- & 2 & 5 & 1 & 3 & 4 & ------------- & 3 & 4 & 5 & 2 & 1 \\
\hline 27-------- & 1 & 4 & 2 & 5 & 3 & ---------- & 1 & 4 & 3 & 5 & 2 \\
\hline 28---------- & 3 & 2 & 5 & 4 & 1 & ------------- & 3 & 1 & 2 & 5 & 4 \\
\hline 29--------- & 5 & 3 & 4 & 1 & 2 & ------------ & 2 & 1 & 4 & 5 & 3 \\
\hline 30--------- & 1 & 4 & 3 & 2 & 5 & ------------- & 1 & 4 & 5 & 2 & 3 \\
\hline 31---------- & 3 & 1 & 2 & 4 & 5 & ------------- & 3 & 2 & 4 & 1 & 5 \\
\hline 32-------- & 3 & 1 & 2 & 5 & 4 & ----------- & 2 & 3 & 4 & 1 & 5 \\
\hline 33---------- & 4 & 2 & 5 & 3 & 1 & ------------- & 1 & 4 & 3 & 2 & 5 \\
\hline 34--------- & 1 & 2 & 3 & 5 & 4 & ------------ & 3 & 4 & 1 & 2 & 5 \\
\hline 35-------- & 3 & 4 & 1 & 5 & 2 & ---------- & 5 & 4 & 1 & 3 & 2 \\
\hline 36--------- & 4 & 5 & 3 & 1 & 2 & ------------- & 5 & 1 & 3 & 4 & 2 \\
\hline 37--------- & 5 & 1 & 2 & 3 & 4 & ------------ & 5 & 3 & 2 & 1 & 4 \\
\hline 38---------- & 3 & 4 & 5 & 2 & 1 & ------------- & 2 & 4 & 5 & 3 & 1 \\
\hline 39-------- & 2 & 4 & 3 & 1 & 5 & ----------- & 3 & 4 & 2 & 5 & 1 \\
\hline
\end{tabular}

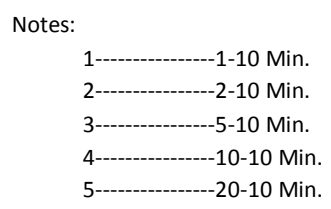




\begin{tabular}{|c|c|c|c|c|c|c|c|c|c|c|c|c|}
\hline $\begin{array}{l}\text { Participant } \\
\text { Number }\end{array}$ & $\begin{array}{c}\text { Alarm Window } \\
\text { Used First } \\
\text { (1=Chronological } \\
\text { 2=Category) }\end{array}$ & $\begin{array}{c}\text { Reason } \\
\text { Rejected }\end{array}$ & $\begin{array}{l}\text { Quiz Score } \\
\text { (6 Possible) }\end{array}$ & $\begin{array}{c}\text { Qualification } \\
\text { Score (4 Possible) }\end{array}$ & Age & Gender & Major & Video Games & $\begin{array}{c}\text { Computer } \\
\text { Skills }\end{array}$ & GPA & $\begin{array}{c}\text { Student } \\
\text { Class }\end{array}$ & $\begin{array}{c}\text { Hydraulic } \\
\text { Software } \\
\text { Use }\end{array}$ \\
\hline 1 & Pilot Study & Pilot Study & Pilot Study & Pilot Study & 26 & M & gen studies: minor: $\mathrm{cm}$, psych, socl & Sometimes & 3 & 2.7 & B.S & $\mathrm{N}$ \\
\hline 2 & Pilot Study & Pilot Study & Pilot Study & Pilot Study & 25 & M & Construction Management (B.S.) & Never & 3 & 2.5 & B.S & $\mathrm{N}$ \\
\hline 3 & Pilot Study & Pilot Study & Pilot Study & Pilot Study & 24 & M & Construction Management (B.S.) & Sometimes & 4 & 2 & B.S & $\mathrm{N}$ \\
\hline 4 & Pilot Study & Pilot Study & Pilot Study & Pilot Study & 23 & $\mathrm{~F}$ & Construction Management (B.S.) & Never & 3 & 3 & B.S & $\mathrm{N}$ \\
\hline 5 & 1 & Pass & 6 & 4 & 31 & M & Construction Management (B.S.) & Sometimes & 4 & 2.5 & B.S & $\mathrm{N}$ \\
\hline 6 & 2 & Pass & 6 & 3 & 24 & M & Construction Management (B.S.) & Never & 3 & 3.4 & B.S & $\mathrm{N}$ \\
\hline 7 & 1 & Pass & 6 & 4 & & & & & & & & \\
\hline 8 & 1 & Pass & 6 & 2 & 20 & M & Construction Management (B.S.) & 1Hr./Day & 4 & 3.1 & B.S & $\mathrm{N}$ \\
\hline 9 & 2 & Pass & 6 & 2 & 22 & M & Construction Management (B.S.) & Never & 3 & 2.7 & B.S & $\mathrm{N}$ \\
\hline 10 & 2 & Pass & 4 & 4 & 23 & M & Civil Engineering (B.S.) & 1-30Min./Day & 3 & 2.8 & B.S & $\mathrm{N}$ \\
\hline 11 & 2 & Pass & 5 & 3 & 20 & M & Construction Management (B.S.) & 1-30Min./Day & 3 & 2.9 & B.S & $\mathrm{N}$ \\
\hline 12 & 1 & Pass & 6 & 4 & 22 & $\mathrm{~F}$ & Construction Management (B.S.) & Sometimes & 2 & 2.4 & B.S & $\mathrm{N}$ \\
\hline 13 & 1 & Pass & 5 & 4 & 21 & M & Construction Management (B.S.) & Sometimes & 4 & 3 & B.S & $\mathrm{N}$ \\
\hline 14 & 1 & Pass & 5 & 3 & 20 & M & Construction Management (B.S.) & Never & 3 & 2.8 & B.S & $\mathrm{N}$ \\
\hline 15 & 2 & Pass & 6 & 4 & 21 & M & Construction Management (B.S.) & Never & 2 & 3.3 & B.S & $\mathrm{N}$ \\
\hline 16 & 2 & Pass & 6 & 4 & 23 & M & Construction Management (B.S.) & Never & 2 & 2.8 & B.S & $\mathrm{N}$ \\
\hline 17 & 1 & Pass & 6 & 3 & 32 & M & Construction Management (B.S.) & 1Hr./Day & 3 & 2.7 & B.S & $\mathrm{N}$ \\
\hline 18 & 2 & Pass & 6 & 4 & 23 & M & Construction Management (B.S.) & Sometimes & 2 & 3.4 & B.S & $\mathrm{N}$ \\
\hline 19 & 2 & Pass & 6 & 4 & 28 & M & Industrial Engineering (M.S. in I.E.) & Sometimes & 4 & 3.25 & MS & $\mathrm{N}$ \\
\hline 20 & 2 & Pass & 5 & 2 & 25 & M & Industrial Engineering (B.S.) & Sometimes & 4 & 2.9 & BS & $\mathrm{N}$ \\
\hline 21 & 1 & Pass & 6 & 4 & 20 & M & Industrial Engineering (B.S.) & Sometimes & 3 & 2.5 & BS & $\mathrm{N}$ \\
\hline 22 & 1 & Pass & 6 & 4 & 23 & $\mathrm{M}$ & Engineering Science (M.S. in E.S.) & 1-30 min per day & 4 & 3.0 & MS & $\mathrm{N}$ \\
\hline 23 & 1 & Pass & 6 & 3 & 22 & M & Industrial Engineering (B.S.) & Sometimes & 3 & 2.8 & BS & $\mathrm{N}$ \\
\hline 24 & 2 & Pass & 6 & 4 & 22 & M & Industrial Engineering (B.S.) & 1-30 min per day & 3 & 2.6 & BS & $\mathrm{N}$ \\
\hline 25 & 2 & Pass & 6 & 3 & 23 & M & Industrial Engineering (B.S.) & Sometimes & 3 & 3.5 & MS & $\mathrm{N}$ \\
\hline 26 & Failed Qual. & $\begin{array}{l}\text { Failed } \\
\text { Qual. }\end{array}$ & Failed Qual. & Failed Qual. & 22 & M & Computer Engineering (B.S.) & Sometimes & 3 & 3.6 & MS & $\mathrm{N}$ \\
\hline 27 & 2 & Pass & 6 & 4 & 20 & M & Petroleum Engineering (B.S.) & 1-30 min per day & 3 & 3.2 & BS & $\mathrm{N}$ \\
\hline 28 & 2 & Pass & 6 & 4 & 19 & M & Petroleum Engineering (B.S.) & Sometimes & 3 & 4.0 & BS & $\mathrm{N}$ \\
\hline 29 & Failed Qual. & $\begin{array}{l}\text { Failed } \\
\text { Qual. }\end{array}$ & Failed Qual. & Failed Qual. & 22 & M & Engineering Science (M.S. in E.S.) & Sometimes & 5 & & MS & $\mathrm{N}$ \\
\hline 30 & 1 & Pass & 6 & 4 & 21 & M & Mechanical Engineering (B.S.) & $5+$ hr per day & 4 & 2.8 & BS & $\mathrm{N}$ \\
\hline 31 & 1 & Pass & 6 & 4 & 25 & M & Construction Management (B.S.) & Sometimes & 3 & 2.5 & BS & $\mathrm{N}$ \\
\hline 32 & 1 & Pass & 6 & 4 & 22 & M & Engineering Science (M.S. in E.S.) & Sometimes & 4 & 3.0 & MS & $\mathrm{N}$ \\
\hline 33 & 1 & Pass & 6 & 3 & 22 & M & Engineering Science (M.S. in E.S.) & $1 \mathrm{hr}$ per day & 4 & 3.0 & MS & $\mathrm{N}$ \\
\hline 34 & 2 & Pass & 6 & 3 & 20 & M & Petroleum Engineering (B.S.) & 1-30 min per day & 1 & 3.5 & BS & $\mathrm{N}$ \\
\hline 35 & 1 & Pass & 6 & 2 & 22 & M & Engineering Science (M.S. in E.S.) & $3 \mathrm{hr}$ per day & 3 & 2.7 & MS & $\mathrm{N}$ \\
\hline 36 & Eliminated & Eliminated & Eliminated & Eliminated & 22 & $\mathrm{~F}$ & Environmental Engineering (B.S.) & Sometimes & 2 & 3.8 & BS & $\mathrm{Y}$ \\
\hline 37 & 2 & Pass & 6 & 4 & 20 & $\mathrm{~F}$ & Industrial Engineering (B.S.) & Never & 3 & 3.5 & BS & $\mathrm{N}$ \\
\hline 38 & 2 & Pass & 6 & 4 & 23 & M & Construction Management (B.S.) & Sometimes & 2 & 3.4 & BS & $\mathrm{N}$ \\
\hline 39 & 1 & Pass & 6 & 4 & 21 & M & Petroleum Engineering (Ph.D.) & Sometimes & 2 & 3.3 & BS & $\mathrm{N}$ \\
\hline
\end{tabular}




\section{By: Glen Uhack II \\ PARTICIPANTTRAINING GUIDE}

\section{Overview of Experimental Method}

- Training

- Presentation.

- Demonstration/Familiarization.

- Quiz.

- Participant Qualification Test.

- Demographic Questionnaire

- Experiment

- Total of 10 experiments with a duration of 10 minutes each.

- Day 1

Approximately $1 \mathrm{Hr}$. 30Min.

Training

Demographic Questionnaire

Complete first 5 experiments

- Day 2

Approximately $1 \mathrm{Hr}$.

Refresher training.

Complete remaining 5 experiments.

Subjective Usability Questionnaire 


\section{Introduction}

o This guide will train participants to successfully identify, analyze, and act during abnormal situations.

○ Abnormal situations can include any of the following.

- Leak events

- Power failures

- Equipment malfunctions

- Equipment failures

\section{Pipeline Overview}

( ) Section of line approximately 70 miles in length.

( 9 Main transfer lines.

○ 8 pumping stations.

( ) 2-4 pumps per station

( ) Stations 2 - 8 have Main Station Discharge Pipes and Bypass Station Discharge Pipes.

○ Pipeline will be transporting "Water" (SCL). 


\section{Alarm Priority Levels}

Yellow - Caution.

White - Low priority alarms.

\section{Standard Operating Procedure}

○ Every alarm will have a defined response!

- Leaks

- Identify origin of flow leaving the pipeline.

- Initiate shutdown sequence for specific pump or reroute flow through Bypass Station Discharge Pipes. Do not shutdown an entire station to stop a leak at one pump! Use the Start/Shutdown sequence button. Dpi]

- Submit maintenance request.

o Pump Trip/Power Interruption

- Attempt to restart pump.

- Submit maintenance request.

- Equipment Malfunction

- Attempt to return equipment to normal operating mode

- Submit maintenance request. 


\section{Cont'd}

○ Equipment Failures

- Ensure safe operating conditions are obtained.

- Submit maintenance request.

\section{Overview Display}

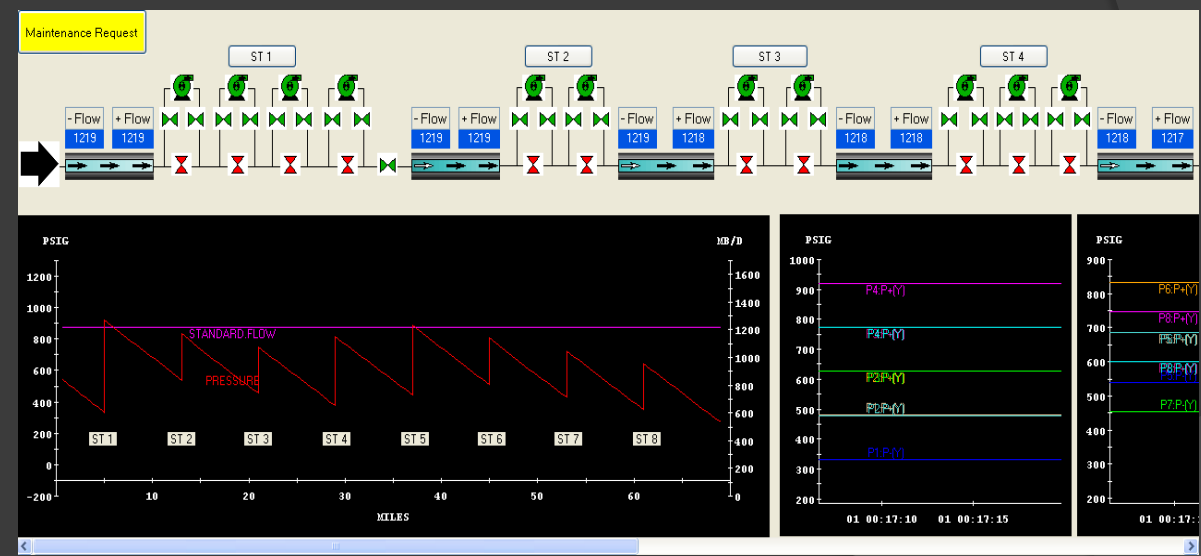




\section{Detailed Station Display}

Start/Shutdown

sequence

button

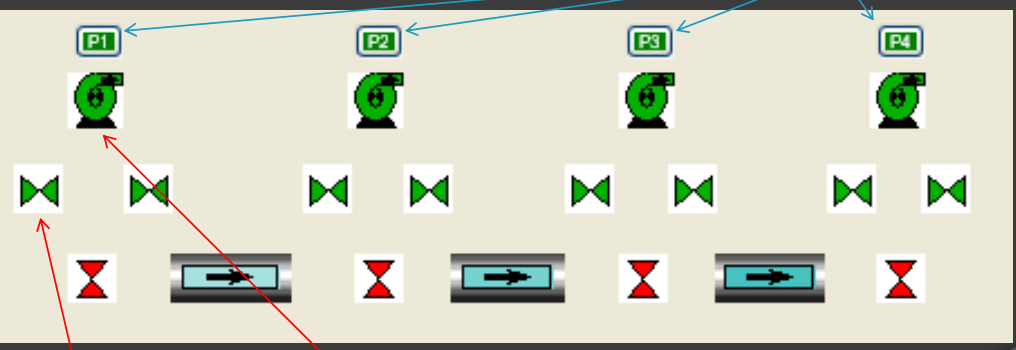

Block

Valve

Pump

\section{Detailed Station Display}

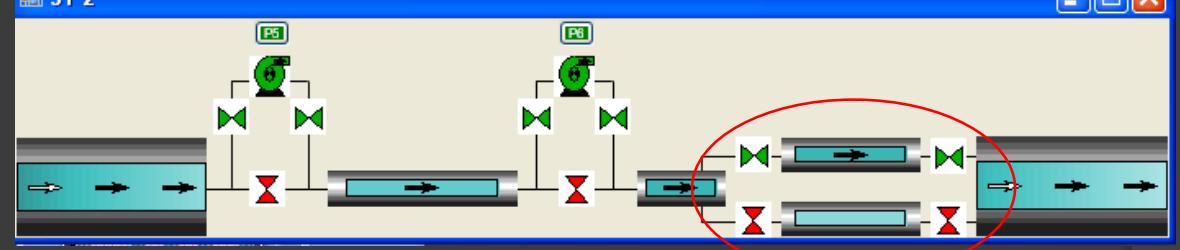




\section{Device Info}

( ) LEFT Click on a device to display its current Process Variable values.

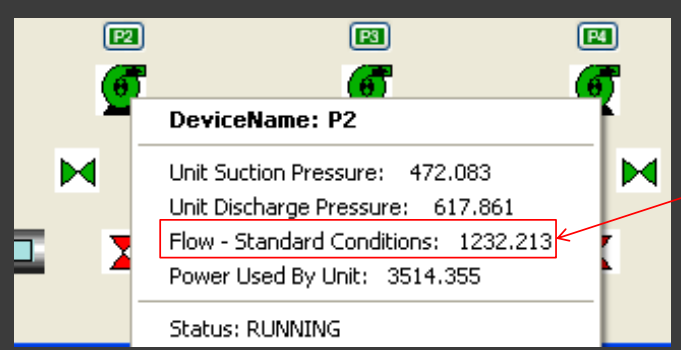

\section{Manual Overrides}

○ RIGHT Click on a device to access its manual override controls.

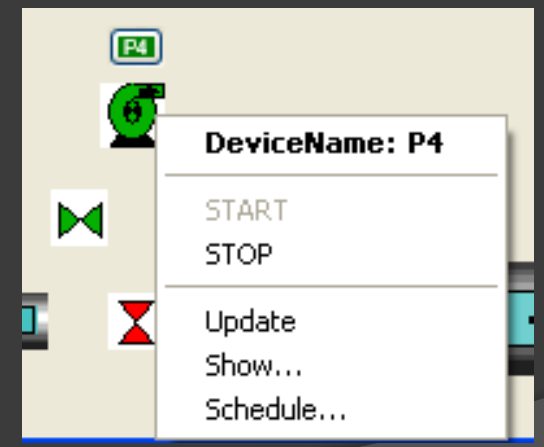




\section{Distance Plot - Steady State}

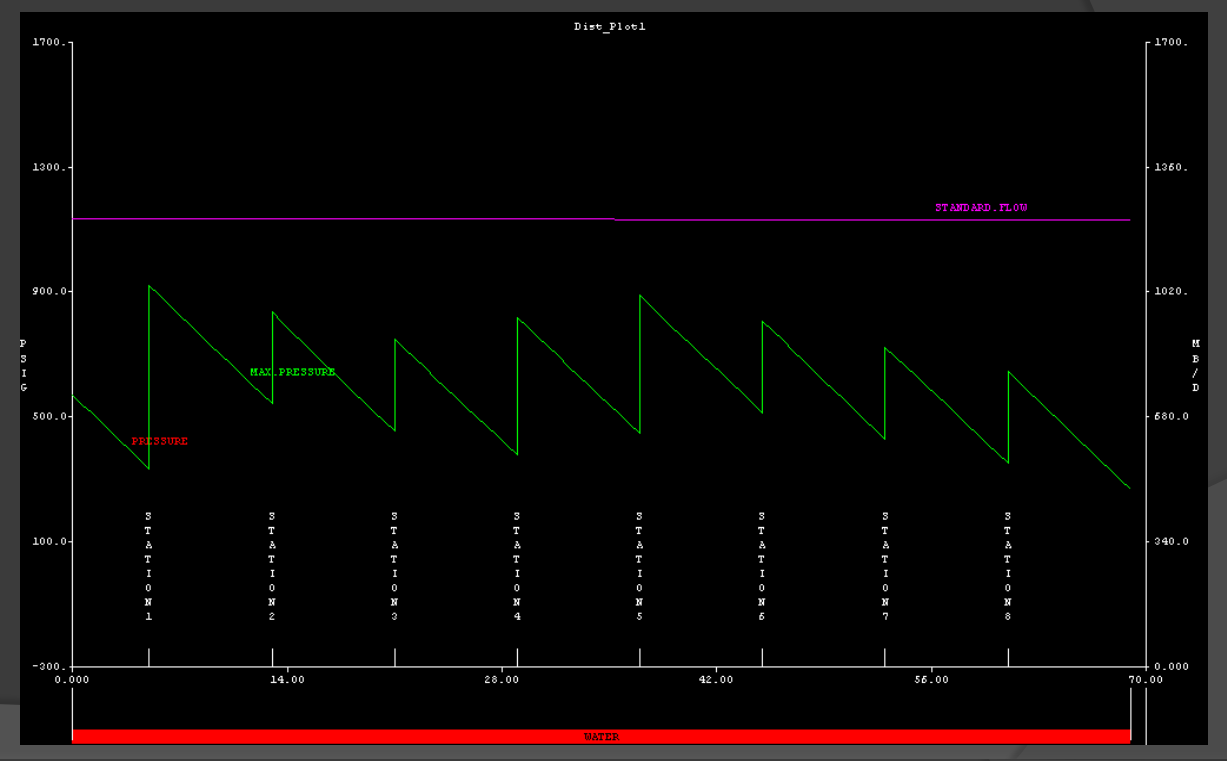

\section{Pump Trip \& Leak Example}
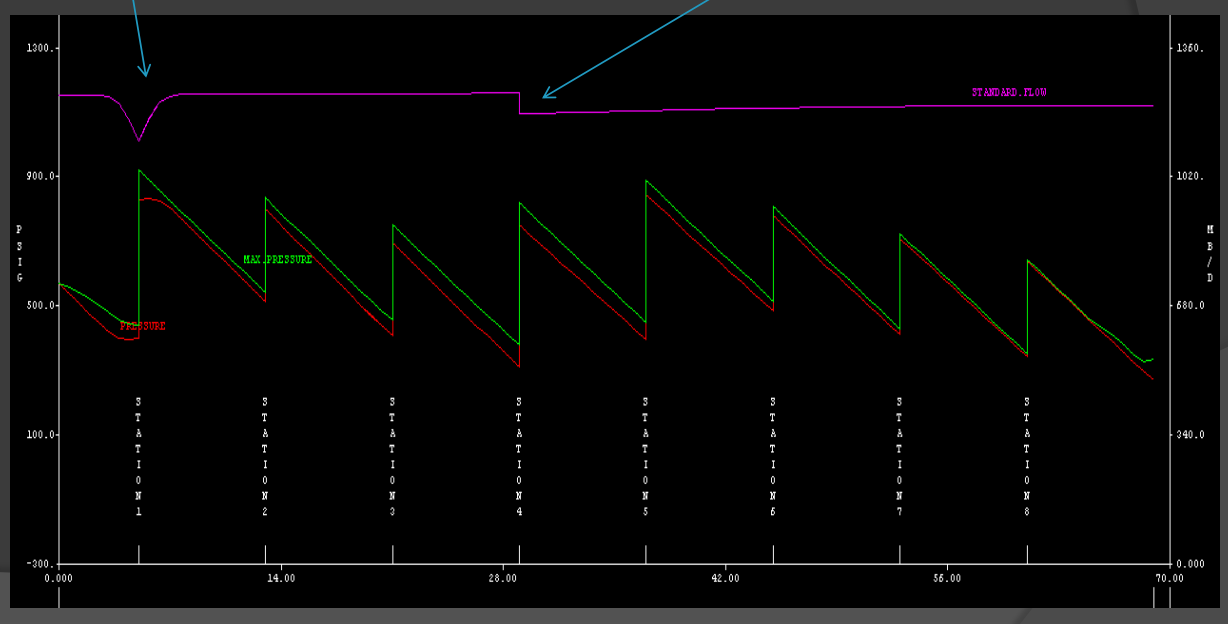


\section{Time Plots}
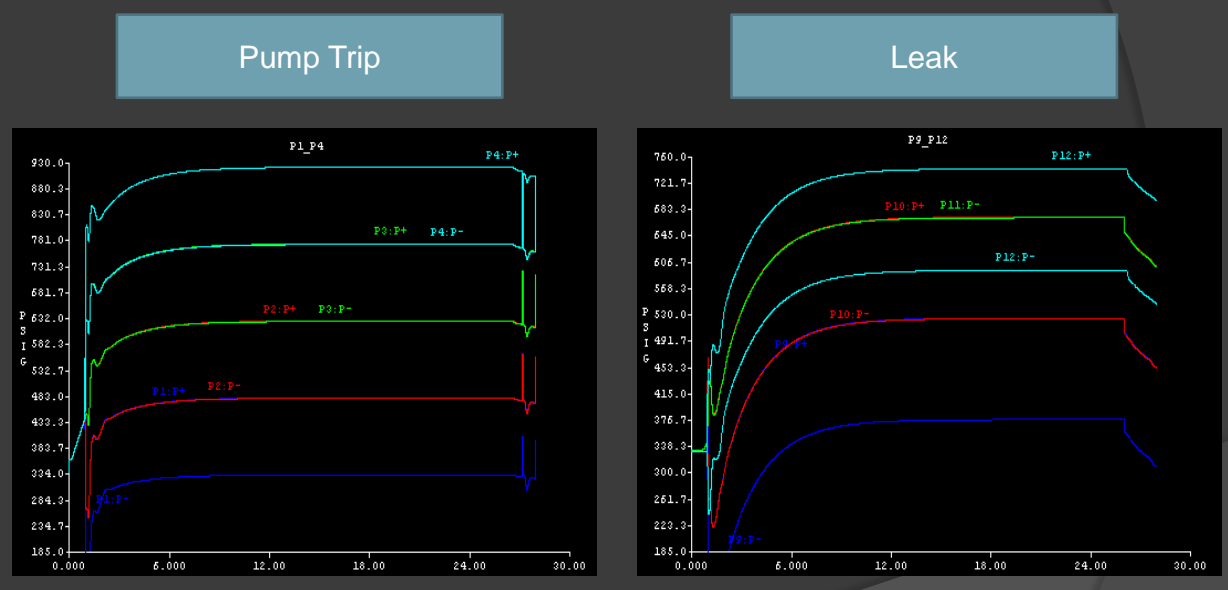

Questions??? 


\section{APPENDIX 5 - DEMOGRAPHIC SURVEY}

1. Age

2. Gender

3. Major

4. Student Classification

5. GPA

6. Rate you computing literacy: Ex. 5 would be a programmer ( 1 being not Fluent---5 being very fluent)

7. How often do you play computer games?

8. Have you ever used Stoner Pipeline Simulator or other hydraulic analysis software? 


\section{APPENDIX 6 - GENERAL KNOWLEDGE QUIZ}

\section{General knowledge Quiz}

Participant \#:

List the name associated with the pipeline device and answer any questions.

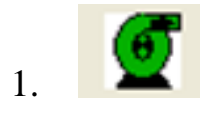

a. What is the status of this device?

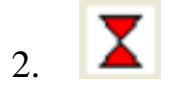

a. What is the status of this device?

3.

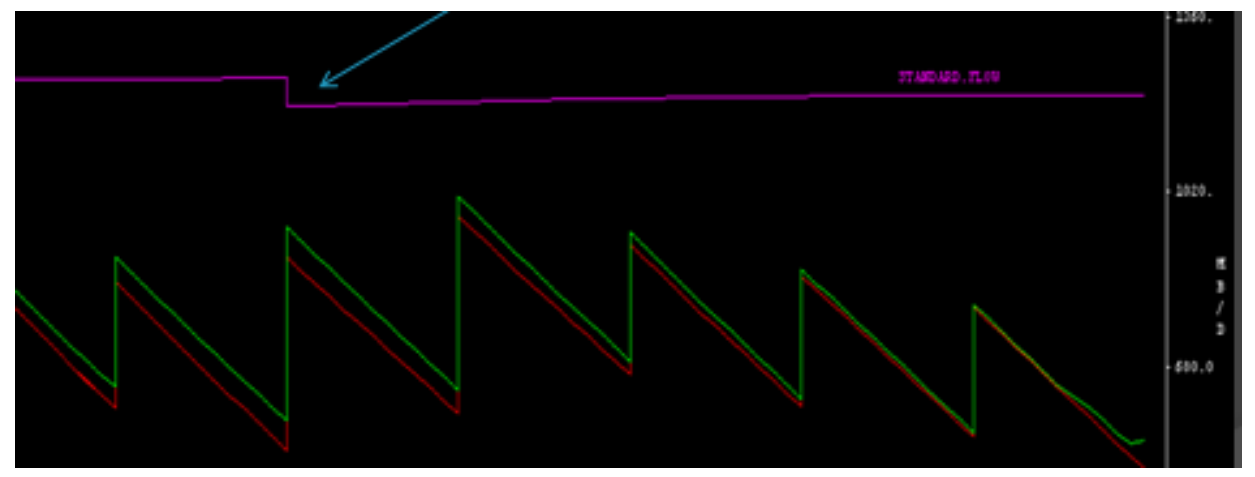

What type of abnormal situation does this chart suggest has occurred?

4. When is it necessary to submit a maintenance request?
a. Leak events
b. Power Trips
c. Equipment failures
d. Equipment malfunction
e. All of the above 


\section{APPENDIX 7 - SUBJECTIVE USABILITY QUESTIONNAIRE AND SUMMARY DATA}

For each of the statements below, circle the rating of your choice.

1. Overall, I am satisfied with the ease of completing tasks using this system.

STRONGLY

$\begin{array}{lllllll}\text { AGREE } & 1 & 2 & 3 & 4 & 5 & \text { DISAGREE }\end{array}$

COMMENTS:

2. Overall, I am satisfied with the support information (messages, documentation) when completing tasks using this system.

STRONGLY

$\begin{array}{lllllll}\text { AGREE } & 1 & 2 & 3 & 4 & 5 & \text { DISAGREE }\end{array}$

COMMENTS:

3. Overall, I am satisfied with how easy it is to use this system.

STRONGLY

$\begin{array}{llllllll}\text { AGREE } & 1 & 2 & 3 & 4 & 5 & \text { DISAGREE }\end{array}$

COMMENTS:

4. It was simple to use this system.

\section{STRONGLY}

AGREE

COMMENTS:

$\begin{array}{lllll}1 & 2 & 3 & 4 & 5\end{array}$

5

STRONGLY

DISAGREE

5. I could effectively complete the tasks and scenarios using this system.

STRONGLY

AGREE

COMMENTS: $\begin{array}{lllll}1 & 2 & 3 & 4 & 5\end{array}$

\section{5}

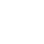

6. I was able to efficiently complete the tasks and scenarios using this system.

STRONGLY

AGREE COMMENTS:

$\begin{array}{lllll}1 & 2 & 3 & 4 & 5\end{array}$

5
STRONGLY

DISAGREE 
7. I felt comfortable using this system.

STRONGLY

$\begin{array}{llllllll}\text { AGREE } & 1 & 2 & 3 & 4 & 5 & \text { DISAGREE }\end{array}$
COMMENTS:

8. It was easy to learn how to use this system.

STRONGLY

AGREE

$\begin{array}{lllll}1 & 2 & 3 & 4 & 5\end{array}$

STRONGLY

COMMENTS:

$\begin{array}{llll}1 & 2 & 3 & 4\end{array}$

DISAGREE

9. I believe I could become productive quickly using this system.

STRONGLY

$\begin{array}{lllllll}\text { AGREE } & 1 & 2 & 3 & 4 & 5 & \text { DISAGREE }\end{array}$

COMMENTS:

10. The information (on-screen messages and other documentation) provided with this system was clear.

STRONGLY

$\begin{array}{llllllll}\text { AGREE } & 1 & 2 & 3 & 4 & 5 & \text { DISAGREE }\end{array}$

COMMENTS:

11. It was easy to find the information I needed to complete tasks.

STRONGLY

$\begin{array}{lllllll}\text { AGREE } & 1 & 2 & 3 & 4 & 5 & \text { DISAGREE }\end{array}$

COMMENTS:

12. The information provided for the system was easy to understand.

STRONGLY

$\begin{array}{lllllll}\text { AGREE } & 1 & 2 & 3 & 4 & 5 & \text { DISAGREE }\end{array}$

COMMENTS:

13. The information was effective in helping me complete the tasks and scenarios.

STRONGLY

$\begin{array}{lllllll}\text { AGREE } & 1 & 2 & 3 & 4 & 5 & \text { DISAGREE }\end{array}$

COMMENTS:

14. The organization of information on the system screens was clear.

STRONGLY

AGREE

$\begin{array}{lllll}1 & 2 & 3 & 4 & 5\end{array}$

STRONGLY

DISAGREE 
COMMENTS:

15. I liked using the interface of this system.

STRONGLY

$\begin{array}{lllllll}\text { AGREE } & 1 & 2 & 3 & 4 & 5 & \text { DISAGREE }\end{array}$

COMMENTS:

16. This system has all the functions and capabilities I expect it to have.

STRONGLY

AGREE

$\begin{array}{lllll}1 & 2 & 3 & 4 & 5\end{array}$

STRONGLY

DISAGREE

17. Overall, I am satisfied with this system.

STRONGLY

STRONGLY
DISAGREE

AGREE

COMMENTS:

18. Which alarm window (categorical vs. chronological) did you prefer using and why? 


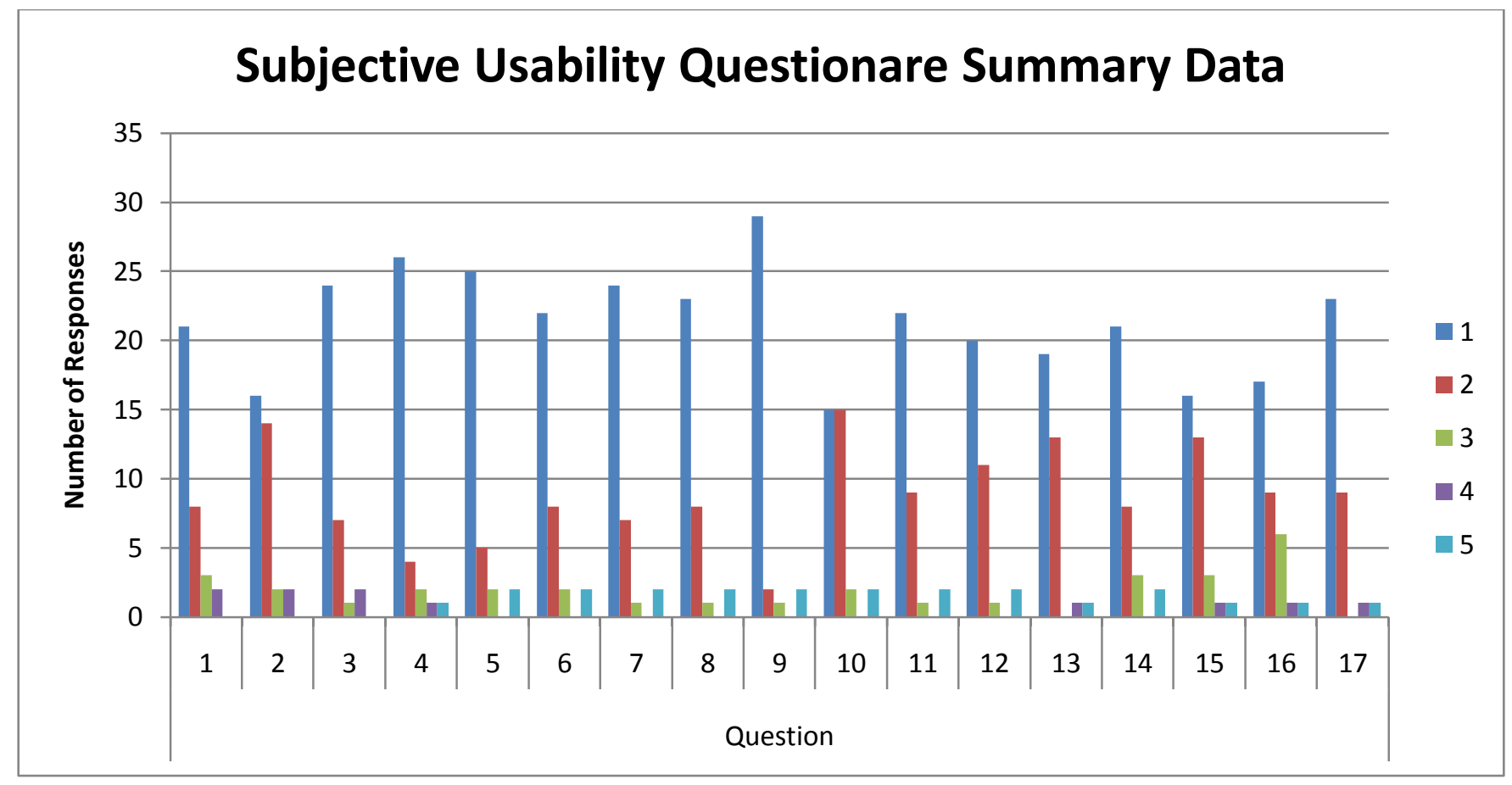

Subjective Comparision Between Different Alarm Windows Studied (Question 18)

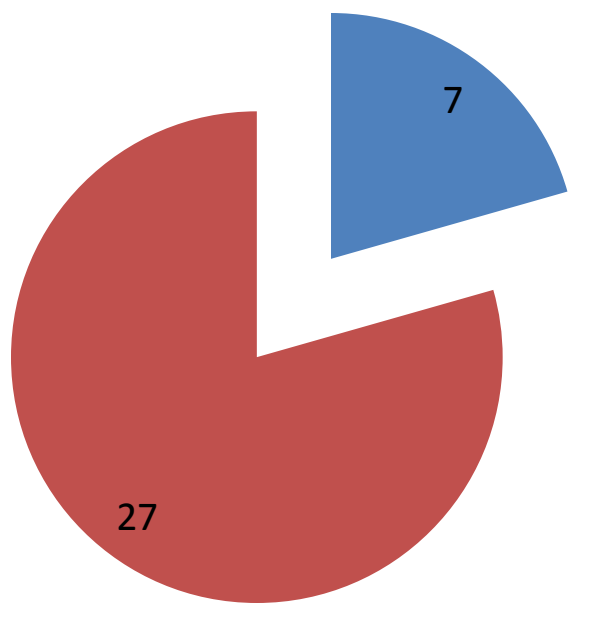

Time

Categorical 


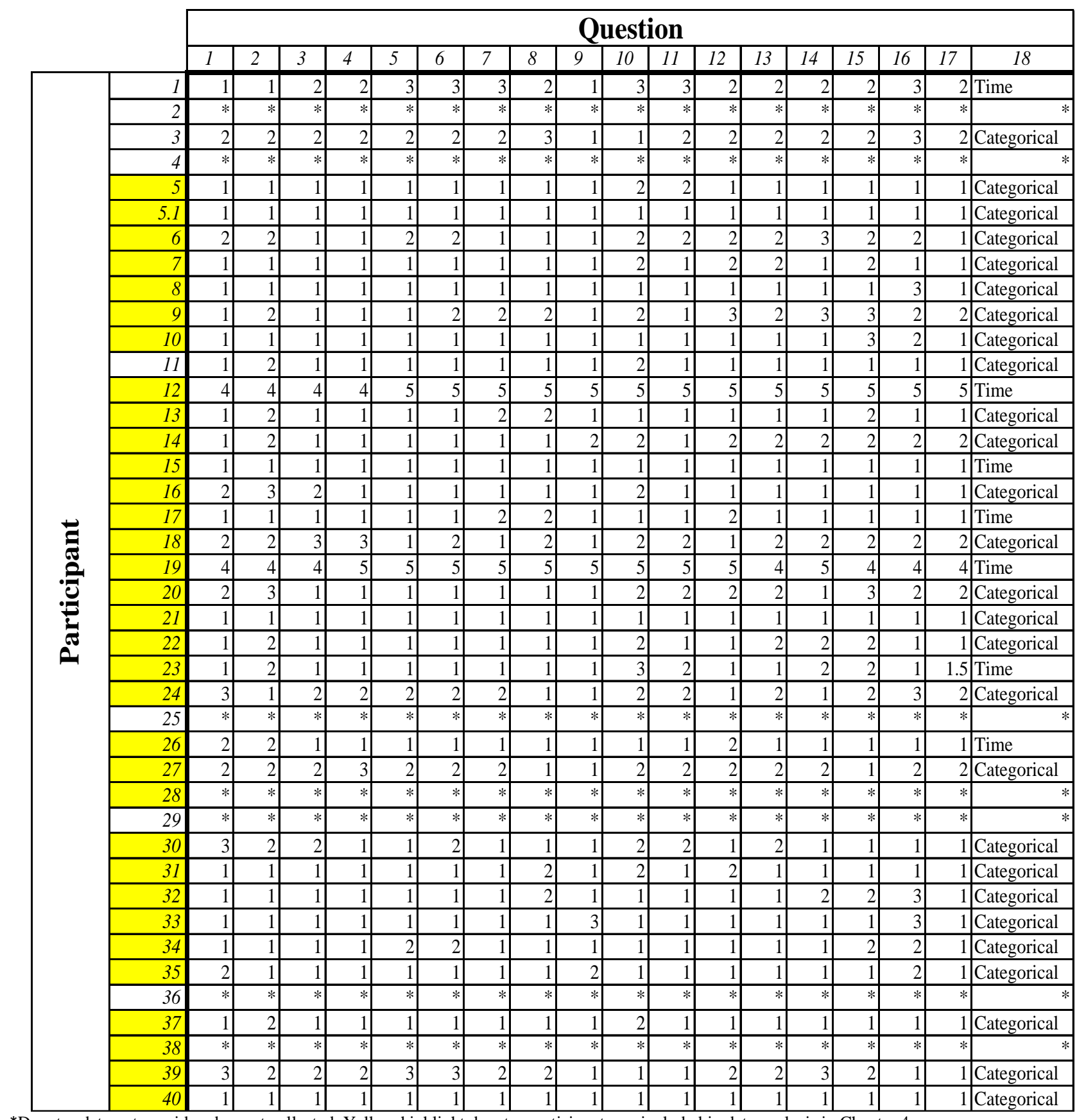

*Denotes data not considered or not collected. Yellow highlight denotes participant was included in data analysis in Chapter 4.

\section{Question}

\begin{tabular}{|c|c|c|c|c|c|c|c|c|c|c|c|c|c|c|c|c|c|c|}
\hline \multirow{6}{*}{ 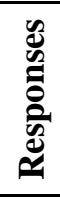 } & 1 & & & & & & & & & & & & & & & & & \\
\hline & 1 & 21 & 16 & 24 & 26 & 25 & 22 & 24 & 23 & 29| & 15 & 2 & 20 & 19 & $21 \mid$ & 16 & 17 & 23 \\
\hline & 2 & 8 & 14 & 7 & 4 & 5 & 8 & 7 & 8 & 2 & 15 & 9 & 11 & 13 & 8 & 13 & 9 & $s$ \\
\hline & 3 & 3 & 2 & 1 & 2 & 2 & 2 & 1 & 1 & 1 & 2 & 1 & 1 & 0 & 3 & 3 & 6 & c \\
\hline & 4 & 2 & 2 & 2 & 1 & 0 & 0 & 0 & 0 & 0 & 0 & 0 & 0 & 1 & 0 & 1 & 1 & 1 \\
\hline & & 0 & 0 & 0 & 1 & 2 & 2 & 2 & 2 & 2 & 2 & 2 & 2 & 1 & 2 & 1 & 1 & 1 \\
\hline \multicolumn{2}{|r|}{ AVERAGE } & 1.6 & 1.7 & 1.4 & 1.4 & 1.5 & 1.6 & 1.5 & 1.5 & 1.4 & 1.8 & 1.6 & 1.6 & 1.6 & 1.6 & 1.8 & 1.8 & 1.5 \\
\hline
\end{tabular}


APPENDIX 8 - DIFFERENCES IN ACCURACY OF RESPONSE (ALL ALARMS)

Analysis of Variance

\begin{tabular}{|c|c|c|c|c|c|c|}
\hline Source & DF & Sum of & Squares & Mear & quare & F Ratic \\
\hline Model & 9 & & 7.33149 & & 14610 & 6.050 \\
\hline Error & 2346 & 31 & 5.87903 & & 34646 & Prob > \\
\hline C. Total & 2355 & & 3.21053 & & & $<.00$ \\
\hline Effect Te & & & & & & \\
\hline Source & & Nparm & $\begin{array}{l}\text { D Sum } \\
\text { F }\end{array}$ & of Squares & F Ratio & Prob $>$ F \\
\hline Alarm Ra & & 4 & 4 & 6.4710102 & 12.0149 & $<.0001$ \\
\hline Cat.(2)/C & & 1 & 1 & 0.0403008 & 0.2993 & 0.5844 \\
\hline Alarm Ra & 2)/Chron(1) & 4 & 4 & 0.3103990 & 0.5763 & 0.6798 \\
\hline
\end{tabular}

Level Least Sq Mean

210 A $\quad 1.9677419$

110 A $\quad 1.9516129$

1010 A $\quad 1.9145161$

$510 \quad$ A $\quad 1.9129032$

2010 B $\quad 1.8201613$

***Levels not connected by same letter are significantly different 


\section{APPENDIX 9 - DIFFERENCES IN ACCURACY OF RESPONSE (LOW PRIORITY ALARMS)}

\section{Analysis of Variance}

$\begin{array}{lrrrr}\text { Source } & \text { DF } & \text { Sum of Squares } & \text { Mean Square } & \text { F Ratio } \\ \text { Model } & 5 & 9.62366 & 1.92473 & 7.4111 \\ \text { Error } & 552 & 143.36022 & 0.25971 & \text { Prob > F } \\ \text { C. Total } & 557 & 152.98387 & & <.0001\end{array}$

\section{Effect Tests}

Source

Alarm Rate

Cat.(2)/Chron(1)

Alarm Rate*Cat.(2)/Chron(1)

$\begin{array}{rrrrr}\text { Nparm } & \text { D } & \text { Sum of Squares } & \text { F Ratio } & \text { Prob }>\text { F } \\ & \text { F } & & & \\ 2 & 2 & 9.3467742 & 17.9946 & <.0001 \\ 1 & 1 & 0.0454301 & 0.1749 & 0.6759 \\ 2 & 2 & 0.0600358 & 0.1156 & 0.8909\end{array}$

\section{Level Least Sq Mean}

$510 \quad A$

1010 A

2010
1.8709677

1.8467742

B
1.5806452 
APPENDIX 10 - DIFFERENCES IN RESPONSE TIME (LOW PRIORITY ALARMS)

\begin{tabular}{|c|c|c|c|c|c|c|}
\hline \multicolumn{7}{|c|}{ Analysis of Variance } \\
\hline Source & DF & \multicolumn{2}{|c|}{ Sum of Squares } & \multicolumn{2}{|c|}{ Mean Square } & F Ratio \\
\hline Model & 5 & \multicolumn{2}{|c|}{2694913} & \multicolumn{2}{|c|}{538983} & 19.5543 \\
\hline Error & 539 & \multicolumn{2}{|c|}{14856654} & \multicolumn{2}{|c|}{27563} & Prob $>F$ \\
\hline C. Total & 544 & \multicolumn{4}{|c|}{17551567} & $<.0001$ \\
\hline \multicolumn{7}{|c|}{ Effect Tests } \\
\hline \multicolumn{2}{|l|}{ Source } & Nparm & $\begin{array}{l}\text { D Sum } \\
F\end{array}$ & of Squares & F Ratio & Prob $>F$ \\
\hline \multicolumn{2}{|c|}{ Alarm Rate } & 2 & 2 & 2344114.0 & 42.5223 & $<.0001$ \\
\hline \multicolumn{2}{|c|}{ Cat.(2)/Chron(1) } & 1 & 1 & 41864.5 & 1.5188 & 0.2183 \\
\hline \multicolumn{2}{|c|}{ Alarm Rate*Cat. (2)/Chron(1) } & 2 & 2 & 109167.1 & 1.9803 & 0.1390 \\
\hline
\end{tabular}

Level Least Sq Mean

$2010 \quad$ A $\quad 161.59242$

$510 \quad$ B $\quad 32.56559$

$1010 \quad$ B $\quad 18.76613$

***Levels not connected by same letter are significantly different 


\section{APPENDIX 11 - DIFFERENCES IN RESPONSE TIME (CAUTION PRIORITY ALARMS)}

\section{Analysis of Variance}

$\begin{array}{lrrrr}\text { Source } & \text { DF } & \text { Sum of Squares } & \text { Mean Square } & \text { F Ratio } \\ \text { Model } & 7 & 300726.5 & 42960.9 & 8.8414 \\ \text { Error } & 852 & 4139916.9 & 4859.1 & \text { Prob }>\text { F } \\ \text { C. Total } & 859 & 4440643.4 & & <.0001\end{array}$

\section{Effect Tests}

Source

Alarm Rate

Cat.(2)/Chron(1)

Alarm Rate*Cat.(2)/Chron(1)

$\begin{array}{rrrrr}\text { Nparm } & \text { D } & \text { Sum of Squares } & \text { F Ratio } & \text { Prob }>\text { F } \\ & \text { F } & & & \\ 3 & 3 & 241654.41 & 16.5776 & <.0001 \\ 1 & 1 & 17000.83 & 3.4988 & 0.0618 \\ 3 & 3 & 9500.57 & 0.6517 & 0.5820\end{array}$

Level Least Sq Mean

2010 A $\quad 63.719626$

$1010 \quad$ B $\quad 32.891129$

$510 \quad$ B $\quad 30.590323$

$210 \quad$ B $\quad 21.661290$

${ }^{\star \star \star}$ Levels not connected by same letter are significantly different 
APPENDIX 12 - DIFFERENCES IN RESPONSE TIME (HIGH PRIORITY ALARMS)

\begin{tabular}{lrrrr}
\multicolumn{2}{l}{ Analysis of Variance } & & \\
Source & DF & Sum of Squares & Mean Square & F Ratio \\
Model & 9 & 294518.9 & 32724.3 & 7.0093 \\
Error & 906 & 4229825.9 & 4668.7 & Prob > F \\
C. Total & 915 & 4524344.8 & & $<.0001$
\end{tabular}

\section{Effect Tests}

Source

Nparm D Sum of Squares F Ratio Prob $>$ F

Alarm Rate

Cat.(2)/Chron(1)

Alarm Rate*Cat.(2)/Chron(1)

$\begin{array}{rrrrrr} & \mathbf{F} & & & \\ 4 & 4 & 173378.28 & 9.2841 & <.0001 \\ 1 & 1 & 18786.51 & 4.0239 & 0.0452 \\ 4 & 4 & 35571.03 & 1.9048 & 0.1076\end{array}$

Level Least Sq Mean

2010 A $\quad 63.819053$

$510 \quad$ B $\quad 41.107258$

$1010 \quad$ B $\quad 37.180219$

$210 \quad$ B $\quad 36.580645$

$110 \quad$ B $\quad 27.451613$

Level Least Sq Mean

$\begin{array}{lll}1 & \text { A } & 47.163893\end{array}$

$\begin{array}{lll}2 & \text { B } & 35.291622\end{array}$

Note

1-Chronological
2-Categorical $\quad{ }^{* * *}$ Levels not connected by same letter are significantly different 
APPENDIX 13 - DIFFERENCES IN RESPONSE TIME (ALL ALARMS)

\begin{tabular}{lrrrr}
\multicolumn{2}{l}{ Analysis of Variance } & & \\
Source & DF & Sum of Squares & Mean Square & F Ratio \\
Model & 9 & 2590480 & 287831 & 25.8014 \\
Error & 2311 & 25780633 & 11156 & Prob $>$ F \\
C. Total & 2320 & 28371113 & & $<.0001$
\end{tabular}

\section{Effect Tests}

Source

Alarm Rate

Cat.(2)/Chron(1)

Alarm Rate*Cat.(2)/Chron(1)

\begin{tabular}{rrrrrr} 
Nparm & \multicolumn{2}{l}{ D Sum of Squares } & F Ratio & Prob > F \\
& F & & & \\
4 & 4 & 2137765.9 & 47.9078 & $<.0001$ \\
1 & 1 & 34194.5 & 3.0652 & 0.0801 \\
4 & 4 & 137439.4 & 3.0800 & 0.0153
\end{tabular}

Least Sq Mean

92.846672

35.192151

31.749911

29.120968

27.451613

***Levels not connected by same letter are significantly different 


\begin{tabular}{|c|c|c|}
\hline Level & & Least Sq Mean \\
\hline 2010,1 & A & 111.83361 \\
\hline 2010,2 & B & 73.85974 \\
\hline 510,1 & $\mathrm{C}$ & 38.67097 \\
\hline 1010,1 & C & 35.64821 \\
\hline 210,1 & $\mathrm{C}$ & 31.77419 \\
\hline 510,2 & $\mathrm{C}$ & 31.71333 \\
\hline 110,1 & C & 30.41935 \\
\hline 1010,2 & $\mathrm{C}$ & 27.85161 \\
\hline 210,2 & $\mathrm{C}$ & 26.46774 \\
\hline 110,2 & C & 24.48387 \\
\hline
\end{tabular}


APPENDIX 14 - DIFFERENCES IN ACKNOWLEDGEMENT TIME (ALL ALARMS)

\begin{tabular}{|c|c|c|c|c|}
\hline \multicolumn{5}{|c|}{ Analysis of Variance } \\
\hline Source & DF & Sum of Squares & Mean Square & F Ratio \\
\hline Model & 9 & 3268769 & 363197 & 33.2889 \\
\hline Error & 2340 & 25530457 & 10910 & Prob $>$ F \\
\hline C. Total & 2349 & 28799226 & & $<.0001$ \\
\hline
\end{tabular}

\section{Effect Tests}

Source

$\begin{array}{rrrrr}\text { Nparm } & \text { D } & \text { Sum of Squares } & \text { F Ratio } & \text { Prob }>\text { F } \\ & \text { F } & & & \\ 4 & 4 & 2430548.7 & 55.6931 & <.0001 \\ 1 & 1 & 29650.9 & 2.7177 & 0.0994 \\ 4 & 4 & 387829.7 & 8.8867 & <.0001\end{array}$

Alarm Rate
Cat.(2)/Chron(1)
Alarm Rate*Cat.(2)/Chron(1)

Level Least Sq Mean

2010,1 A

115.12258

2010,2 B

63.29194

$510,2 \quad$ C

31.07333

210,1 C

28.24194

210,2 C

26.46774

510,1

C

25.49032

1010,1

C

25.22258

1010,2

C

22.50645

110,1

C

18.83871

110,2

C

9.76667

***Levels not connected by same letter are significantly different

Note

1-Chronological

2-Categorical 


\section{APPENDIX 15 - DIFFERENCES IN ACKNOWLEDGEMENT TIME (LOW PRIORITY ALARMS)}

\section{Analysis of Variance}

$\begin{array}{lrrrr}\text { Source } & \text { DF } & \text { Sum of Squares } & \text { Mean Square } & \text { F Ratio } \\ \text { Model } & 5 & 2627324 & 525465 & 20.4327 \\ \text { Error } & 551 & 14169988 & 25717 & \text { Prob }>\text { F } \\ \text { C. Total } & 556 & 16797312 & & <.0001\end{array}$

\section{Effect Tests}

Source

Alarm Rate

Cat.(2)/Chron(1)

Alarm Rate*Cat.(2)/Chron(1)

$\begin{array}{rrrrr}\text { Nparm } & \text { D } & \text { Sum of Squares } & \text { F Ratio } & \text { Prob }>\text { F } \\ & \text { F } & & & \\ 2 & 2 & 2097237.9 & 40.7755 & <.0001 \\ 1 & 1 & 26476.3 & 1.0295 & 0.3107 \\ 2 & 2 & 211021.1 & 4.1028 & 0.0170\end{array}$

\section{Level Least Sq Mean}

2010,1 A

2010,2 B

$510,2 \quad$ C

510,1

1010,1

1010,2

${ }^{* \star *}$ Levels not connected by same letter are significantly different

Note

1-Chronological

2-Categorical
191.29032

116.43548

49.20000

C $\quad 27.32258$

C $\quad 17.51613$

C $\quad 16.87097$ 


\section{APPENDIX 16 - DIFFERENCES IN ACKNOWLEDGEMENT TIME (CAUTION PRIORITY ALARMS)}

\section{Analysis of Variance}

$\begin{array}{ll}\text { Source } & \text { D } \\ \text { Model } & \\ \text { Error } & 858 \\ \text { C. Total } & 865 \\ \text { Effect Tests } & \\ \text { Source } & \end{array}$

Alarm Rate
Cat.(2)/Chron(1)
Alarm Rate*Cat.(2)/Chron(1)

Sum of Squares
967381.2
6198633.3
7166014.5
Mean Square
7225

F Ratio 19.1289 858

Prob $>$ F $<.0001$

Level

Least Sq Mean

2010,1 A

106.74654

2010,2 B

52.15207

1010,1 B

27.47581

1010,2 B

27.33065

510,2

B

26.93333

510,1

B

22.80645

210,

18.48387

210,2

B

15.32258

${ }^{\star \star \star}$ Levels not connected by same letter are significantly different

Note
1-Chronological
2-Categorical




\section{APPENDIX 17 - DIFFERENCES IN ACKNOWLEDGEMENT TIME (HIGH PRIORITY ALARMS)}

\begin{tabular}{|c|c|c|c|c|c|c|}
\hline \multicolumn{7}{|c|}{ Analysis of Variance } \\
\hline Source & DF & \multicolumn{2}{|c|}{ Sum of Squares } & \multicolumn{2}{|c|}{ Mean Square } & F Ratio \\
\hline Model & 9 & \multicolumn{2}{|c|}{193965.1} & \multicolumn{2}{|c|}{21551.7} & 7.8461 \\
\hline Error & 917 & \multicolumn{2}{|c|}{2518830.7} & \multicolumn{2}{|c|}{2746.8} & Prob $>$ F \\
\hline C. Total & 926 & \multicolumn{4}{|c|}{2712795.8} & $<.0001$ \\
\hline \multicolumn{7}{|c|}{ Effect Tests } \\
\hline \multicolumn{2}{|l|}{ Source } & Nparm & $\begin{array}{l}\text { D Sum } \\
F\end{array}$ & of Squares & F Ratio & Prob $>$ F \\
\hline \multicolumn{2}{|c|}{ Alarm Rate } & 4 & 4 & 97027.092 & 8.8309 & $<.0001$ \\
\hline \multicolumn{2}{|c|}{ Cat.(2)/Chron(1) } & 1 & 1 & 11348.992 & 4.1317 & 0.0424 \\
\hline \multicolumn{2}{|c|}{ Alarm Rate*Cat.(2)/Chron(1) } & 4 & 4 & 36354.471 & 3.3088 & 0.0105 \\
\hline
\end{tabular}

$\begin{array}{lrrr}\text { Level } & & & \text { Least Sq Mean } \\ 2010,1 & \text { A } & & 58.211982 \\ 210,1 & \text { A } & \text { B } & 38.000000 \\ 210,2 & \text { A } & \text { B } & 37.612903 \\ 2010,2 & \text { B } & 28.880184 \\ 510,1 & \text { B } & 27.258065 \\ 1010,1 & \text { B } & 26.822581 \\ 510,2 & \text { B } & 26.150000 \\ 1010,2 & \text { B } & 20.500000 \\ 110,1 & \text { B } & 18.838710 \\ 110,2 & \text { B } & 9.766667\end{array}$

***Levels not connected by same letter are significantly different

\begin{tabular}{|l|}
\hline Note \\
1-Chronological \\
2-Categorical \\
\hline
\end{tabular}




\section{APPENDIX 18 - DESCRIPTIVE STATISTICS}

\begin{tabular}{|c|c|c|c|c|c|c|c|}
\hline & & \multicolumn{2}{|c|}{ Mean(ACK-Sec) } & \multicolumn{2}{|c|}{ Std Dev(ACK-Sec) } & \multicolumn{2}{|c|}{ N(ACK-Sec) } \\
\hline & & Category & Chronological & Category & Chronological & Category & Chronological \\
\hline 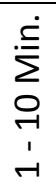 & High & 10 & 19 & 12 & 24 & 30 & 31 \\
\hline$\stackrel{\dot{\sum}}{\sum}$ & Caution & 15 & 18 & 13 & 22 & 31 & 31 \\
\hline$\dot{v}$ & High & 38 & 38 & 75 & 69 & 31 & 31 \\
\hline$\doteq$ & Low & 49 & 27 & 118 & 45 & 30 & 31 \\
\hline 욱 & Caution & 27 & 23 & 42 & 22 & 60 & 62 \\
\hline in & High & 26 & 27 & 37 & 44 & 60 & 62 \\
\hline$\dot{\Sigma}$ & Low & 17 & 18 & 20 & 22 & 62 & 62 \\
\hline$\stackrel{-}{\circ}$ & Caution & 27 & 27 & 49 & 37 & 124 & 124 \\
\hline 욱 & High & 21 & 27 & 25 & 31 & 124 & 124 \\
\hline$\dot{\equiv}$ & Low & 116 & 191 & 163 & 217 & 186 & 186 \\
\hline$\stackrel{\circ}{\circ}$ & Caution & 52 & 107 & 69 & 145 & 217 & 217 \\
\hline ํ & High & 29 & 58 & 30 & 86 & 217 & 217 \\
\hline
\end{tabular}



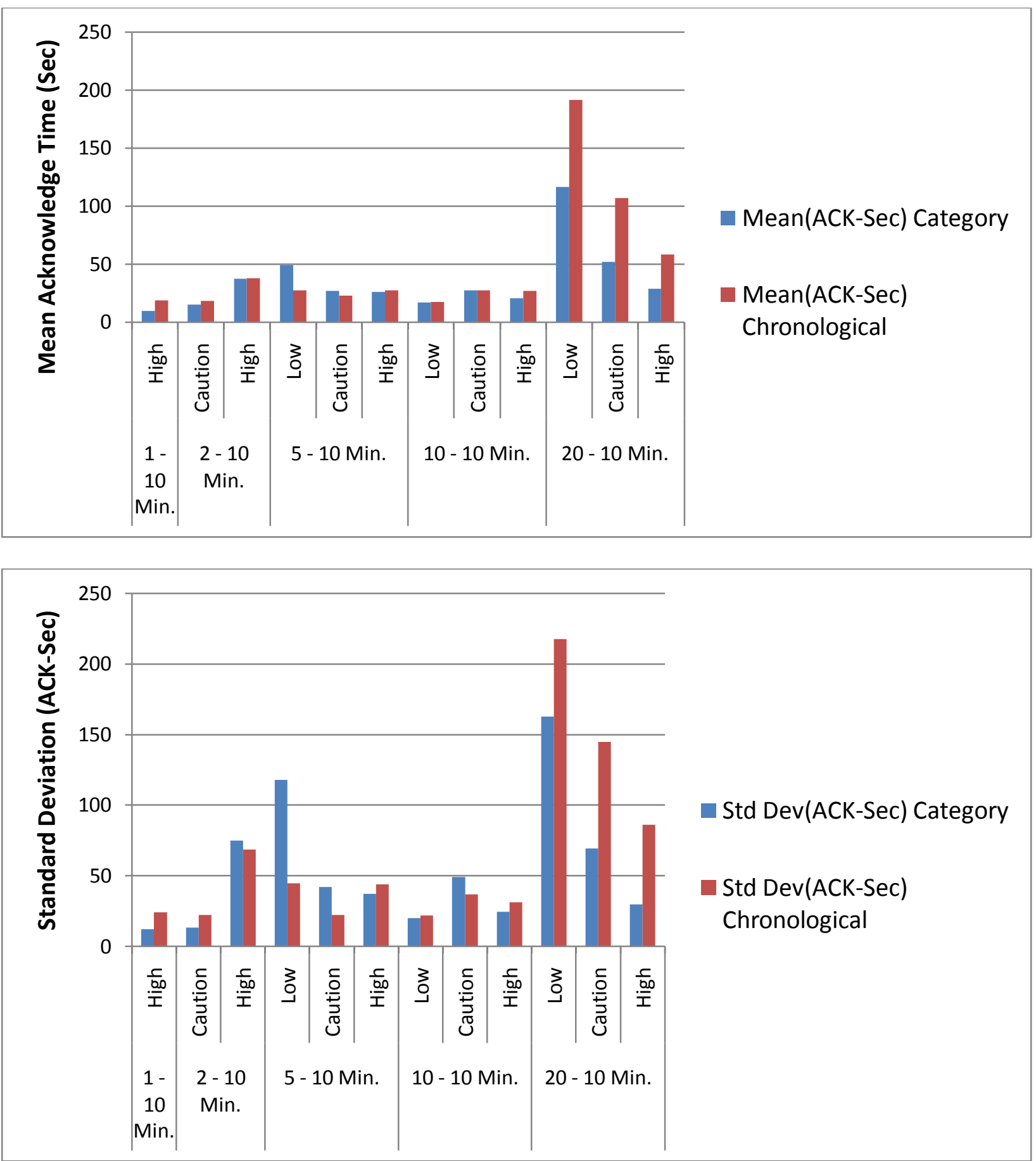


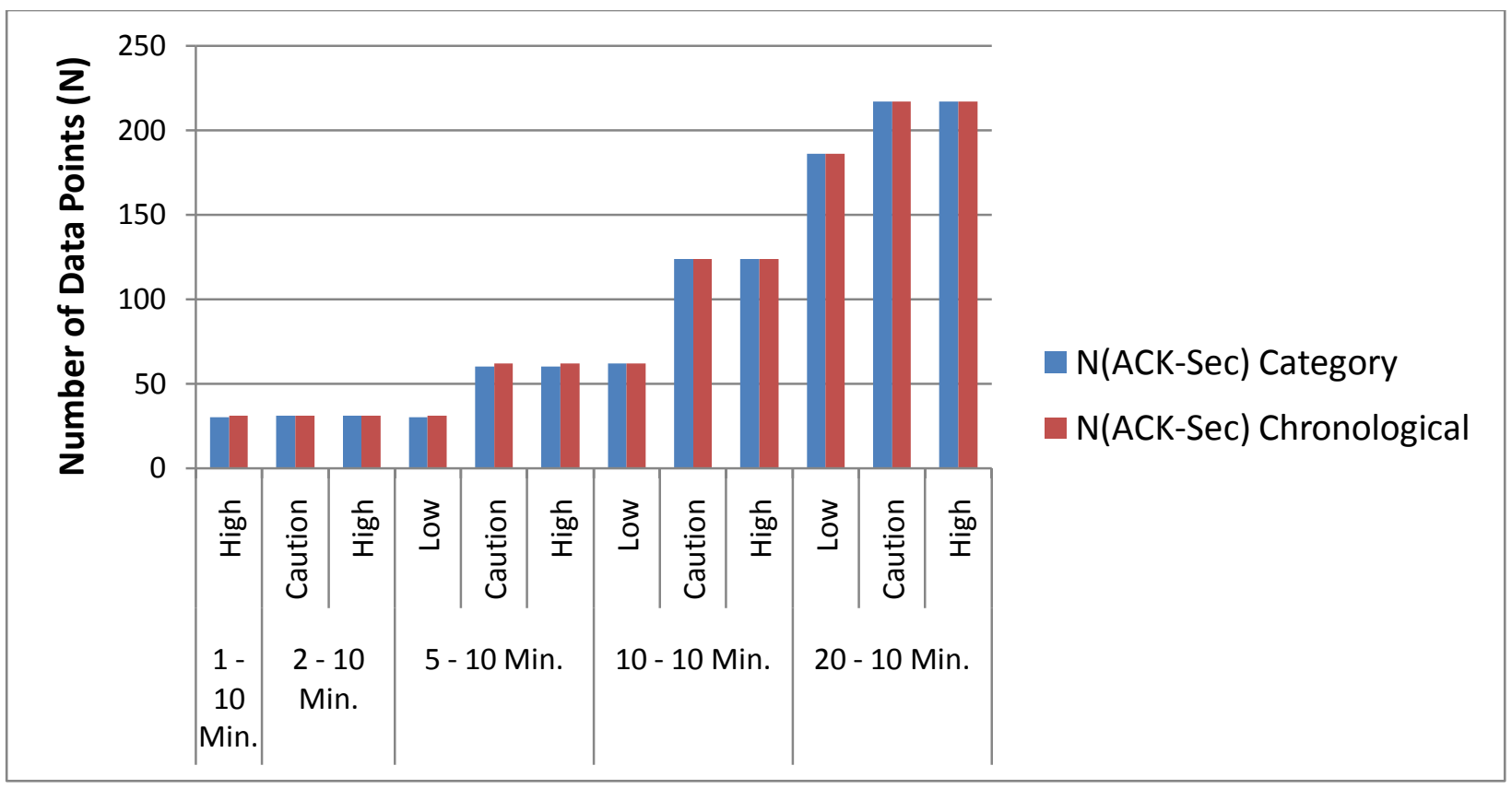




\begin{tabular}{|c|c|c|c|c|c|c|c|}
\hline & & \multicolumn{2}{|c|}{ Mean(RT-Sec) } & \multicolumn{2}{|c|}{ Std Dev(RT-Sec) } & \multicolumn{2}{|c|}{ N(RT-Sec) } \\
\hline & & Category & Chronological & Category & Chronological & Category & Chronological \\
\hline $\begin{array}{l}\stackrel{\dot{\Sigma}}{\sum} \\
0 \\
\stackrel{+}{1} \\
1 \\
-1\end{array}$ & High & 24 & 30 & 15 & 14 & 31 & 31 \\
\hline \multirow{2}{*}{ 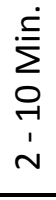 } & Caution & 18 & 25 & 8 & 17 & 31 & 31 \\
\hline & High & 35 & 38 & 20 & 25 & 31 & 31 \\
\hline \multirow{3}{*}{ 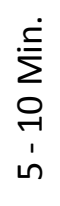 } & Low & 29 & 36 & 45 & 88 & 30 & 31 \\
\hline & Caution & 27 & 34 & 23 & 38 & 60 & 62 \\
\hline & High & 38 & 45 & 26 & 34 & 60 & 62 \\
\hline \multirow{3}{*}{ 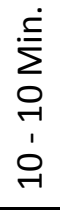 } & Low & 19 & 18 & 25 & 10 & 62 & 62 \\
\hline & Caution & 28 & 38 & 25 & 60 & 124 & 124 \\
\hline & High & 32 & 42 & 20 & 48 & 124 & 121 \\
\hline \multirow{3}{*}{ 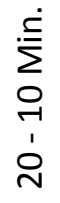 } & Low & 131 & 192 & 173 & 226 & 178 & 182 \\
\hline & Caution & 53 & 75 & 63 & 111 & 214 & 214 \\
\hline & High & 47 & 80 & 61 & 119 & 214 & 211 \\
\hline
\end{tabular}



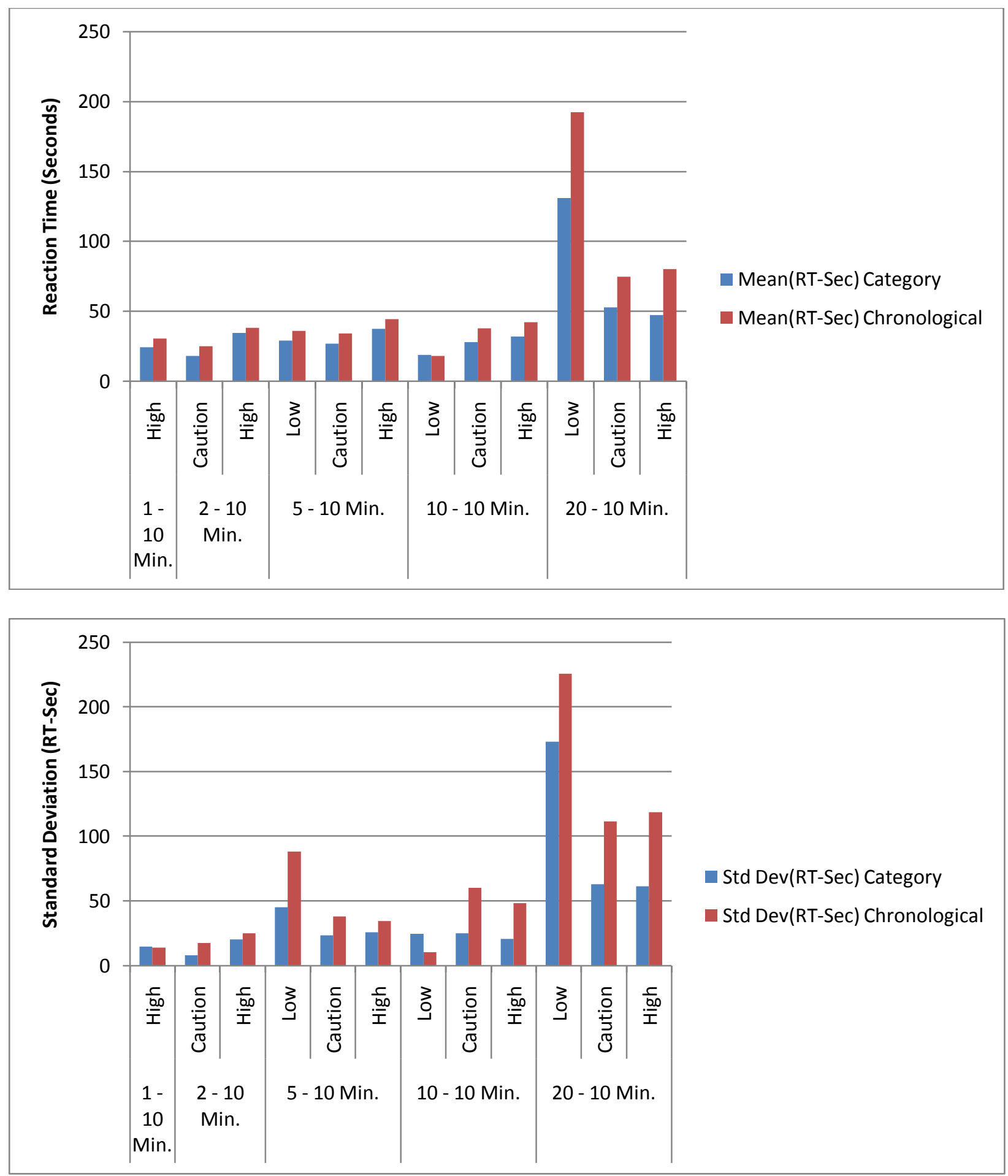


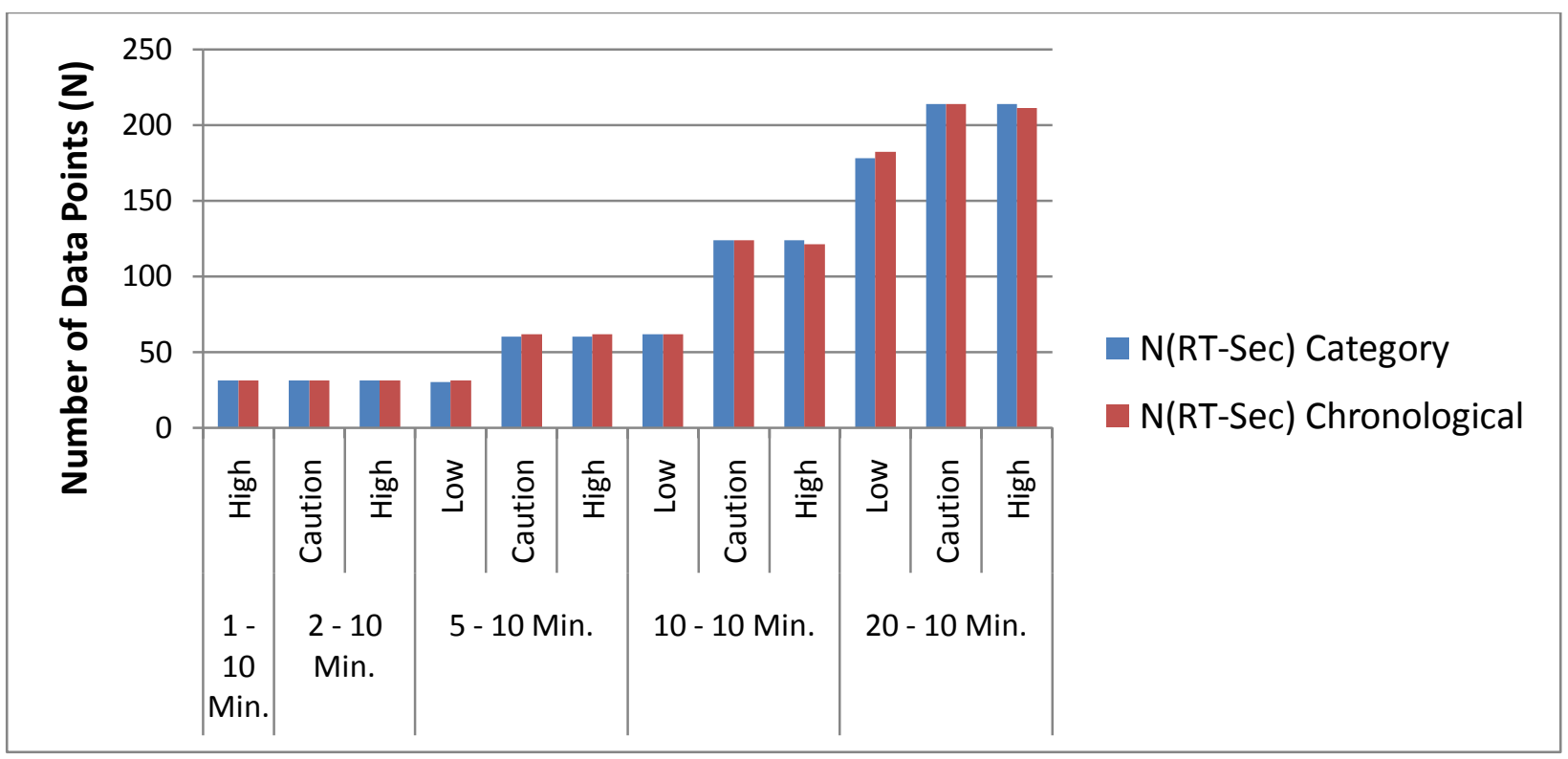




\section{VITA}

Glen D. Uhack II was born in New Orleans, Louisiana in 1985. He received a bachelor's degree in business administration at the University of New Orleans, New Orleans in May 2007. He started his work towards the degree of master's in industrial engineering after graduating with his bachelor's. He worked as a research assistant during his time as a master's student in the Department of Industrial Engineering.

Glen is a first degree black belt American Taekwondo Foundation, student member of

Instrumentation, Systems, and Automation Society (ISA), and automotive technician by trade. The degree of Master of Science in Industrial Engineering will be conferred at the May 2010 commencement. 